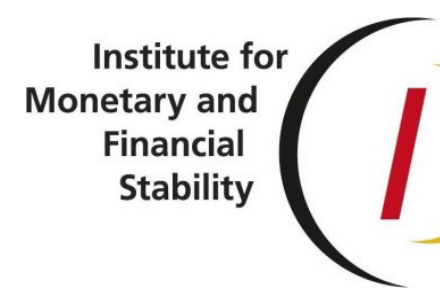

Volker Wieland, Tobias CWIK, Gernot J. Müller, SEBASTIAN SCHMIDT AND MAIK WOLTERS

A New Comparative Approach to Macroeconomic Modeling and Policy Analysis

Institute for Monetary and Financial Stability JoHANn WolfGang GoEthe-Universität FrankFuRT Am MaIN 
Prof. Dr. Dr. H.C. Helmut Siekmann (HrSG.)

INSTITUTE FOR MONETARY AND FINANCIAL STABILITY

PROFESSUR FÜR GELD-, WÄHRUNGS- UND NOTENBANKRECHT JOHANN WOLFGANG GOETHE-UNIVERSITÄT

GRÜNEBURGPLATZ 1

60629 FRANKFURT AM MAIN

TELEFON: $\quad$ (069) $798-34014$

TELEFAX: (069) $798-33913$

E-MAIL: GELD-UND-WAEHRUNG@IMFS-FRANKFURT.DE 


\section{VolKer Wieland, TOBiAs CWIK, GeRNOt J. MÜLler, SEBASTIAN SCHMIDT AND MAIK WOLTERS}

\section{A New Comparative Approach to Macroeconomic Modeling and Policy Analysis}

Institute for Monetary and Financial Stability JOHANN WOLFGANG GOETHE-UNIVERSITÄT FRANKFURT AM MAIN 


\title{
A New Comparative Approach to Macroeconomic Modeling and Policy Analysis*
}

\author{
Volker Wieland, Tobias Cwik, Gernot J. Müller, \\ Sebastian Schmidt and Maik Wolters ${ }^{\dagger}$
}

This Version: January 23, 2012

\begin{abstract}
In the aftermath of the global financial crisis, the state of macroeconomic modeling and the use of macroeconomic models in policy analysis has come under heavy criticism. Macroeconomists in academia and policy institutions have been blamed for relying too much on a particular class of macroeconomic models. This paper proposes a comparative approach to macroeconomic policy analysis that is open to competing modeling paradigms. Macroeconomic model comparison projects have helped produce some very influential insights such as the Taylor rule. However, they have been infrequent and costly, because they require the input of many teams of researchers and multiple meetings to obtain a limited set of comparative findings. This paper provides a new approach that enables individual researchers to conduct model comparisons easily, frequently, at low cost and on a large scale. Using this approach a model archive is built that includes many well-known empirically estimated models that may be used for quantitative analysis of monetary and fiscal stabilization policies. A computational platform is created that allows straightforward comparisons of models' implications. Its application is illustrated by comparing different monetary and fiscal policies across selected models. Researchers can easily include new models in the data base and compare the effects of novel extensions to established benchmarks thereby fostering a comparative instead of insular approach to model development.
\end{abstract}

Keywords: $\quad$ Macroeconomic Models, Model Uncertainty, Policy Rules, Robustness, Monetary Policy, Fiscal Policy, Model Comparison.

JEL-Codes: E52, E58, E62, F41

\footnotetext{
${ }^{*}$ We are grateful for very helpful advice by John B. Taylor and his support of the model comparison initiative. Wieland acknowledges funding support from European Community grant MONFISPOL under grant agreement SSH-CT-2009225149. Furthermore, we want to thank those model developers who supplied the original code for simulating their models, in particular, John B. Taylor, John C. Williams, Christopher Erceg, Frank Smets, Raf Wouters, Michael Kiley, Rochelle Edge, Jean-Phillipe Laforte, Marco Ratto, Werner Roeger, Guenter Coenen, Stephan Laseen, Athanasios Orphanides, Keith Kuester, Thomas Laubach, Malin Adolfson, Ferre De Graeve, Michael Funke, Paolo Gelain, Peter Karadi, Juan Pablo Medina, Stephen Murchison, Pau Rabanal and many others. We are also grateful for helpful comments by Michel Juillard, Frank Smets, Willi Semmler and an anonymous referee. All remaining errors are our own.

${ }^{\dagger}$ Corresponding Author: Volker Wieland; Mailing address: Goethe University of Frankfurt, Grueneburgplatz 1, Goethe Universitaet, House of Finance, 60323 Frankfurt am Main, Germany, E-mail: wieland@wiwi.uni-frankfurt.de. Other Authors: Tobias Cwik; Mailing address: Board of Governors of the Federal Reserve System, Division of Research and Statistics, 20th Street and Constitution Avenue NW, Washington DC 20551, US; Gernot J. Müller; Mailing address: University of Bonn, Adenauerallee 24-42, 53113 Bonn, Germany; Sebastian Schmidt and Maik Wolters; Mailing address: Goethe University of Frankfurt, Grueneburgplatz 1, House of Finance, 60323 Frankfurt am Main, Germany.
} 


\section{Introduction}

The global financial crisis came as a surprise to many policy makers and their advisers as well as many professionals including business forecasters, financial advisors, bankers and researchers in finance and macroeconomics. Media and other commentators have criticized macroeconomists in particular for failing to predict the great recession of 2008-09 or at least failing to provide adequate warning of the risk of such a recession ahead of time. Practitioners have attributed this failure to academic and central bank researchers' use of a particular modeling paradigm. They blame so-called dynamic stochastic general equilibrium (DSGE) models for misdirecting their attention. Indeed, even some well-known academics-cum-bloggers have published scathing commentaries on the current state of macroeconomic modeling. In March 2009, Willem Buiter wrote " ... the typical graduate macroeconomics and monetary economics training received at Anglo-American universities during the past 30 years or so, may have set back by decades serious investigations of aggregate economic behavior and economic policy-relevant understanding." He was echoed by Nobel Prize Winner Paul Krugman in the Economist, June 2010, " Most work in macro-economics in the past 30 years has been useless at best and harmful at worst." Of course, not all experts agree on this judgement as indicated, for example, by the recent award of the Nobel Prize in 2011 to macroeconomists Thomas Sargent and Christopher Sims for "their empirical research on cause and effect in the macroeconomy".

Against this background, the present paper aims to develop a more constructive proposal for how to use macroeconomic modeling - whether state-of-the-art or 1970s-vintage - in practical policy design. In the spirit of the 1992 call by leading economists - among them Nobel prize winners Paul Samuelson and Franco Modigliani - for a pluralistic yet rigorous economics, we propose a systematic comparative approach to macroeconomic modeling with the objective of identifying policy recommendations that are robust to model uncertainty. ${ }^{1}$ This approach is open to a wide variety of modeling paradigms. Scientific rigor demands a level-playing field on which models can compete. Instead of using rhetoric to dismiss competing approaches, models should be required to satisfy empirical benchmarks. For example, models used for monetary policy analysis should be estimated to fit key time series such as output, inflation and nominal interest rates. Models should also be able to provide answers to typical policymakers' questions.

Macroeconomic data, however, are unlikely to provide sufficient testing grounds for selecting a single, preferred model for policy purposes. If many of the competing models describe historical data of key aggregates reasonably well, one could use these models to establish robustness of policy recommendations. Such an approach is recommended by McCallum (1988, 1999), Blanchard and

\footnotetext{
${ }^{1}$ The undersigned were concerned with "the threat to economic science posed by intellectual monopoly" and pleaded for "a new spirit of pluralism in economics, involving critical conversation and tolerant communication between different approaches". See the advertisement section of the American Economic Review - AEA Papers and Proceedings issue of May 1992.
} 
Fischer (1989), Taylor (1999) and many others. McCallum (1999), for example, proposes " to search for a policy rule that possesses robustness in the sense of yielding reasonably desirable outcomes in policy simulation experiments in a wide variety of models. " 2 In 2010, ECB President Jean-Claude Trichet expressed the need for robustness as follows:

"We need macroeconomic and financial models to discipline and structure our judgemental analysis. How should such models evolve? The key lesson I would draw from our experience is the danger of relying on a single tool, methodology or paradigm. Policymakers need to have input from various theoretical perspectives and from a range of empirical approaches. Open debate and a diversity of views must be cultivated - admittedly not always an easy task in an institution such as a central bank. We do not need to throw out our DSGE and asset-pricing models: rather we need to develop complementary tools to improve the robustness of our overall framework". ${ }^{3}$

Yet, systematic comparisons of the empirical implications of a large variety of available models are rare. Evaluating the performance of different policies across many models typically is work intensive and costly. The seven comparison projects reported in Bryant, Henderson, Holtham, Hooper, and Symansky (1988), Bryant, Currie, Frenkel, Masson, and Portes (1989), Klein (1991), Bryant, Hooper, and Mann (1993), Taylor (1999), Hughes-Hallett and Wallis (2004) and Coenen, Erceg, Freedman, Furceri, Kumhof, Lalonde, Laxton, Linde, Mourougane, Muir, Mursula, de Resende, Roberts, Roeger, Snudden, Trabandt, and in't Veld (2012) have involved multiple teams of researchers, each team working only with one or a small subset of available models. While these initiatives have helped produce some very influential insights such as the Taylor rule, ${ }^{4}$ the range of systematic, comparative findings has remained limited.

This paper provides a new comparative approach to model-based research and policy analysis that enables individual researchers to conduct systematic model comparisons and policy evaluations easily and at low cost. Following this approach it is straightforward to include new models and compare their empirical and policy implications to a large number of established benchmarks.

We start by presenting a formal exposition of our approach to model comparison. A general class of nonlinear dynamic stochastic macroeconomic models is augmented with a space of common comparable variables, parameters and shocks. Augmenting models in this manner is a necessary precondition for a systematic comparison of particular model characteristics. On this basis, common

\footnotetext{
${ }^{2}$ Taylor and Wieland (2011) follow this recommendation and investigate the policy implications of three well-known models of the U.S. economy that are also made available in the data base presented in this paper.

${ }^{3}$ This quote is taken from a speech titled "Reflections on the nature of monetary policy non-standard measures and finance theory" by Jean-Claude Trichet, then-President of the European Central Bank, on the occasion of the ECB Central Banking Conference Frankfurt, 18 November 2010.

${ }^{4}$ Taylor (1993a) credits the comparison project summarized in Bryant et al. (1993) as the crucial testing ground for what later became known as the Taylor rule.
} 
policy rules can be defined as model input. Then we derive comparable objects that may be produced as model output. These objects are defined in terms of common variables, parameters and shocks. Examples for such objects are impulse response functions, autocorrelation functions and unconditional distributions of key macroeconomic aggregates. An illustrative example with two well-known small New Keynesian models is provided.

Next, we give a brief overview of the model archive that we have built. This data base includes many well-known empirically-estimated macroeconomic models that may be used for quantitative analysis of monetary and fiscal stabilization policies. There are many models of the United States and euro area economies. Furthermore, the archive includes several multi-country models and openeconomy models of Canada, Chile and Brazil. Some of the models are fairly small and focus on explaining output, inflation and interest rate dynamics (cf. Clarida, Gali, and Gertler (1999), Rotemberg and Woodford (1997), Fuhrer and Moore (1995b), McCallum and Nelson (1999), Coenen and Wieland (2005), etc.). Others are of medium scale and cover many key macroeconomic aggregates (cf. Christiano, Eichenbaum, and Evans (2005), Coenen, Orphanides, and Wieland (2004), Smets and Wouters $(2003,2007))$. Some models in the data base are fairly large in scale such as the Federal Reserve's FRB-US model of Reifschneider, Tetlow, and Williams (1999), the model of the G7 economies of Taylor (1993b) or the ECB's Area-wide model of Dieppe, Kuester, and McAdam (2005).

Most of the models can be classified as New Keynesian models because they incorporate rational expectations, imperfect competition and wage or price rigidities. Many of these New-Keynesian models fully incorporate recent advances in terms of microeconomic foundations. Such models are often referred to as monetary business cycle models or monetary dynamic stochastic general equilibrium (DSGE) models. Well-known examples of this class are models by Christiano et al. (2005), Smets and Wouters (2003, 2007), Laxton and Pesenti (2003) and Adolfson, Laseen, Linde, and Villani (2007). In addition, we have included models that assign little role to forward-looking behavior by economic agents (cf. the ECB's first area-wide model) or none at all (cf. Rudebusch and Svensson (1999) and Orphanides (2003)).

We have created a computational platform that implements our approach to model comparison. It allows users to solve structural models and conduct comparative analysis. ${ }^{5}$ Comparisons of impulse response functions of common variables in response to common shocks, or of autocorrelation functions of common variables in response to model-specific shocks, or of unconditional distributions of common variables are generated. It can also be used to conduct a systematic investigation of policy rules across models. The platform admits nonlinear as well as linear models and allows for perturbation-based approximation of nonlinear models with forward-looking variables as well as two-

\footnotetext{
${ }^{5}$ The computational platform and model archive have been made publicly available online. The Macroeconomic Model Database Release 1.2. can be downloaded from http://www.macromodelbase.com.
} 
point boundary value-based approximation. ${ }^{6}$ New models may easily be introduced and compared to established benchmarks thereby fostering a comparative rather than insular approach to model building. New modeling approaches may offer more sophisticated explanations of the sources of the great recession of 2008-09 and carry the promise of improved forecasting performance. This promise can be put to the test by applying the approach to forecasting competitions in Wieland and Wolters (2011).

Finally, the comparative approach to modeling and policy analysis is illustrated with several examples. We compare monetary and fiscal policy shocks under alternative monetary policy rules, and investigate the predictions of different models and different policies for inflation and output persistence. A detailed description of the model comparison software and of the models included in the data base is provided in the appendices $\mathrm{A}$ and $\mathrm{B}$, respectively.

\section{A general approach to model comparison}

Macroeconomic models differ in terms of modeling assumptions. They may include different economic concepts and therefore different variables and parameters; they may use different policy rules; and invariably they tend to use different notation and definitions of the same key macroeconomic aggregates. As a consequence, model output is not directly comparable. In the following, we describe formally how to augment any model in a way that renders comparison of policy implications across models straightforward, while keeping the number of necessary modifications of the original models at a minimum.

\subsection{Augmenting models for the purpose of comparison}

We start by introducing the notation for a general nonlinear macroeconomic model of the economy. The letter $m$ is used to refer to a specific model considered in the comparison. Thus, $m=$ $(1,2,3, \ldots, M)$ will appear as a superscript on any variables or parameters that are part of this model. ${ }^{7}$ These variables or parameters need not be comparable across models nor follow particular naming conventions across models. Our notation regarding the vectors of model-specific variables, parameters, and shocks is summarized in Table 1.

We distinguish two types of model equations, policy rules, which we denote by $g_{m}($.$) , and the$ other equations and identities that make up the rest of the model, that we denote by $f_{m}($.$) . The two$ types of equations together determine the endogenous model variables, which are denoted by the vector $x_{t}^{m}$. The model variables are functions of each other, of model-specific shocks, $\left[\begin{array}{ll}\epsilon_{t}^{m} & \eta_{t}^{m}\end{array}\right]$, and

\footnotetext{
${ }^{6}$ This software is written for MATLAB and utilizes DYNARE software for model solution. For further information on DYNARE see Juillard (2001) and Juillard (1996).

${ }^{7}$ In the computational implementation $m$ may be associated with a particular list of model names rather than a list of numbers.
} 
Table 1: Model-Specific Variables, Parameters, Shocks and Equations

\begin{tabular}{ll}
\hline Notation & Description \\
\hline$x_{t}^{m}$ & endogenous variables in model $m$ \\
$x_{t}^{m, g}$ & policy variables in model $m$ (also included in $x_{t}^{m}$ ) \\
$\eta_{t}^{m}$ & policy shocks in model $m$ \\
$\epsilon_{t}^{m}$ & other economic shocks in model $m$ \\
$g_{m}()$. & policy rules in model $m$ \\
$f_{m}()$. & other model equations in model $m$ \\
$\gamma^{m}$ & policy rule parameters in model $m$ \\
$\beta^{m}$ & other economic parameters in model $m$ \\
$\Sigma^{m}$ & covariance matrix of shocks in model $m$ \\
\hline
\end{tabular}

of model parameters $\left[\begin{array}{ll}\beta^{m} & \gamma^{m}\end{array}\right]$. A particular model $m$ may then be defined as follows:

$$
\begin{aligned}
& E_{t}\left[g_{m}\left(x_{t}^{m}, x_{t+1}^{m}, x_{t-1}^{m}, \eta_{t}^{m}, \gamma^{m}\right)\right]=0 \\
& E_{t}\left[f_{m}\left(x_{t}^{m}, x_{t+1}^{m}, x_{t-1}^{m}, \epsilon_{t}^{m}, \beta^{m}\right)\right]=0
\end{aligned}
$$

The superscript $m$ refers to the original version of the respective model as supplied by its developers. The model may include current values, lags and the expectation of leads of endogenous variables. In equations (1) and (2) the lead- and lag-lengths are set to unity for notational convenience. ${ }^{8}$

The model may also include innovations that are random variables with zero mean and covariance matrix, $\Sigma^{m}$ :

$$
\begin{aligned}
E\left(\left[\eta_{t}^{m} \epsilon_{t}^{m}\right]^{\prime}\right) & =0 \\
E\left(\left[\eta_{t}^{m \prime} \epsilon_{t}^{m \prime}\right]^{\prime}\left[\eta_{t}^{m \prime} \epsilon_{t}^{m \prime}\right]\right) & =\Sigma^{m}=\left(\begin{array}{cc}
\Sigma_{\eta}^{m} & \Sigma_{\eta \epsilon}^{m} \\
\Sigma_{\eta \epsilon}^{m} & \Sigma_{\epsilon}^{m}
\end{array}\right)
\end{aligned}
$$

In the following we refer to innovations interchangeably as shocks. Some model authors instead differentiate between serially correlated economic shocks that are themselves functions of random innovations. This practice does not prevent us from including such models in a comparison. The serially correlated economic shocks of these authors would appear as elements of the vector of endogenous variables $x_{t}^{m}$ and only their innovations would appear as shocks in our notation. Equation (4) distinguishes the covariance matrices of policy shocks and other economic shocks as $\Sigma_{\eta}^{m}$ and $\Sigma_{\epsilon}^{m}$. The correlation of policy shocks and other shocks is typically assumed to be zero, $\Sigma_{\eta \epsilon}^{m}=0$.

To compare the implications of different models, it is necessary to define a set of comparable variables, shocks and parameters that will be in common to all models considered in the comparison exercise. It is then possible to express policies in terms of particular parameters, variables and policy

\footnotetext{
${ }^{8}$ Further leads and lags can be accounted for by appropriately defined auxiliary variables. Even so, our software implementation does not restrict the lead- and lag-lengths of participating models.
} 
shocks that are identical across models, and study the consequences of these policies for a set of endogenous variables that are defined in a comparable manner across models. Our notation for common endogenous variables, policy instruments, policy shocks, policy rules and parameters is introduced in Table 2.

Table 2: Comparable Common Variables, Parameters, Shocks and Equations

\begin{tabular}{ll}
\hline Notation & Description \\
\hline$z_{t}$ & common variables in all models \\
$z_{t}^{g}$ & common policy variables in all models (also included in $\left.z_{t}\right)$ \\
$\eta_{t}$ & common policy shocks in all models \\
$g()$. & common policy rules \\
$\gamma$ & common policy rule parameters \\
\hline
\end{tabular}

Any model that is meant to be included in a comparison first has to be augmented with common variables, parameters and shocks. Augmenting the model implies adding equations. These additional equations serve to define the common variables in terms of model specific variables. We denote these definitional equations or identities by $h_{m}($.$) . By their nature they are model-specific. A further step$ is to replace the original model-specific policy rules with the common policy rules. All the other equations, variables, parameters and shocks may be preserved in the original notation of the model developers. As a result, the augmented model consists of three components: (i) the common policy rules, $g($.$) , expressed in terms of common variables, z_{t}$, policy shocks, $\eta_{t}$, and policy rule parameters, $\gamma$; (ii) the model-specific definitions of common variables in terms of original model-specific endogenous variables, $h_{m}($.$) , with parameters \theta^{m}$; (iii) the original set of model-specific equations $f_{m}($.$) that determine the endogenous variables. Thus, the augmented model may be represented as$ follows:

$$
\begin{aligned}
E_{t}\left[g\left(z_{t}, z_{t+1}, z_{t-1}, \eta_{t}, \gamma\right)\right] & =0 \\
E_{t}\left[h_{m}\left(z_{t}, x_{t}^{m}, x_{t+1}^{m}, x_{t-1}^{m}, \theta^{m}\right)\right] & =0 \\
E_{t}\left[f_{m}\left(x_{t}^{m}, x_{t+1}^{m}, x_{t-1}^{m}, \epsilon_{t}^{m}, \beta^{m}\right)\right] & =0
\end{aligned}
$$

Models augmented in this manner can be used in comparison exercises. For example, it is possible to compare the implications of a particular policy rule for the dynamic properties of those endogenous variables that are defined in a comparable manner across models. An advantage of this approach is that it requires only a limited set of common elements. With regard to the remainder of the model the original notation used by model authors can be left unchanged, in particular the variable names and definitions of endogenous variables, $x_{t}^{m}$, the other economic shocks $\epsilon_{t}^{m}$, the equations $f_{m}($.$) with$ model parameters $\beta^{m}$ and the covariance matrix of shocks $\Sigma_{\epsilon}^{m}$. The covariance matrix of policy 
shocks $\Sigma_{\eta}$ may be treated as an element of the vector of policy parameters or may be constrained to zero.

The essential step in introducing a new model in a comparison exercise is to define the common variables in terms of model-specific variables. It involves setting up the additional equations, $h_{m}($.$) ,$ and determining the definitional parameters, $\theta^{m}$. We illustrate this process with an example.

\section{A simple example}

The vector of common variables, $z_{t}$, is assumed to contain six variables that are meant to be comparable across models:

$$
z_{t}=\left[\begin{array}{llllll}
i_{t}^{z} & g_{t}^{z} & \pi_{t}^{z} & p_{t}^{z} & y_{t}^{z} & q_{t}^{z}
\end{array}\right]^{\prime}
$$

These variables are characterized in Table 3. They are expressed in percentage deviations from steady state values, because the example applies to linear models. The monetary policy instrument is the an-

Table 3: Comparable Common Variables

\begin{tabular}{ll}
\hline Notation & Description \\
\hline$i_{t}^{z}$ & annualized quarterly money market rate \\
$g_{t}^{z}$ & discretionary government purchases (share in GDP) \\
$\pi_{t}^{z}$ & year-on-year rate of inflation \\
$p_{t}^{z}$ & annualized quarter-to-quarter rate of inflation \\
$y_{t}^{z}$ & quarterly real GDP \\
$q_{t}^{z}$ & quarterly output gap (dev. from flex-price level) \\
\hline
\end{tabular}

nualized short-term money market rate in quarter $t$ denoted by $i_{t}^{z}$. The fiscal policy instrument is defined as the component of government purchases in the respective model that does not respond systematically to lagged endogenous variables. In Table 3 they are labeled "discretionary" government purchases. They are expressed in terms of their share in GDP and denoted by $g_{t}^{z}$. Economic outcomes are measured with regard to inflation, real output and the output gap. $\pi_{t}^{z}$ denotes the year-on-year rate of inflation, while $p_{t}^{z}$ refers to the annualized quarter-to-quarter rate of inflation. $y_{t}^{z}$ is quarterly real GDP. $q_{t}^{z}$ refers to the output gap defined as the difference between actual output and the level of output that would be realized if the price level were flexible. ${ }^{9}$

Next, we define common decision rules for monetary and fiscal policy makers. The monetary policy rule serves to set the nominal interest rate, $i_{t}^{z}$. It includes a systematic response to output and inflation, defined in comparable terms, as well as a monetary policy shock. The fiscal rule determines discretionary government spending, $g_{t}^{z}$. It is simply defined as the product of a random innovation

\footnotetext{
${ }^{9}$ The latter concept of potential output is used in whichever way a particular model defines it. Another interesting exercise would be to compare different concepts of potential output and output gaps across models by introducing additional common variables.
} 
and a policy parameter:

$$
\begin{aligned}
i_{t}^{z} & =\gamma_{i} i_{t-1}^{z}+\gamma_{p} p_{t}^{z}+\gamma_{q} q_{t}^{z}+\eta_{t}^{i} \\
g_{t}^{z} & =\gamma_{g} \eta_{t}^{g}
\end{aligned}
$$

The common policy shocks and parameters are denoted by:

$$
\begin{aligned}
\eta_{t} & =\left[\begin{array}{ll}
\eta_{t}^{i} & \eta_{t}^{g}
\end{array}\right] \\
\gamma & =\left[\begin{array}{llll}
\gamma_{i} & \gamma_{p} & \gamma_{q} & \gamma_{g}
\end{array}\right]
\end{aligned}
$$

Having defined common variables, shocks and policy parameters, we proceed to consider two small-scale New-Keynesian models for conducting a model comparison, $m=\{1,2\}$. One model is taken from Clarida et al. (1999), ( $m=1$ refers to the model name $N K \_C G G 99$ ), while the other one is from Woodford (2003) and based on Rotemberg and Woodford (1997), ( $m=2$ refers to $\left.N K \_R W 97\right)$. These models are well-known benchmarks in the literature. We present the original model equations as published by the authors and then show how to augment them appropriately for a comparison exercise.

Table 4: Model 1 - The hybrid model of Clarida et al. (1999) (NK_CGG99)

\begin{tabular}{ll}
\hline Description & Equations and Definitions \\
\hline Original Model & \\
$\quad$ variables & $x_{t}^{1}=\left[\begin{array}{lll}i_{t} & x_{t} & \pi_{t}\end{array}\right]^{\prime}, \quad x_{t}^{1, g}=\left[\begin{array}{ll}i_{t}\end{array}\right]$ \\
$\quad$ shocks & $\epsilon_{t}^{1}=\left[\begin{array}{lll}g_{t} & u_{t}\end{array}\right]^{\prime}$ \\
$\quad$ parameters & $\beta^{1}=\left[\begin{array}{lll}\varphi & \theta & \phi\end{array}\right]^{\prime}, \quad \gamma^{1}=\left[\begin{array}{lll}\alpha & \gamma_{\pi} & \gamma_{x}\end{array}\right]^{\prime}$ \\
$\quad$ model equations & \\
$g_{1}()$. & $i_{t}=\alpha+\gamma_{\pi}\left(\pi_{t}-\bar{\pi}\right)+\gamma_{x} x_{t}$ \\
$f_{1}()$. & $x_{t}=-\varphi\left(i_{t}-E_{t} \pi_{t+1}\right)+\theta x_{t-1}+(1-\theta) E_{t} x_{t+1}+g_{t}$ \\
$\quad \ldots$ & $\pi_{t}=\lambda x_{t}+\phi \pi_{t-1}+(1-\phi) \beta E_{t} \pi_{t+1}+u_{t}$ \\
Augmented Model & \\
$z_{t}, \eta_{t}, \gamma, g()$. & \\
$f_{1}()$. & as defined by equations $(8-12)$. \\
$h_{1}\left(z_{t}, x_{t}^{1}, E_{t} x_{t+1}^{1}, x_{t-1}^{1}, \theta^{1}\right)$ & $i_{t}^{z}=4 i_{t}$ \\
$\ldots$ & $\pi_{t}^{z}=\pi_{t}+\pi_{t-1}+\pi_{t-2}+\pi_{t-3}$ \\
$\ldots$ & $p_{t}^{z}=4 \pi_{t}$ \\
$\ldots$ & $q_{t}^{z}=x_{t}$ \\
\hline
\end{tabular}

The Clarida et al. (1999) model is presented in Table 4. The model in the authors' notation consists of three equations: (i) a Phillips curve relating quarterly inflation, $\pi_{t}$, to inflation expectations, 
past inflation, the output gap, $x_{t}$, and a cost-push shock, $u_{t}$; (ii) an IS equation relating the current output gap to past and expected future gaps, the expected real interest rate, $i_{t}-E_{t} \pi_{t+1}$, and a demand shock, $g_{t}$; (iii) and a policy rule relating the quarterly interest rate to inflation and the output gap. ${ }^{10}$ Clarida et al. (1999) call it the hybrid model because it involves forward- and backward-looking elements in the Phillips and IS curves.

In the augmented version of the model the original policy rule is replaced with the common rule, equation (9). The other equations from the original model, $f_{m}()=.f_{1}($.$) , remain unchanged.$ The additional equations in the augmented model, $h_{m}\left(., \theta^{m}\right)=h_{1}\left(., \theta^{1}\right)$, provide the appropriate definitions of common comparable variables in terms of model-specific variables. This model is defined in terms of the output gap relative to a variable called flexible-price output without further information on the definition of said variable. Thus, a comparable definition of the level of output is not available in this model. Therefore, this model remains silent on the time series characteristics of the level of output, $y_{t}^{z}$, in the comparison exercise. It is important that a systematic approach to model comparison identifies such cases so as to avoid comparing apples and oranges. Furthermore, the model does not explicitly include government spending. Therefore, it also remains silent with regard to the common variable labeled discretionary or non-systematic government purchases, $g_{t}^{z}$.

The Rotemberg and Woodford (1997) model is presented in Table 5. The version shown is the linearized approximation of the original nonlinear model. ${ }^{11}$ There are some interesting differences relative to the hybrid model of Clarida et al. (1999). The Rotemberg-Woodford model does not exhibit endogenous persistence due to the inclusion of lagged inflation and output in the Phillips and IS curves. Instead, however, it allows for persistence in the exogenous shocks. Furthermore, it includes government spending, the natural real interest rate and the natural level of output explicitly. The model in the notation of Woodford (2003) consists of eight equations ${ }^{12}$ : (i) a policy rule setting the nominal interest rate, $\hat{i_{t}}$; (ii) a purely forward-looking Phillips curve equation that determines quarterly inflation, $\pi_{t}$; (iii) a forward-looking IS equation determining the quarterly output gap $x_{t}$; (iv) a definition of the natural rate of interest, $\hat{r}_{t}^{n}$; (v,vi) definitions of serially correlated government spending dynamics, $g_{t}$, and cost-push shocks $u_{t}$ with random innovations, ${ }^{13} \epsilon_{g, t}$ and $\epsilon_{u, t}$; (vii,viii) and definitions of output, $y_{t}$, and the natural level of output, $y_{t}^{n}$.

In the augmented version of the model the original monetary policy rule is replaced with the common rule, equation (9). The other equations from the original model, $f_{m}()=.f_{2}($.$) , remain un-$

\footnotetext{
${ }^{10}$ These are equations 6.1, 6.2 and 7.1 in Clarida et al. (1999) respectively.

${ }^{11}$ Of course, the general notation regarding model augmentation in equations (1) to (7) allows for nonlinearities. Accordingly, it is possible to augment a nonlinear version of the Rotemberg-Woodford model that is nested in equations (1) and (2) for comparison purposes.

${ }^{12}$ See Woodford (2003), page 246-247, equations 1.12-1.14, 2.2-2.4.

${ }^{13}$ In the quantitative analysis we rely on estimates of the autoregressive parameters in the shock processes provided by Adam and Billi (2006), while we obtained the structural parameters from Woodford (2003).
} 
Table 5: Model 2 - The New-Keynesian model of Woodford (2003) (NK_RW97)

\begin{tabular}{|c|c|}
\hline Description & Equations and Definitions \\
\hline \multicolumn{2}{|l|}{ Original Model } \\
\hline variables & $x_{t}^{2}=\left[\begin{array}{llllllll}\hat{i}_{t} & \pi_{t} & x_{t} & \hat{r}_{t}^{n} & g_{t} & u_{t} & y_{t} & y_{t}^{n}\end{array}\right]^{\prime}, \quad x_{t}^{2, g}=\left[\hat{i}_{t}\right]$ \\
\hline shocks & $\epsilon_{t}^{2}=\left[\epsilon_{u, t}\right] \quad \eta_{t}^{2, g}=\left[\epsilon_{g, t}\right]$ \\
\hline parameters & $\beta^{2}=\left[\begin{array}{llllll}\beta & \kappa & \sigma & \rho_{g} & \rho_{u} & \omega\end{array}\right]^{\prime}, \quad \gamma^{2}=\left[\begin{array}{llll}\phi_{\pi} & \phi_{x} & \bar{\pi} & \bar{x}\end{array}\right]^{\prime}$ \\
\hline \multicolumn{2}{|l|}{ model equations } \\
\hline$g_{2}()$. & $\hat{i_{t}}=\overline{i_{t}}+\phi_{\pi}\left(\pi_{t}-\bar{\pi}\right)+\frac{\phi_{x}}{4}\left(x_{t}-\bar{x}\right)$ \\
\hline$f_{2}()$. & $\pi_{t}=\beta E_{t} \pi_{t+1}+\kappa x_{t}+u_{t}$ \\
\hline$\ldots$ & $x_{t}=E_{t} x_{t+1}-\sigma\left(\hat{i}_{t}-E_{t} \pi_{t+1}-\hat{r}_{t}^{n}\right)$ \\
\hline$\cdots$ & $\hat{r}_{t}^{n}=\sigma^{-1}\left[\left(g_{t}-y_{t}^{n}\right)-E_{t}\left(g_{t+1}-y_{t+1}^{n}\right)\right]$ \\
\hline$\cdots$ & $g_{t}=\rho_{g} g_{t-1}+\epsilon_{g, t}$ \\
\hline$\cdots$ & $u_{t}=\rho_{u} u_{t-1}+\epsilon_{u, t}$ \\
\hline$\ldots$ & $y_{t}=x_{t}+y_{t}^{n}$ \\
\hline$\cdots$ & $y_{t}^{n}=\frac{\sigma^{-1}}{\omega+\sigma^{-1}} g_{t}$ \\
\hline \multicolumn{2}{|l|}{ Augmented Model } \\
\hline$z_{t}, \eta_{t}, \gamma, g()$. & as defined by equations ( $8-12)$. \\
\hline$f_{2}()$. & as defined above in original model. \\
\hline$h_{2}\left(z_{t}, x_{t}^{2},, E_{t} x_{t+1}^{2}, x_{t-1}^{2} \theta^{2}\right)$ & $i_{t}^{z}=4 \hat{i}_{t}$ \\
\hline$\cdots$ & $g_{t}^{z}=\epsilon_{g, t}$ \\
\hline$\ldots$ & $\pi_{t}^{z}=\pi_{t}+\pi_{t-1}+\pi_{t-2}+\pi_{t-3}$ \\
\hline$\ldots$ & $p_{t}^{z}=4 \pi_{t}$ \\
\hline$\ldots$ & $y_{t}^{z}=y_{t}$ \\
\hline$\ldots$ & $q_{t}^{z}=x_{t}$ \\
\hline
\end{tabular}

changed. Even so, the common fiscal rule for discretionary government purchases plays a meaningful role in the augmented Rotemberg-Woodford model. The second equation among the additional equations of the augmented model, $h_{m}\left(., \theta^{m}\right)=h_{2}\left(., \theta^{2}\right)$, defines discretionary government purchases, $g_{t}^{z}$, in terms of the government spending innovation of the original model, $\epsilon_{g, t}$. Furthermore, the augmented model defines the level of output, $y_{t}^{z}$, (in deviation from steady-state) as well as the output gap, $q_{t}^{z}$, among the common variables (see the fifth and sixth equation in $h_{2}\left(., \theta^{2}\right)$ ).

\subsection{Conducting a comparison}

Given models augmented with common policy rules and comparable variables it is possible to conduct a proper comparison. It requires solving the augmented models, constructing appropriate objects for comparison, and defining a metric that quantifies the differences of interest. 


\section{Model solution.}

A solution to the general nonlinear structural model augmented with common variables, that is defined by equations (5), (6) and (7), is obtained by solving out the expectations of future variables conditional on the available information. This step requires an assumption of how expectations are formed. So far, we have used the statistical expectation that is appropriate for models with rational expectations. Solution methods for linear and nonlinear models with rational expectations are available and implemented in the computational platform provided with the paper. Most of the models in the data base assume rational expectations. However, other assumptions regarding expectations formation can also be admitted. ${ }^{14}$ Existence and uniqueness of equilibrium also need to be checked in the solution step. In linear models the Blanchard-Kahn conditions provide the necessary information. In nonlinear models one may have to resort to search by means of numerical methods. The solution of the structural model may then be expressed in terms of the following reduced-form equations:

$$
\begin{aligned}
z_{t} & =k_{z}\left(z_{t-1}, x_{t-1}^{m}, \eta_{t}, \epsilon_{t}^{m}, \kappa_{z}\right) \\
x_{t}^{m} & =k_{x}\left(z_{t-1}, x_{t-1}^{m}, \eta_{t}, \epsilon_{t}^{m}, \kappa_{x}\right)
\end{aligned}
$$

If the structural model is nonlinear, then the reduced-form equations would also be nonlinear. $\left(\kappa_{z}, \kappa_{x}\right)$ denote the reduced-form parameters, which are complex functions of the structural parameters, $\beta^{m}$, the policy parameters, $\gamma$, and the covariance matrix, $\Sigma^{m}$.

Nonlinear models may be solved approximately with numerical methods, for example, perturbationbased, projection-based or two-point-boundary-value algorithms (see Judd (1998), Fair and Taylor (1983), Collard and Juillard (2001)). Alternatively, the model may first be linearized around a deterministic steady state, either analytically as in the case of the Rotemberg-Woodford model of the preceding section, or numerically. Then, the methods of Uhlig (1995) (generalized eigenvalueeigenvector problem), Klein (2000) (generalized Schur decomposition), Sims (2001) (QZ decomposition), Christiano (2002) (undetermined coefficients) and others may be used to solve the linear system of expectational difference equations.

In the remainder of this section we consider the linear first-order approximation to the reduced form solution of the augmented nonlinear model and show how it may be used to obtain particular objects for comparison defined in terms of comparable variables. The linear approximation to the nonlinear solution (or the linear solution to originally linear models) is given by:

$$
\left(\begin{array}{c}
z_{t} \\
x_{t}^{m}
\end{array}\right)=K_{m}(\gamma)\left(\begin{array}{c}
z_{t-1} \\
x_{t-1}^{m}
\end{array}\right)+D_{m}(\gamma)\left(\begin{array}{c}
\eta_{t} \\
\epsilon_{t}^{m}
\end{array}\right)
$$

\footnotetext{
${ }^{14}$ Examples would be the introduction of adaptive learning in the Smets and Wouters (2007) model by Slobodyan and Wouters (2007), or a version of the FRB-US model with VAR-based expectations instead of rational expectations.
} 
where the reduced-form matrices $K_{m}(\gamma)$ and $D_{m}(\gamma)$ are complicated functions of the structural parameters including the policy parameters, $\gamma$. We denote the dependence on the other (model specific) parameters $\beta^{m}$ with the subcript $m$.

\section{Objects for comparison.}

With the linear reduced form in hand one can derive particular objects for comparison, for example, the dynamic response of a particular common variable (an element of $z$ ) to a policy shock conditional on a certain policy rule. Impulse response functions describe the isolated effect of a single shock on the dynamic system holding everything else constant. Formally, the impulse response functions in period $t+j$ to the common monetary policy shock $\eta_{t}^{i}$ are defined as:

$$
I R_{t+j}^{m}\left(\gamma ; \eta^{i}\right)=\left(\begin{array}{c}
E\left[z_{t+j} \mid z_{t-1}, x_{t-1}^{m}, I_{t}\right]-E\left[z_{t+j} \mid z_{t-1}, x_{t-1}^{m}\right] \\
E\left[x_{t+j}^{m} \mid z_{t-1}, x_{t-1}^{m}, I_{t}\right]-E\left[x_{t+j}^{m} \mid z_{t-1}, x_{t-1}^{m}\right]
\end{array}\right)=K_{m}(\gamma)^{j} D_{m}(\gamma) I_{t}
$$

where $I_{t}$ is a vector of zeros that is augmented with a single entry equal to the size of the common policy shock, for which the impulse response is computed. Using the ordering from equation (8) and setting $I_{t}(1)=-1$, the sixth entry of $I R_{t+j}^{1}\left(\gamma ; \eta^{i}\right)$ gives the impulse response of the output gap in the first model ( $\left.N K \_C G G 99\right)$ to an unexpected reduction in the interest rate of 1 percentage point. Similarly, the sixth entry of $I R_{t+j}^{2}\left(\gamma ; \eta^{i}\right)$ gives the impulse response of the output gap in the second model ( $N K_{-} R W 97$ ) to the same type of shock.

It is then straightforward to compare the impulse responses of common variables to common shocks across models and policy rules. Such a comparison provides interesting insights into the transmission channels of monetary policy. We define a metric $s$ that measures the distance between two or more models for a given characteristic of economic time series like an impulse response function. For example, the difference in the cumulative sum of the response of the output gap to a monetary policy shock of -1 percent for the models $N K_{-} C G G 99(m=1)$ and $N K \_R W 97(m=2)$ is given by the sixth entry of:

$$
s\left(\gamma, l^{z}\right)=\sum_{j=0}^{\infty}\left(I R_{t+j}^{1}\left(\gamma ; \eta^{i} ; l^{z}\right)-I R_{t+j}^{2}\left(\gamma ; \eta^{i} ; l^{z}\right)\right) .
$$

The index $l^{z}$ counts the elements of the vector $z$ of common variables. It serves as a reminder that we can only compare the entries in the impulse response vector for the common variables, but not the model-specific variables. For the two models in the example we obtain a value of $s(\gamma, 6)=-0.0399$ under the Taylor rule, that is when the policy parameters $\gamma$ set the inflation reaction coefficient to 1.5 , the output gap reaction to 0.5 and the coefficient on the lagged interest rate to zero. This value of $s$ quantifies the cumulative difference in the GDP impact of a monetary policy shock in the two models when the central bank is assumed to set interest rates according to Taylor's rule following the shock. ${ }^{15}$

\footnotetext{
${ }^{15}$ Note, since the flexible-price output or natural output level does not respond to a monetary shock by definition, the
} 
Other possible characteristics for comparison are unconditional variances and serial correlation functions. The unconditional contemporaneous covariance matrix $V_{0}^{m}$ for $\left(\left[z x^{m}\right]^{\prime}\right)$ is given by:

$$
V_{0}^{m}=\sum_{j=0}^{\infty} K_{m}{ }^{j} D_{m} \Sigma^{m} D_{m}{ }^{\prime} K_{m}{ }^{j \prime}
$$

The variance is defined by the implicit expression $V_{0}^{m}=K_{m} V_{0}^{m} K_{m}{ }^{\prime}+D_{m} \Sigma^{m} D_{m}{ }^{\prime}$ and is solved for with an algorithm for Lyapunov equations. Given $V_{0}^{m}$ the autocovariance matrices of $\left(\left[z x^{m}\right]^{\prime}\right)$ are readily computed using the relationship:

$$
V_{j}^{m}=K_{m}^{j} V_{0}^{m}
$$

Again, we can compute objects for comparison between models in terms of the unconditional variance or the serial correlations and cross-correlations of common variables. Then, suitable metrics for measuring the distance between two or more models may be calculated. For example, the absolute difference of the unconditional variance for the two models given by:

$$
\omega=\left|V_{0}^{1}(z)-V_{0}^{2}(z)\right|
$$

The sixth entry on the diagonal of $\omega$ constitutes the difference of the unconditional variance of the output gaps of the two simple New-Keynesian models considered. Its value is given by $\omega(6,6)=$ 10.7919 .

It is straightforward to construct other metrics that measure differences between the models. In section 4 of this paper, for example, we will also study autocorrelation functions of comparable variables in different models of the U.S. economy.

\section{A data base of macroeconomic models}

Implementing the approach to model comparison outlined in the preceding section on a broader scale requires an archive of benchmark models. Individual researchers may then expand this model data base by introducing new models and conducting comparative analysis. The data base that we have created includes many well-known empirically-estimated macroeconomic models. The 50 models implemented in the Macroeconomic Model Data Base and available online at http://www.macromodelbase.com as of October 2011 are summarized in Table 6. A more detailed overview of most of the models is provided in appendix B. The data base may easily be expanded. The description of the model comparison software in Appendix A also includes a section explaining how to incorporate new models in the data base and augment them with comparable variables. ${ }^{16}$

impact of this shock on the output gap, that is the deviation of output from the natural level, is the same as the impact of this shock on the level of output in deviation from steady state.

${ }^{16}$ In the future, we hope to develop an interactive software that helps automate the process of including models that model authors have already implemented in a MATLAB environment using DYNARE software for model solution. 
Currently, the data base includes many estimated and calibrated models of the United States and euro area economies. There are also models of the economies of Canada, Chile, Brazil and Hongkong. Furthermore, there are several multi-country models which cover the economies of Japan, Spain, Italy, Germany, the United Kingdom and France in addition to the United States and the euro area.

Most but not all models could be classified as New Keynesian because they incorporate rational expectations, imperfect competition and wage or price rigidities. All models are dynamic, stochastic, economy-wide models. Only a subset of the models could be characterized as monetary business cycle models where all behavioral equations are derived in a completely consistent manner from the optimization problems of representative households and firms. Many authors use the term dynamic stochastic general equilibrium (DSGE) models to refer to this particular class of models. Thus, our data base offers interesting opportunities for comparing policy implications of this class of models to a broader set of empirically estimated macroeconomic models. While most of the models assume that market participants form rational, forward-looking expectations, we have also included some models which assume little or no forward-looking behavior. ${ }^{17}$ In our view, comparative analysis of these classes of models will be useful to evaluate recently voiced criticisms that the new models are rendered invalid by the experience of the global financial crisis.

The models are grouped in five categories in Table 6. The first category includes small-scale calibrated New Keynesian models such as the two models discussed in section 2. These models concentrate on explaining output, inflation and interest rate dynamics. Some of them are calibrated to U.S. data. Most of these models are derived from microeconomic foundations in terms of optimizing households and firms. There are models which expand on the simple model of Rotemberg and Woodford discussed previously by including a foreign sector (Gali and Monacelli (2005)), money demand and real balance effects (Ireland (2004)), labor market rigidities (Christoffel et al. (2009)) or financial frictions (Bernanke et al (1999)).

\footnotetext{
${ }^{17}$ For example, the models of Rudebusch and Svensson (1999) and Orphanides (2003) are essentially structural VAR models with additional restrictions on some of the coefficients. The ECB's Area-Wide Model is a medium-size structural model but with a relatively limited role for forward-looking behavior compared to the other structural, rational expectations models in the data base.
} 
Table 6: Models Available in the Macroeconomic Model Database: Release 1.2. OCTOBER 2011

\section{Small Calibrated Models}

$\begin{array}{lll}1.1 & \text { NK_RW97 } & \text { Rotemberg and Woodford (1997) } \\ 1.2 & \text { NK_LWW03 } & \text { Levin et al. (2003) } \\ 1.3 & \text { NK_CGG99 } & \text { Clarida et al. (1999) } \\ 1.4 & \text { NK_CGG02 } & \text { Clarida et al. (2002) } \\ 1.5 & \text { NK_MCN99cr } & \text { McCallum and Nelson (1999), (Calvo-Rotemberg model) } \\ 1.6 & \text { NK_IR04 } & \text { Ireland (2004) } \\ 1.7 & \text { NK_BGG99 } & \text { Bernanke et al. (1999) } \\ 1.8 & \text { NK_GM05 } & \text { Gali and Monacelli (2005) } \\ 1.9 & \text { NK_GK09 } & \text { Gertler and Karadi (2009) } \\ 1.10 & \text { NK_CK08 } & \text { Christoffel and Kuester (2008) } \\ 1.11 & \text { NK_CKL09 } & \text { Christoffel et al. (2009) } \\ 1.12 & \text { NK_RW06 } & \text { Ravenna and Walsh (2006) }\end{array}$

\section{ESTIMATED US MODELS}

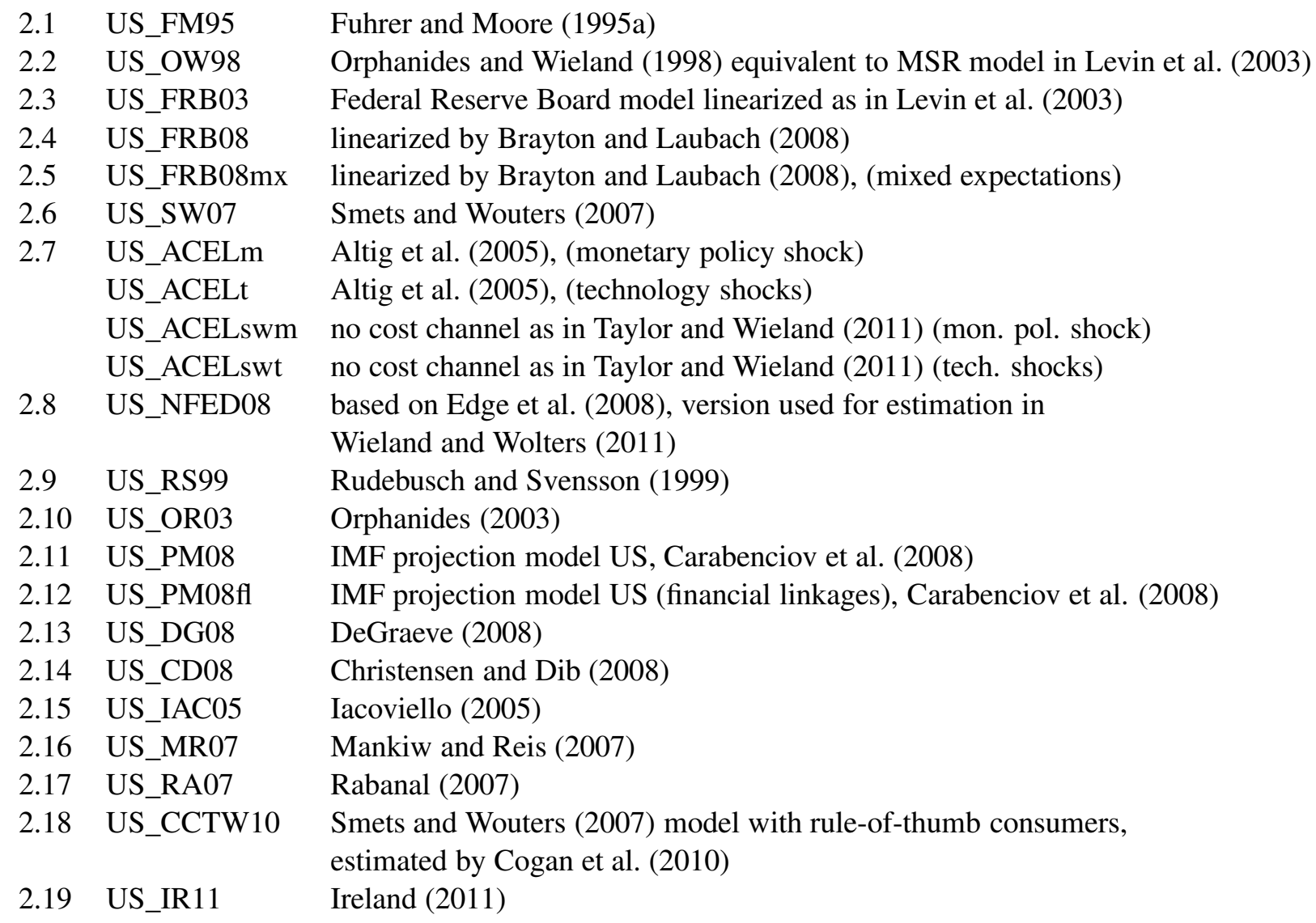




\section{Estimated Euro Area Models}

3.1 EA_CW05ta Coenen and Wieland (2005), (Taylor-staggered contracts)

3.2 EA_CW05fm Coenen and Wieland (2005), (Fuhrer-Moore-staggered contracts)

3.3 EA_AWM05 ECB's area-wide model linearized as in Dieppe et al. (2005)

3.4 EA_SW03 Smets and Wouters (2003)

3.5 EA_SR07 Sveriges Riksbank euro area model of Adolfson et al. (2007)

3.6 EA_QUEST3 QUEST III Euro Area Model of the DG-ECFIN EU, Ratto et al. (2009)

3.7 EA_CKL09 Christoffel et al. (2009)

3.8 EA_GE10 Gelain (2010)

\section{Estimated/CAlibrated Multi-Country Models}

4.1 G7_TAY93 Taylor (1993b) model of G7 economies

4.2 G3_CW03 Coenen and Wieland (2002) model of USA, Euro Area and Japan

4.3 EACZ_GEM03 Laxton and Pesenti (2003) model calibrated to Euro Area and Czech republic

4.4 G2_SIGMA08 The Federal Reserve's SIGMA model from Erceg et al. (2008) calibrated to the U.S. economy and a symmetric twin.

4.5 EAUS_NAWM08 Coenen et al. (2008), New Area Wide model of Euro Area and USA

4.6 EAES_RA09 Rabanal (2009)

\section{Estimated MOdels OF OTHER COUNTRIES}

5.1 CL_MS07 Medina and Soto (2007), model of the Chilean economy

5.2 CA_ToTEM10 ToTEM model of Canada, based on Murchison and Rennison (2006), 2010 vintage

5.3 BRA_SAMBA08 Gouvea et al. (2008), model of the Brazilian economy

5.4 CA_LS07 Lubik and Schorfheide (2007), small-scale open-economy model of the Canadian economy

5.5 HK_FPP11 Funke et al. (2011), open-economy model of the Hong Kong economy

The second category covers estimated models of the U.S. economy. It includes small models of output, inflation and interest rate dynamics such as Fuhrer and Moore (1995a) and Rudebusch and Svensson (1999). Other models are of medium scale such as Orphanides and Wieland (1998) or the well-known models of Christiano, Eichenbaum and Evans (2005) and Smets and Wouters (2007) that fully incorporate recent advances in terms of microeconomic foundations. The data base includes the version of Christiano, Eichenbaum and Evans model estimated by Altig et al. (2005) because it contains other economic shocks in addition to the monetary policy shock studied by Christiano et al (2005). ${ }^{18}$ The largest model of the U.S economy in the data base is the Federal Reserve's FRB-

\footnotetext{
${ }^{18}$ To make sure that we correctly capture the different timing assumptions on monetary and other shocks from the original
} 
US model of Reifschneider et al. (1999). We have included a linearized version of this model with rational expectations that was previously used in Levin et al (2003) as well as a more recent update of this model from 2008. ${ }^{19}$ There is also a recent medium-size DSGE model developed at the Federal Reserve by Edge et al (2008). In addition, this category includes several recently developed models that address some of the criticisms raised in the introduction, for example DSGE models with housing market dynamics (Iacoviello (2005)) and credit market imperfections (De Graeve (2008), Christensen and Dib (2008)) or the model with sticky information by Mankiw and Reis (2007).

The third category in Table 6 covers estimated models of the euro area economy. Four of these models have been used in a recent study of robust monetary policy design for the euro area by Kuester and Wieland (2010): the medium scale model of Smets and Wouters (2003), two small models by Coenen and Wieland (2005) that differ by the type of staggered contracts inducing inflation rigidity, and a linearized version of the Area-Wide Model used at the ECB for forecasting purposes. In addition, we have included fairly large-scale estimated DSGE models of the euro area developed at the Sveriges Riksbank (Adolfson et al. (2007)) and the European Commission (Ratto et al. (2009)). The Commission's QUEST model includes a detailed fiscal sector and the authors have used it to study the impact of fiscal policies in the euro area. The model of Christoffel et al. (2009) incorporates unemployment in labor market dynamics while the model of Gelain (2010) accounts for credit market imperfections.

The fourth category includes estimated and calibrated models of two or more economies. Currently, the largest model in the data base in terms of country coverage is the estimated model of the G7 economies of Taylor (1993). The estimated model of Coenen and Wieland (2003) with rational expectations and price rigidities aims to explain inflation, output and interest rate dynamics and spillover effects between the U.S.A., the euro area and Japan. The model of Laxton and Pesenti (2003) is a two-country model with extensive microeconomic foundations calibrated to the economies of the euro area and the Czech republic. The Federal Reserve's SIGMA model is similarly rich in microeconomic foundations. The parameters in the two-country version of this model from Erceg et al (2008) are calibrated to the U.S. economy and a symmetric twin. The model of Coenen et al. (2008) is a two-economy calibrated version of the New-Area-Wide-Model (NAWM) of the European Central Bank. It is a new DSGE model with optimizing households and firms and a variety of economic frictions. A single-economy euro area version has been estimated with Bayesian techniques and is

model in our DYNARE implementation, we provide two versions, one version for simulating the consequences of the monetary policy shock and the other version for simulating the consequences of the other economic shocks in the model. Furthermore, we have included an additional version of the Altig et al (2005) model used in Taylor and Wieland (2011) that omits the cost-channel of monetary policy. This version was created in Taylor and Wieland (2011) to evaluate the effect of this assumption in comparing the Altig et al (2005) model with the model of Smets and Wouters (2007) that features no such cost channel.

${ }^{19}$ The 2008 linearized version of FRB-US is available in two versions, one version assumes rational expectations while the other version models expectations with a small VAR. 
in use in the forecasting process of the European Central Bank. The calibrated two-economy version has been used by Coenen et al. (2008) to compare the implications of taxation policies in the United States and the euro area. Finally, Rabanal (2009) presents a recent estimated two-economy DSGE model that makes it possible to study spillover effects between the Spanish economy and the rest of the euro area.

Finally, the fifth category covers estimated macroeconomic models of other countries. Ultimately, we hope to incorporate models of most highly developed and emerging economies in the data base in cooperation with researchers from the central banks of these countries. So far, we have two models of the Canadian economy, including a version of the ToTEM model developed and used at the Bank of Canada (see Murchison and Rennison (2006)). The other three models are estimated on data from Brazil (see Gouvea et al. (2008)), Chile (see Medina and Soto (2007)) and Hongkong (Funke et al. (2011)). All of these models belong to the class of New Keynesian DSGE models. The ToTEM model and the model of the Chilean economy account for a special role of a natural resource production sector. The model of the economy of HongKong studies housing dynamics and asset markets.

\section{Comparing monetary and fiscal policies across models: An example}

We have created a computational platform that renders comparisons of impulse response functions of common variables in response to common shocks, comparisons of autocorrelation functions of common variables in response to model-specific shocks and systematic investigations of policy rules across models straightforward. This result may be described by paraphrasing Lucas $(1980)^{20}$ as follows: we have completed the task of writing a program that will accept specific economic policy rules as common comparable input for multiple economic models and will generate as output a comparison across models of statistics describing the operating characteristics of time series we care about, which are predicted to result from these policies according to different economic models.

The computational platform is written for MATLAB and employs the DYNARE software for model solution that is widely-used among macroeconomists. ${ }^{21}$ New models may easily be introduced and compared to established benchmarks thereby fostering a comparative rather than insular approach to model building. A detailed description of the model comparison software is provided in appendix

A.

\footnotetext{
${ }^{20}$ According to Robert Lucas the objective of macroeconomic model building is" to provide fully articulated, artificial economic systems that can serve as laboratories in which policies that would be prohibitively expensive to experiment with in actual economies can be tested out at much lower cost. [...] Our task as I see it [...] is to write a FORTRAN program that will accept specific economic policy rules as 'input' and will generate as 'output' statistics describing the operating characteristics of time series we care about, which are predicted to result from these policies."

${ }^{21}$ DYNARE admits nonlinear as well as linear models and allows approximating nonlinear rational expectations models with perturbation or two-point-boundary-value methods. For further information on DYNARE see Juillard (2001) and Juillard (1996). DYNARE is available for download from www.dynare.org. Our software for model comparison including the model archive may be obtained from www.macromodelbase.com.
} 


\section{Monetary policy rules.}

The software implementation and model database contain a generalized interest rate rule that allows for much richer specifications than the rule previously defined in equation (9) and used in the model augmentation example in section 2.1. In the following, we consider five parameterizations of this generalized rule that are taken from Taylor (1993a), Levin et al. (2003), Smets and Wouters (2007), Christiano, Eichenbaum and Evans (2005) and Gerdesmeier and Roffia (2004), respectively. The specific formulas are shown in Table 7.

Table 7: POLICY RULES

$$
\begin{array}{lll}
\text { Taylor (1993a): } & i_{t}^{z}=\sum_{j=0}^{3} 0.38 p_{t-j}^{z}+0.50 q_{t}^{z}+\eta_{t}^{i} \\
\text { Levin et al. (2003): } & i_{t}^{z}=0.76 i_{t-1}^{z}+\sum_{j=0}^{3} 0.15 p_{t-j}^{z}+1.18 q_{t}^{z}-0.97 q_{t-1}^{z}+\eta_{t}^{i} \\
\text { Smets and Wouters (2007): } & i_{t}^{z}=0.81 i_{t-1}^{z}+0.39 p_{t}^{z}+0.97 q_{t}^{z}-0.90 q_{t-1}^{z}+\eta_{t}^{i} \\
\text { Christiano et al. (2005) } & i_{t}^{z}=0.8 i_{t-1}^{z}+0.3 E_{t} p_{t+1}^{z}+0.08 q_{t}^{z}+\eta_{t}^{i} \\
\text { Gerdesmeier and Roffia (2004): } & i_{t}^{z}=0.66 i_{t-1}^{z}+\sum_{j=0}^{3} 0.17 p_{t-j}^{z}+0.10 q_{t}^{z}+\eta_{t}^{i}
\end{array}
$$

The first rule in the table — the simple monetary policy rule of Taylor (1993a) — is well-known beyond academic economics and central banks. In the 1990s Taylor's rule received much attention because it described Federal Reserve interest rate decisions since 1987 surprisingly well. More recently, the large downward deviation of Federal Reserve policy from this rule between 2002 and 2006 has been referred to as a source of cheap money that helped fuel a housing bubble in the United States that triggered the global financial crisis. It is a little know fact, however, that this rule originates from an earlier model comparison exercise. Taylor (1993b) credits the comparison exercise of Bryant et al (1993) as the crucial testing ground that helped select this particular simple rule. Variations of the rule, motivated either by empirical estimation or model performance, abound in the literature. Here we consider four additional rules.

The second rule was originally estimated with U.S. data by Orphanides and Wieland (1998) and simulated in five models of the U.S. economy by Levin et al. (2003) (LWW). Their selection of models is included in our data base. The LWW rule allows for interest-rate smoothing and includes the lag of the output gap in addition to the current output gap and current inflation. Smets and Wouters (2007) (SW) have estimated the same type of rule with interest-rate smoothing, current inflation, current and past output gaps using Bayesian techniques together with the other structural parameters of their 
model. Christiano, Eichenbaum and Evans (2005) consider a different policy rule that they attribute to Clarida, Gali and Gertler (1999). Their rule includes a response to the forecast of inflation rather than current inflation. It has also been studied in Taylor and Wieland (2011). Furthermore, we add a rule estimated with Euro area data. This rule is due to Gerdesmeier and Roffia (2004) and has been simulated in Kuester and Wieland (2010) in four models of the euro area economy that are also included in our data base.

The remainder of this section serves to illustrate the comparative approach to macroeconomic modeling and policy analysis with a few simple examples. First, we compare the consequences of monetary and fiscal policy shocks in a range of models of the U.S. economy under different assumptions regarding the systematic, rule-oriented component of monetary policy. Then, we evaluate models' predictions regarding the persistence of output and inflation under different monetary rules.

\section{Policy shocks.}

Figure 1 reports comparative information regarding the effect of an expansionary monetary policy shock, that is an unexpected reduction in the short-term nominal interest rate. It shows the impact on output (left column of panels) and inflation (right column) under three different monetary rules: the Taylor rule (top row of panels), the LWW rule (middle row) and the SW rule (bottom row). Each panel contains four lines that indicate the outcomes in four different models of the U.S. economy: (i) the calibrated small-scale New-Keynesian model of Rotemberg and Woodford (1997) summarized previously in Table 5 (solid blue line: $N K_{-} R W 97$ ); (ii) the Federal Reserve's FRB-US model from Levin et al. (2003) (dashed red line: US_FRB03); (iii) the New Keynesian DSGE model of Altig et al. (2005) (dotted pink line: US_ACELm); and (iv) the model of Smets and Wouters (2007) (dashed-dotted green line: US_SW07). The magnitude of the interest rate shock is 1 percentage point. Following this unexpected rate cut the nominal interest rate continues to be set according to the specified monetary policy rule. 
Figure 1: An EXPAnsionary Monetary Policy Shock
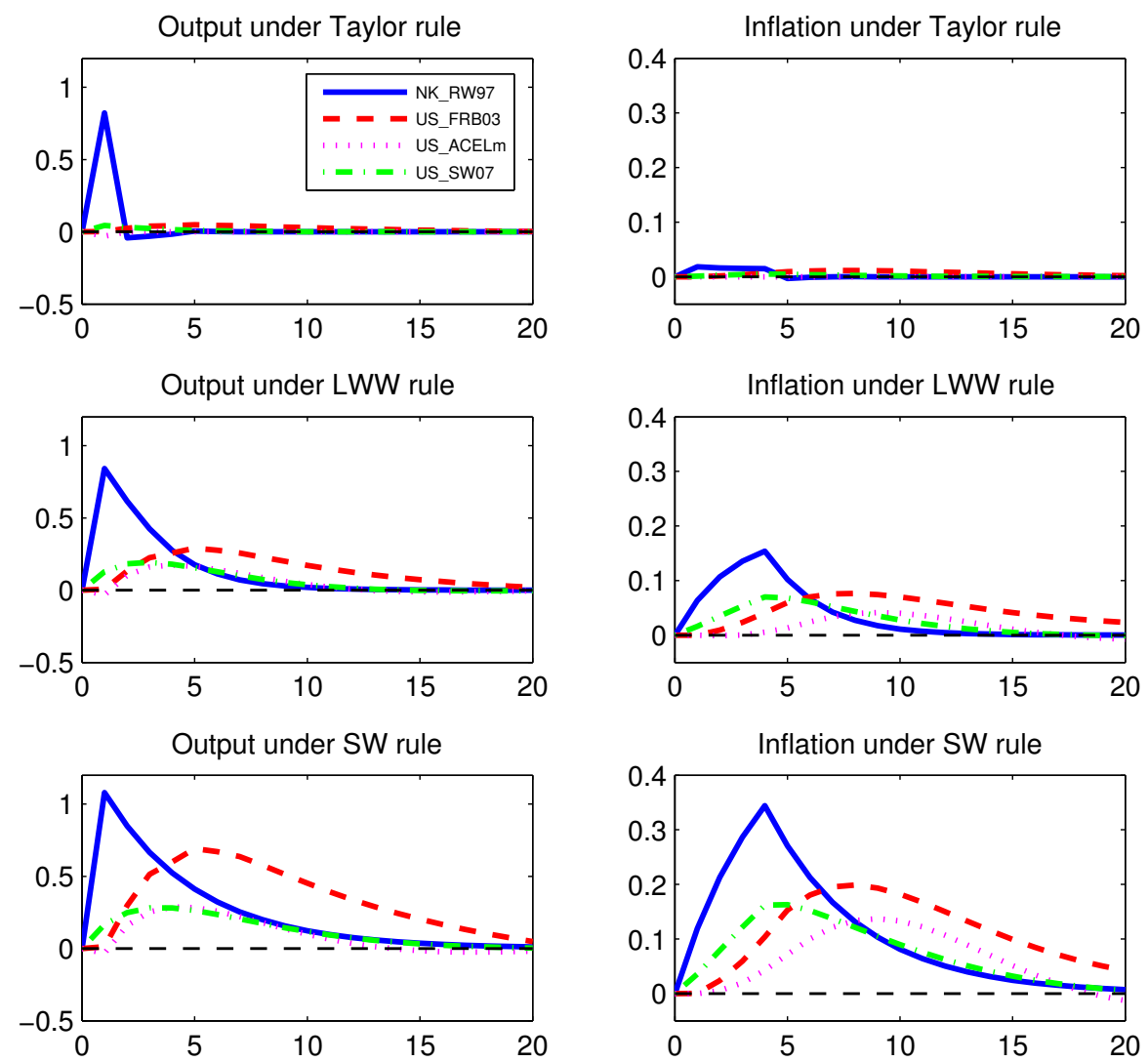

All four models indicate that a reduction in the central bank rate boosts real GDP. The sign of this effect is more or less hard-wired into these models. Due to the assumption of sticky prices, the nominal rate cut translates into a lower real interest rate, which stimulates current consumption and investment. This additional demand triggers more production. The magnitude and timing of the GDP impact of the monetary policy shock differs across models and policy rules. Under the Taylor rule, the effect on output is short-lived. It is also very small with the exception of $N K \_R W 97$ model. This model indicates a sharp but temporary boost to output under the Taylor rule. If interest rates in subsequent periods are set according to the LWW or SW rule the increase in output lasts much longer, between two and five years in the different models. Contrary to the Taylor rule, these rules incorporate interest rate smoothing in form of a near-unity coefficient on the lagged interest rate. Thus, the initial rate reduction is followed by a period during which the interest rate slowly returns to its long-run equilibrium value. The anticipation of a period of lower rates induces a greater and more lasting effect on spending in these models, because all of them assign an important role to forward-looking 
decision making by households and firms.

In the $N K \_R W 97$ model the sharp initial boost is followed by a slow decline. However, since its parameters are calibrated rather than estimated, this model's quantitative predictions should be considered with a lot of caution. In the three estimated models, the effect builds up over a few quarters and then declines. Interestingly, the US_FRBO3 model implies that the peak is only reached in the second year, while the US_ACELm and US_SW07 models indicate the peak effect within 2 to 4 quarters. Thus, the two DSGE models that were estimated more recently and incorporate advances in microeconomic foundations contradict conventional policy maker wisdom regarding long policy lags of more than a year. Taylor and Wieland (2011) point out that the earlier New Keynesian model of Taylor (1993b) agrees with the more recent DSGE models in its estimate of the impact of such policy shocks. These findings, together, suggest that the Federal Reserve's model may be over-estimating the time it takes for a change in policy to be fully transmitted to the real economy. Possible reasons may be that the US_FRBO3 model overstates the extent of adjustment costs faced by forward-looking households and firms or the importance of backward-looking, adaptive behavior.

As indicated by the right column of panels, an unexpected interest rate cut leads to an increase in inflation. However, it occurs later than the increase in GDP. The reason is price stickiness. As more and more price setters adjust to higher demand, inflation rises. Again, the calibrated $N K \_R W 97$ model indicates a sharper response than the empirically-estimated models that appears too extreme. The effect lasts for the longest period in the US_FRBO3 model.

The other policy shock that is specified in a common manner in our model comparison exercise is a shock to the non-systematic or discretionary component of government purchases. As discussed previously in section 2 the fiscal policy rule for discretionary government purchases is defined by equation (10) with a coefficient $\gamma_{g}$ of unity. We consider an expansionary shock in the magnitude of 1 percent of GDP. The estimated degree of persistence of such a shock to government purchases differs in each model. Figure 2 reports the implications of this shock for output (left column of panels) and inflation (right column). Each panel contains three lines representing the simulation outcomes in the NK_RW97, US_FRB03 and US_SW07 model, respectively. The US_ACELm model is omitted because it does not include a variable for government spending.

In all three models, the initial shock causes output to increase in the same quarter followed by a slow drawn-out decline over subsequent years. This profile holds under all three monetary policy rules that were considered previously for the monetary shock: the Taylor, SW and LWW rules. The magnitude of the effect is rather similar for these monetary rules, but it differs a lot across models. The impact effect is smallest in the calibrated small-scale $N K \_R W 97$ model at around 0.4 percent of output, compared to about 1 percent of output in the other two models. In the $N K \_R W 97$ model, the increase in government spending immediately displaces private spending. This crowding-out effect is 
due to the anticipation of higher future interest rates and future taxes by forward-looking households. In the other two models, government purchases crowd out private consumption and investment in the periods following the initial shock. Output declines faster in the US_FRBO3 model than in the US_SW07 model, because the systematic component of government spending is less persistent in the US_FRBO3 model. Of course, comparative investigations of the consequences of fiscal stimulus are of great interest because of the amount of resources spent on such measures in a number of countries following the 2008-2009 recession. We will point out some recent studies in the outlook section.

Figure 2: An ExPANSIONARY FISCAL Policy SHOCK
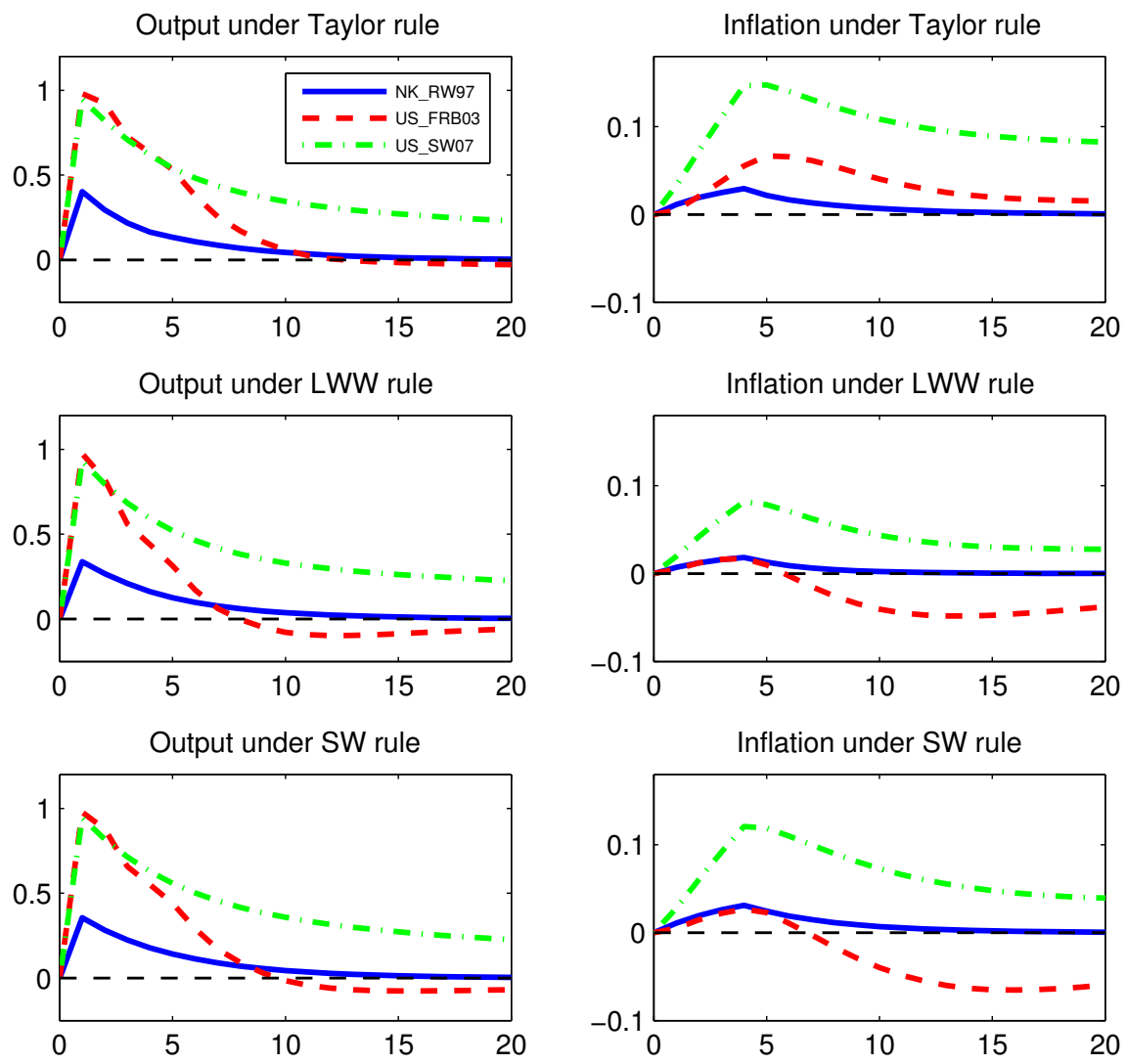

\section{Output and inflation persistence.}

Next, we turn to a comparison of the typical degree of persistence in output and inflation across models and monetary rules. It is measured by the autocorrelation functions that are obtained under the empirical distributions of structural shocks - excluding the monetary policy shock - in the different models. Figure 3 reports the autocorrelation functions of output (left column of panels) and inflation 
(right column) under the Taylor (top row), LWW (middle row) and SW (bottom row) rules.

Figure 3: AUtOCORRELATION FUnCTIONS
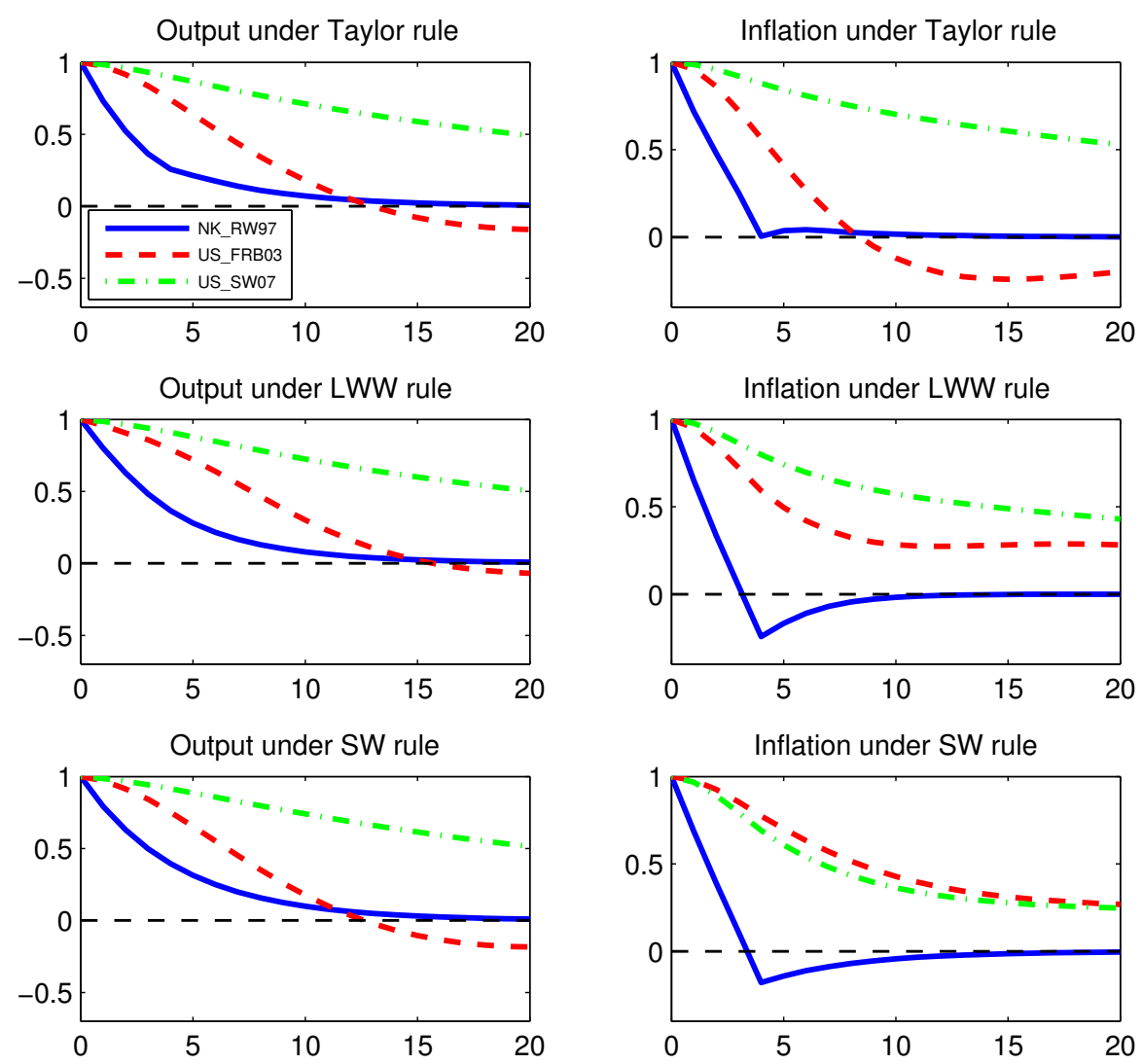

The Altig et al. (2005) model is omitted from the comparison because the two non-monetary shocks in that model only explain a relatively small part of the empirical output and inflation volatility in the U.S. economy (see Taylor and Wieland (2011)). The calibrated small-scale $N K \_R W 97$ model exhibits the lowest degree of output and inflation persistence for any of the three monetary rules. As discussed in section 2 this model does not allow for lagged terms of inflation and output in the New-Keynesian IS and Phillips curves. Only the exogenous shocks incorporate persistence.

The two models that are estimated to fit U.S. macroeconomic data exhibit substantial output and inflation persistence. The empirical fit of the Federal Reserve's US_FRBO3 model is due to a richer set of dynamics and adjustment costs that imply the appearance of one or more lags of endogenous variables in key behavioral equations. The estimated, medium-scale $U S \_S W$ model implements all restrictions arising from optimizing and forward-looking households and firms just as in the small-scale $N K \_R W 97$ model. However, this model renders decision making subject to additional constraints 
such as habit formation in consumption, adjustment costs in investment and capital utilization, wage rigidities and price indexation. Thus, output and inflation persistence arises from lags of endogenous variables as well as exogenous shocks. Surprisingly, the $U S \_S W$ model even exhibits a higher degree of output persistence than the US_FRBO3 model under all three policy rules. One might have expected that this model with microeconomic foundations would lie somewhere in between the small calibrated model of Rotemberg and Woodford (1997) and the Federal Reserve's model. Models such as US_FRBO3 were often criticized for introducing too many adjustment costs and therefore too much endogenous persistence. Given our findings one might therefore suspect that Smets and Wouters (2007) have built in too much persistence in their model, a criticism recently also voiced by Chari, Kehoe, and McGrattan (2009). It would be of interest to further investigate the sources of persistence in this model in future work.

Finally, the serial correlation functions in Figure 3 also show that the choice of monetary policy rule can have a quantitatively significant impact on the degree of output and inflation persistence. For example, inflation persistence in the $U S \_F R B 03$ model is much less pronounced under the Taylor rule than under the two other rules.

\section{Model comparison and the Lucas critique.}

In the preceding exercises we have simulated the implications of different interest rate rules while leaving the values of the non-policy parameters unchanged. All the models in the archive have been used for such alternative policy simulations by their developers. Thus, our simulations do not in any way involve radical departures from the purposes the models were built and used for by the original authors. Our contribution is to offer a comparative perspective that helps uncover typical and special characteristics of particular models. Even so, the question of parameter stability has played an important role in the literature on macroeconomic modeling and may certainly influence the interpretation of our comparative findings.

The famous Lucas critique (Lucas (1976)) emphasizes that forward-looking, optimizing households and firms will observe systematic changes in government policy making and adjust their behavior accordingly. Thus, the non-policy parameters of the reduced-form behavioral equations in macroeconomic models will change along with modifications in the policy rules. As a consequence, models that do not properly capture the forward-looking behavioral response of market participants will not correctly predict the impact of a policy change on the time series characteristics of variables of interest. Lucas therefore concluded that such models should not be used for alternative policy simulations and policy design, (see also Sims (1986)).

The models in our archive incorporate the forward-looking behavior of optimizing market participants to different degrees. Certainly, models with largely adaptive expectations that are specified 
on the level of behavioral equations and were most widely used 30 years ago are subject to the Lucas critique. New Keynesian models incorporate forward-looking behavior and assign an important role to market participants' expectations. The DSGE models developed more recently enforce the parameter restrictions resulting from optimizing behavior by households and firms most stringently. This may provide an argument for giving these models a greater weight in policy design. Generally, the quantitative importance of the Lucas critique also depends on the extent to which the alternative policy rule considered differs from the rule estimated within the respective model.

Even though DSGE models have been developed to improve the robustness of macroeconomic models to the Lucas critique, it is clear that parameter instability under policy changes remains an important issue in practice. Such models not only assume that the estimated parameters describing preferences and technology are invariant to changes in the policy regime, but also the parameters associated with adjustment costs, nominal stickiness and exogenous shock processes. For instance, the dynamics in the exogenous processes may be considered as a short-cut for taking up model misspecification which is most likely sensitive to policy regimes. Del Negro and Schorfheide (2009) provide an extensive discussion and some empirical evidence on these considerations.

Finally, much of the recent criticism of DSGE models is concerned with the admittedly extreme assumptions of fully rational decision making and expectations formation by largely homogenous market participants. To the extent these assumptions are violated in practice, the cross-equation restrictions imposed by DSGE models would be at odds with the data. From this perspective, comparative analysis using earlier vintage models that impose less restrictions can be helpful to robustify policy conclusions. Furthermore, these criticisms will provide fuel for new model development. Our model archive should then prove useful for comparisons between the current model generation and newly developed ones.

\section{Outlook}

Our comparative approach enables individual researchers to conduct model comparisons easily, frequently, at low cost and on a large scale. Researchers can easily include new models in the data base and compare the effects of novel extensions to established benchmarks thereby fostering a comparative instead of insular approach to model development. Wide application of this approach could help dramatically improve the replicability of quantitative macroeconomic analysis, reduce the danger of circular developments in model-based research and strengthen the robustness of policy recommendations.

\section{Model-specific versus robust policies.}

A standard approach to policy design is to use a macroeconomic model for providing recommen- 
dations regarding the optimal policy response to a small number of variables in form of interest rate rules such as those shown previously in Table 7. The estimated values are then replaced by values that optimize a central bank objective function or a measure of household utility in the specific model. Typical central bank objectives would be to minimize the standard deviation of inflation from its policy target, and possibly also output deviations from a measure of potential as well as interest rate volatility. They tend to be justified with reference to central bank mandates and observed behavior. Measures of household welfare are available in recent DSGE models but typically apply to identical representative households.

Model-specific optimized rules, however, can be far from optimal in competing macroeconomic models as shown by comparative studies such as, for example, Levin, Wieland and Williams (1999, 2003). Thus, they are not robust to model uncertainty. Levin et al. (2003), instead, consider model averaging. In this case, the response coefficients of policy rules are chosen to optimize the average value of the objective functions from a range of empirically-estimated macroeconomic models. Such model averaging rules exhibit a more robust stabilization performance across models and avoid disastrous outcomes. Taylor and Wieland (2011) provide a first application using four models from the archive presented in this paper. They consider three recent DSGE models estimated on U.S. data, the US_SW07, US_ACEL and US_DG08 models, together with the earlier-generation G7_TAY93 model.

A Bayesian approach would be to use model probabilities and optimize a probability-weighted average of objective functions. Brock, Durlauf, and West (2007) suggest a decision strategy based on the fit and forecasting performance of the various models. Kuester and Wieland (2010) compare Bayesian decision making and worst-case analysis and investigate policy robustness using four estimated models of the euro area economy that are also contained in our archive. Worst-case analysis implies computing the Minimax policy that delivers maximal insurance against worst-case scenarios. Specifically, Kuester and Wieland (2010) then choose the policy response coefficients that minimize performance losses under the assumption that nature picks the model with the highest loss given the policy choice. In addition, they consider mixtures of Minimax and Bayesian objectives and explore the impact of learning on model posteriors and Bayesian objectives over time. In future research, we aim to make use of the larger number of models available from our model archive, including more recent innovations in financial sector modeling, in order to revisit the robustness properties of simple policy rules.

\section{Fiscal policy design.}

Relative to monetary rules, the study of fiscal rules for macroeconomic stabilization purposes is still in its infancy. Many of the models available in our archive have been developed for monetary policy analysis and are not well suited for evaluating a large range of fiscal policies. However, some 
of the models in the archive were built with the specific purpose of fiscal analysis by their original authors. For example, the open-economy euro area model of Ratto et al. (2009) was built at the European Commission specifically for the joint analysis of fiscal and monetary policy and provides a thorough treatment of the government sector. It includes policy rules for government consumption, government investment and government transfers and uses data on these variables in estimation. It also accounts for distortionary taxes on consumption, capital and labor income. Furthermore, it allows for the possibility that many households follow "rules of thumb" like the original Keynesian consumption function with a constant marginal propensity to consume. Also, the model of Coenen et al. (2008) available in our data base was used by the authors to examine the euro area tax structure and the potential benefits and spillovers of a tax reform aiming to reduce labor market distortions. It is a two-country calibrated version of the European Central Bank's New Area-Wide model.

Many medium- and large-scale models used at policy institutions nowadays contain a rather detailed treatment of the fiscal sector with various types of distortionary taxes and explicit modeling of the different components of government spending and transfers. These models can be used to evaluate discretionary as well as rule-based fiscal policy initiatives. They are most useful for investigating questions concerning business cycle stabilization and the interaction of monetary and fiscal policy measures in the short to medium run. Of course, there are many fiscal policy questions that focus on distributional issues and longer-term impacts. Other computable general equilibrium models that are more appropriate for such questions are available and they need not include New Keynesian features relevant to shorter-term stabilization questions.

Given the renewed popularity of discretionary fiscal policy following the 2008-2009 global recession, comparative evaluations of the robustness of policy recommendations for fiscal stimulus are particularly urgent. Cogan et al. (2010) provided a first assessment of the American Recovery and Reinvestment Act of 2009 suggesting that the estimates of its GDP impact used by government advisers (cf. Romer and Bernstein (January 8, 2009)) were too optimistic and not robust to model uncertainty. ${ }^{22}$ They estimated a model of the U.S. economy similar to US_SW07 but including ruleof-thumb households, US_CCTW10 in our archive.

More recently, the comparative study by Coenen et al (2012) sponsored by the International Monetary Fund investigated the robustness of their finding. These 17 authors simulate the time profile of ARRA spending documented by Cogan et al in seven macroeconomic models, which are currently used at the IMF, the Federal Reserve, the ECB, the Bank of Canada, the OECD and the European Commission, and compare their results with those obtained in the models estimated by Cogan et al. (2010) and Christiano et al. (2005). The US_CCTW10 model lies well within the range of other model outcomes. ${ }^{23}$ This finding is particularly interesting because the models used at policy institutions

\footnotetext{
${ }^{22}$ For a comparative evaluation of euro area fiscal stimulus measures see Cwik and Wieland (2011).

${ }^{23}$ See the results shown in Figure 7 of Coenen et al (2012).
} 
contain more detailed fiscal sectors. The IMF's GIMF model is especially noteworthy as it includes overlapping-generation households with finite planning horizons. This level of heterogeneity is rare in New Keynesian DSGE models, but relevant for many fiscal policy considerations (see Freedman et al (2010)). As to the stimulative effect of planned ARRA spending, however, the model's predictions remain close to the pessimistic assessment of Cogan et al. In future work, we hope to include some of these larger models from policy institutions in our model comparison platform. Unfortunately these models are coded in TROLL software, which is not widely used in academia.

\section{Model replication, re-estimation and forecasting competition.}

The website associated with the model archive (http://www.macromodelbase.com) also provides software for checking whether certain results from the original model developers' scientific articles can be replicated. Replicability is a crucial scientific standard. We found, however, that there is still substantial need for improvement in our field in this regard. Often printed articles do not provide sufficient information on the rather sophisticated macroeconomic models to allow replication. Even in those cases where software is made available on journal websites, it is not always possible to replicate the published findings exactly. Yet fortunately, the authors of the models included in our archive have typically been very willing to help us in making sure we can replicate their findings.

Currently, the material available for download does not include the original data used by model developers' in estimation, because of lack of personnel resources needed for collecting and preparing these data sets for general use. However, in a recent study, Wieland and Wolters (2011) have put together a data set of key U.S. macroeconomic variables and re-estimated five of the structural models of the U.S. economy that are available in our archive. Their data set includes current as well as historical data vintages. On this basis, they were able to construct successive historical model forecasts that only use the data available at the date the forecast is made. These forecasts are comparable to expert forecasts made at the same dates, because they do not use information that only became available subsequently via revisions of macroeconomic aggregates. The mean model forecast comes surprisingly close to the mean forecasts from the Survey of Professional Forecasters and the Federal Reserve's Greenbook forecasts in terms of accuracy even though the models only make use of a small number of data series. Model forecasts compare particularly well to expert forecasts at a horizon of three to four quarters and during recoveries. The extent of forecast heterogeneity is similar for model and expert forecasts but varies substantially over time. Wieland and Wolters (2011) propose to use such forecasting exercises as a testing ground for model competitions. ${ }^{24}$

In light of the experience of the global financial crisis, it would be very useful to extend the cov-

\footnotetext{
${ }^{24}$ Of course, in re-estimation and forecasting the developers' original policy rules are used.
} 
erage of the model data base for future policy robustness evaluations. In the words of ECB President Trichet $^{25}$, " we need to better integrate the crucial role played by the financial system into our macroeconomic models, ... we may need to consider a richer characterisation of expectation formation, ... We need to deal better with heterogeneity across agents and the interaction among those heterogeneous agents, (and) we need to entertain alternative motivations for economic choices". Thus, we would propose a major research effort to include the following modeling approaches for direct comparison: (i) DSGE models with more realistic treatments of banking and financial risks, (ii) models that deviate from the standard assumption of rational expectations by including imperfect information, learning and heterogeneous beliefs, (iii) models that allow for deviations from the basic microeconomic assumption of rational optimizing behavior by households and firms. This proposal is laid out in more detail in Wieland (2011).

\section{References}

Adolfson, M., Laseen, S., Linde, J., Villani, M., 2007. Bayesian estimation of an open economy DSGE model with incomplete pass-through. Journal of International Economics 72, 481-511.

Altig, D. E., Christiano, L. J., Eichenbaum, M., Linde, J., 2005. Firm-specific capital, nominal rigidities and the business cycle, cEPR Discussion Papers 4858.

Bernanke, B., Gertler, M., Gilchrist, S., 1999. The financial accelerator in a quantitative business cycles framework. In: Taylor, J. B., Woodford, M. (Eds.), Handbook of Macroeconomics Volume 1C. Amsterdam: Elsevier Science, North-Holland.

Blanchard, O., Fischer, S., 1989. Lectures on Macroeconomics. The MIT Press.

Brayton, F., Laubach, T., 2008. Documentation of linearized FRB/US.

Brock, W. A., Durlauf, S., West, K., 2007. Model uncertainty and policy evaluation: Some theory and empirics. Journal of Econometrics 136(2), 629-664.

Bryant, R., Currie, D., Frenkel, J., Masson, P., Portes, R. (Eds.), 1989. Macroeconomic Policies in an Interdependent World. Washington, D.C.: The Brookings Institution.

Bryant, R., Henderson, D. W., Holtham, G., Hooper, P., Symansky, S. A. (Eds.), 1988. Empirical Macroeconomics for Interdependent Economies. Washington, D.C.: The Brookings Institution.

Bryant, R., Hooper, P., Mann, C. (Eds.), 1993. Evaluating Policy Regimes: New Research in Empirical Macroeconomics. Washington, D.C.: The Brookings Institution.

\footnotetext{
${ }^{25}$ Speech on "Reflections on the nature of monetary policy non-standard measures and finance theory", 18 November 2010.
} 
Calvo, G., 1983. Staggered prices in a utility maximizing framework. Journal of Monetary Economics $12,383-398$.

Carabenciov, I., Ermolaev, I., Freedman, C., Juillard, M., Kamenik, O., Korshunov, D., Laxton, D., 2008. A small quarterly projection model of the US economy, iMF Working Paper 08/278.

Chari, V. V., Kehoe, P., McGrattan, E., 2009. New Keynesian models: Not yet useful for policy analysis. American Economic Journal: Macroeconomics 1(1), 242-266.

Christensen, I., Dib, A., 2008. The financial accelerator in an estimated New Keynesian model. Review of Economic Dynamics 11, 155-178.

Christiano, L. J., 2002. Solving dynamic equilibrium models by a method of undetermined coefficients. Computational Economics 20(1-2), 21-55.

Christiano, L. J., Eichenbaum, M., Evans, C. L., 2005. Nominal rigidities and the dynamic effects of a shock to monetary policy. Journal of Political Economy 113(1), 1-45.

Christiano, L. J., Motto, R., Rostagno, M., 2003. The great depression and the Friedman-Schwartz hypothesis. Journal of Money, Credit and Banking 35, 1119-1197.

Christoffel, K., Kuester, K., 2008. Resuscitating the wage channel in models with unemployment fluctuations. Journal of Monetary Economics 55, 865-887.

Christoffel, K., Kuester, K., Linzert, T., 2009. The role of labor markets for euro area monetary policy. European Economic Review 53, 908-936.

Clarida, R., Gali, J., Gertler, M., 1999. The science of monetary policy: A New Keynesian perspective. Journal of Economic Literature 37(4), 1661-1707.

Clarida, R., Gali, J., Gertler, M., 2002. A simple framework for international monetary policy analysis. Journal of Monetary Economics 49, 879-904.

Coenen, G., Erceg, C. J., Freedman, C., Furceri, D., Kumhof, M., Lalonde, R., Laxton, D., Linde, J., Mourougane, A., Muir, D., Mursula, S., de Resende, C., Roberts, J., Roeger, W., Snudden, S., Trabandt, M., in’t Veld, J., 2012. Effects of fiscal stimulus in structural models. American Economic Journal: Macroeconomics 4, 22-68.

Coenen, G., McAdam, P., Straub, R., 2008. Tax reform and labour-market performance in the euro area: A simulation-based analysis using the New Area-Wide Model. Journal of Economic Dynamics \& Control 32(8), 2543-2583.

Coenen, G., Orphanides, A., Wieland, V., 2004. Price stability and monetary policy effectiveness 
when nominal interest rates are bounded at zero. Berkeley Electronic Press: Advances in Macroeconomics 4(1), 1-23.

Coenen, G., Wieland, V., 2002. Inflation dynamics and international linkages: A model of the United States, the Euro Area and Japan, eCB Working Paper Series 181.

Coenen, G., Wieland, V., 2005. A small estimated euro area model with rational expectations and nominal rigidities. European Economic Review 49, 1081-1104.

Cogan, J. F., Cwik, T., Taylor, J. B., Wieland, V., 2010. New Keynesian versus Old Keynesian government spending multipliers. Journal of Economic Dynamics \& Control 34, 281-295.

Collard, F., Juillard, M., 2001. Accuracy of stochastic perturbation methods: The case of asset pricing models. Journal of Economic Dynamics \& Control 25, 979-999.

Cwik, T., Wieland, V., 2011. Keynesian government spending multipliers and spillovers in the euro area. Economic Policy 26, 493-549.

DeGraeve, F., 2008. The external finance premium and the macroeconomy: US post-WWII evidence. Journal of Economic Dynamics and Control 32, 3415-3440.

Dieppe, A., Kuester, K., McAdam, P., 2005. Optimal monetary policy rules for the euro area: An analysis using the area wide model. Journal of Common Market Studies 43 (3), 507-5372.

Edge, R. M., Kiley, M. T., Laforte, J.-P., 2008. Natural rate measures in an estimated DSGE model of the U.S. economy. Journal of Economic Dynamics \& Control 32, 2512-2535.

Erceg, C. J., Guerrieri, L., Gust, C., 2008. Trade adjustment and the composition of trade. Journal of Economic Dynamics \& Control 32, 2622-2650.

Erceg, C. J., Henderson, D., Levin, A., 2000. Optimal monetary policy with staggered wage and price contracts. Journal of Monetary Economics 46, 281-313.

Fagan, G., Henry, J., Mestre, R., 2005. An area-wide model for the euro area. Economic Modelling $22,39-59$.

Fair, R. C., Taylor, J. B., 1983. Solution and maximum likelihood estimation of dynamic nonlinear rational expectations models. Econometrica 51, 1169-1185.

Freedman, C., Kumhof, M., Laxton, D., Muir, D., Mursula, S., 2010. Global effects of fiscal stimulus during the crisis. Journal of Monetary Economics 57, 506-526.

Fuhrer, J. C., Moore, G., 1995a. Inflation persistence. The Quarterly Journal of Economics 110(1), $127-159$. 
Fuhrer, J. C., Moore, G., 1995b. Monetary policy trade-offs and the correlation between nominal interest rates and real output. The American Economic Review 85(1), 219-239.

Funke, M., Paetz, M., Pytlarczyk, E., 2011. Stock market wealth effects in an estimated DSGE model forHong Kong. Economic Modelling 28, 316-334.

Gali, J., Gertler, M., 1999. Inflation dynamics: A structural econometric analysis. Journal of Monetary Economics 113(1), 1-45.

Gali, J., Monacelli, T., 2005. Monetary policy and exchange rate volatility in a small open economy. Review of Economic Studies 72, 707-734.

Gelain, P., 2010. The external finance premium in the euro area: A dynamic stochastic general equilibrium analysis. North American Journal of Economics and Finance 21, 49-71.

Gerdesmeier, D., Roffia, B., 2004. Empirical estimates of reaction functions for the euro area. Swiss Journal of Economics and Statistics 140(1), 37-66.

Gertler, M., Karadi, P., 2009. A model of unconventional monetary policy.

Gouvea, S., Minella, A., Santos, R., Souza-Sobrinho, N., 2008. Samba: Stochastic analytical model with a bayesian approach, manuscript.

Hughes-Hallett, A., Wallis, K. F. (Eds.), 2004. EMU Macroeconomic Model Comparison excercise for the Euroconference 7-8 June 2002. Economic Modelling 21(5).

Iacoviello, M., 2005. House prices, borrowing constraints, and monetary policy in the business cycle. The American Economic Review 95(3), 739-764.

Ireland, P., 2003. Endogenous money or sticky prices? Journal of Monetary Economics 50, 16231648.

Ireland, P., 2004. Money's role in the monetary business cycle. Journal of Money, Credit and Banking 36(6), 969-983.

Ireland, P., 2011. A New Keynesian perspective on the Great Recession. Journal of Money, Credit and Banking 43(1), 31-54.

Judd, K. (Ed.), 1998. Numerical Methods in Economics. MIT Press.

Juillard, M., 1996. Dynare: A program for the resolution and simulation of dynamic models with forward variables through the use of a relaxation algorithm, cEPREMAP working paper, 9602.

Juillard, M., 2001. Dynare: A program for the simulation of rational expectation models, computing 
in Economics and Finance 213.

Kimball, M., 1995. The quantitative analytics of the basic Neomonetarist model. Journal of Money, Credit and Banking 27(4), 1241-1277.

Kiyotaki, N., Moore, J., 1997. Credit cycles. Journal of Political Economy 105(2), 211-48.

Klein, L. (Ed.), 1991. Comparative Performance of U.S. Econometric Models. Oxford, Eng.: Oxford University Press.

Klein, P., 2000. Using the generalized Schur form to solve a multivariate linear rational expectations model. Journal of Economic Dynamics and Control 24(10), 1405-1423.

Kuester, K., Wieland, V., 2005. Insurance policies for monetary policy in the euro area, eCB Working Paper Series 480.

Kuester, K., Wieland, V., 2010. Insurance policies for monetary policy in the euro area. Journal of the European Economic Association 8(4), 872-912.

Laxton, D., Pesenti, P., 2003. Monetary rule for small, open, emerging economies. Journal of Monetary Economics 50, 1109-1146.

Levin, A., Wieland, V., Williams, J. C., 2003. The performance of forecast-based monetary policy rules under model uncertainty. The American Economic Review 93(3), 622-645.

Lubik, T. A., Schorfheide, F., 2007. Do central banks respond to exchange rate movements? a structural investigation. Journal of Monetary Economics 54, 1069-1087.

Lucas, R., 1976. Econometric policy evaluation: A critique. Carnegie-Rochester Conference Series on Public Policy 1, 19-46.

Lucas, R., 1980. Methods and problems in business cycle theory. Journal of Money, Credit and Banking 12(4), 696-715.

Mankiw, N. G., Reis, R., 2007. Sticky information in general equilibrium. Journal of the European Economic Association 5(2-3), 603-613.

McCallum, B., 1988. Robustness properties of a rule for monetary policy. Carnegie-Rochester Conference Series on Public Policy 29, 173-204.

McCallum, B., 1999. Issues in the design of monetary policy rules. In: Taylor, J. B., Woodford, M. (Eds.), Handbook of Macroeconomics. Amsterdam: Elsevier Science, North-Holland.

McCallum, B., Nelson, E., 1999. Performance of operational policy rules in an estimated semi- 
classical structural model. In: Taylor, J. B. (Ed.), Monetary Policy Rules. Chicago: University of Chicago Press.

Medina, J. P., Soto, C., 2007. The Chilean business cycles through the lens of a stochastic general equilibrium model, central Bank of Chile Working Papers 457.

Mortensen, D., Pissarides, C., 1994. Job creation and job desctruction in the theory of unemployment. Review of Economic Studies 61(3), 397-415.

Murchison, S., Rennison, A., 2006. ToTEM: The Bank of Canada's new quarterly projection model, bank of Canada Technical Report No. 97.

Negro, M. D., Schorfheide, F., 2009. Monetary policy analysis with potentially misspecified models. American Economic Review 99 (4), 1415-1450.

Orphanides, A., 2003. The quest for prosperity without inflation. Journal of Monetary Economics 50, 633-663.

Orphanides, A., Wieland, V., 1998. Price stability and monetary policy effectiveness when nominal interest rates are bounded at zero, finance and Economics Discussion Series 98-35, Board of Governors of the Federal Reserve System.

Rabanal, P., 2007. Does inflation increase after a monetary policy tightening? answers based on a estimated DSGE model. Journal of Economic Dynamics \& Control 31, 906-937.

Rabanal, P., 2009. Inflation differentials between Spain and the EMU: A DSGE perspective. Journal of Money, Credit and Banking 41(6), 1141-1166.

Ratto, M., Roeger, W., in 't Veld, J., 2009. QUEST III: An estimated open-economy DSGE model of the euro area with fiscal and monetary policy. Economic Modelling 26(1), 222-233.

Ravenna, F., Walsh, C. E., 2006. Optimal monetary policy with the cost channel. Journal of Monetary Economics 53(2), 199-216.

Reifschneider, D., Tetlow, R., Williams, J. C., 1999. Aggregate disturbances, monetary policy and the macroeconomy: The FRB/US perspective. Federal Reserve Bulletin 85(1), 1-19.

Romer, C., Bernstein, J., January 8, 2009. The job impact of the american recovery and reinvestment plan.

Rotemberg, J. J., 1982. Sticky prices in the United States. Journal of Political Economy 90 (4), 11871211.

Rotemberg, J. J., Woodford, M., 1997. An optimization-based econometric framework for the evalu- 
ation of monetary policy. NBER Macroeconomics Annual 12, 297-346.

Rudebusch, G. D., Svensson, L. E. O., 1999. Policy rules for inflation targeting. In: Taylor, J. B. (Ed.), Monetary Policy Rules. Chicago: University of Chicago Press.

Sims, C., 1986. Are forecasting models usable for policy analysis? Federal Reserve Bank of Minneapolis Quarterly Review 10(1), 2-16.

Sims, C., 2001. Solving linear rational expectations models. Journal of Computational Economics 20(1-2), 1-20.

Slobodyan, S., Wouters, R., 2007. Learning in an estimated medium-scale DSGE model, working paper.

Smets, F., Wouters, R., 2003. An estimated dynamic stochastic general equilibrium model of the euro area. Journal of the European Economic Association. 1 (5), 1123-1175.

Smets, F., Wouters, R., 2007. Shocks and frictions in US business cycles: A bayesian DSGE approach. The American Economic Review 97(3), 586-606.

Taylor, J. B., 1980. Aggregate dynamics and staggered contracts. Journal of Political Economy 88(1), $1-24$.

Taylor, J. B., 1993a. Discretion versus policy rules in practice. Carnegie-Rochester Conference Series on Public Policy 39, 195-214.

Taylor, J. B., 1993b. Macroeconomic Policy in a World Economy. W.W. Norton, New York, online Edition available on: http://www.stanford.edu/ johntayl/MacroPolicyWorld.htm.

Taylor, J. B. (Ed.), 1999. Monetary Policy Rules. The University of Chicago Press.

Taylor, J. B., Wieland, V., 2011. Surprising comparative properties of monetary models: Results from a new data base. Review of Economics and Statistics forthcoming.

Tinsley, P. A., 1993. Fitting both data and theories: Polynomial adjustment costs and error-correction decision rules, fEDS Working Paper 93-21.

Trigari, A., 2006. The role of search frictions and bargaining for inflation dynamics, iGIER Working Paper No. 304.

Uhlig, H., 1995. A toolkit for analyzing nonlinear dynamic stochastic models easily, discussion Paper 97, Tilburg University, Center for Economic Research.

Wieland, V., 2011. Model comparison and robustness: A proposal for policy analysis after the finan- 
cial crisis. In: Solow, R., Touffut, J.-P. (Eds.), What's right with Macroeconomics? Edward Elgar Publishers.

Wieland, V., Wolters, M., 2011. The diversity of forecasts from macroeconomic models of the U.S. economy. Economic Theory 47(2-3).

Woodford, M., 2003. Interest and Prices: Foundations of a Theory of Monetary Policy. Princeton University Press.

Yellen, J. L., 2007. John Taylor's contributions to monetary theory and policy, speech at the Federal Reserve Bank of Dallas Conference: "John Taylor's Contributions to Monetary Theory and Policy".

Yun, T., 1996. Nominal price rigidity, money supply endogeneity, and business cycles. Journal of Monetary Economics 37, 345-370. 


\section{A (MMB Version 1.2) How to use the model comparison software}

Appendix A describes how to install and use the macroeconomic model data base (MMB Version 1.2). After reading subsections A.1 and A.2 you should be able to run the software and conduct comparison exercises employing the models and options contained in the data base. Subsections A.3 and A.4 explain the structure of the files in more detail. Finally, subsection A.5 discusses how one can add additional models to the data base.

\section{A.1 Installation and software requirements}

The complete macroeconomic model data base is contained in a zip file called MMB.zip which you may store to any place on your computer. In order to use the model data base, you have to extract the zip file to retrieve the folder $M M B$. This folder contains the file $M M B . m$, a set of subfolders, one for each model included in the data base, and a few additional MATLAB function files. Figure 4 illustrates the structure of the model data base. Each model subfolder contains a single Dynare modfile in which the particular model is specified.

Since the program is written in MATLAB, you need a version of it installed on your computer. For model solution the program utilizes DYNARE, which can be downloaded freely from the web. ${ }^{26}$ Double-clicking on the downloaded DYNARE exe-file opens a setup which guides you through the installation. After completion, one has to add the DYNARE path to MATLAB. In order to do so, open Matlab and choose Set path from the File menu. Use the option Add folder and browse to the directory where you have installed DYNARE. The DYNARE subfolder that has to be added is called matlab. We have created two versions of the Modelbase software. The first one utilizes DYNARE version 3.065, the second one is compatible with DYNARE version 4.2.

\footnotetext{
${ }^{26}$ The URL of the DYNARE website is $h t t p: / / w w w$. dynare.org.
} 
Figure 4: Structure of the Macro Model Data Base

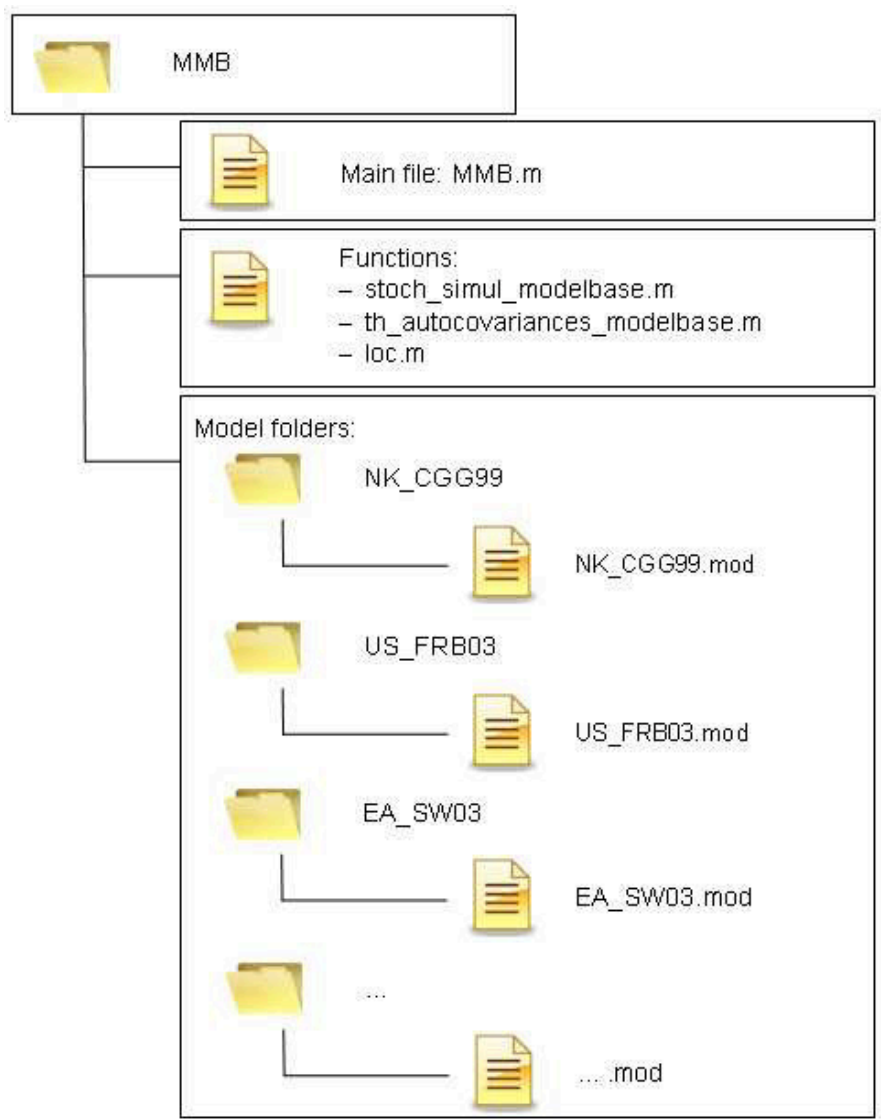

\section{A.2 Using the macro model data base}

MMB. $m$ represents the main file which has to be called when using the model data base. In order to run MMB.m, you can either open the file in MATLAB, which automatically adjusts the current directory of MATLAB to the correct path, and click the run button or you can just start MATLAB and adjust the current directory to the path for the $M M B$ folder manually. In the latter case you type afterwards $M M B$ into the MATLAB command window and press the Enter button. In both cases a user interface opens up that will guide you through a menu of options from which you can choose. These options include the selection of models you want to simulate, the selection of a common monetary policy rule used in each model as well as the selection of the statistics and visual output that you want to be displayed. By default the output generated by the program will be stored in an excel sheet called results.xls in the $M M B$ folder. This output can be customized by the user in the first few lines of the MMB. $m$ file. Once the file is executed, a list of the models included in the data base and its references 
is displayed in the MATLAB command window. The menu structure is illustrated in Figure 5. In the following, each menu option is described step by step.

Figure 5: Macro Model Data Base Menu: Choice of Policy Rule and Models
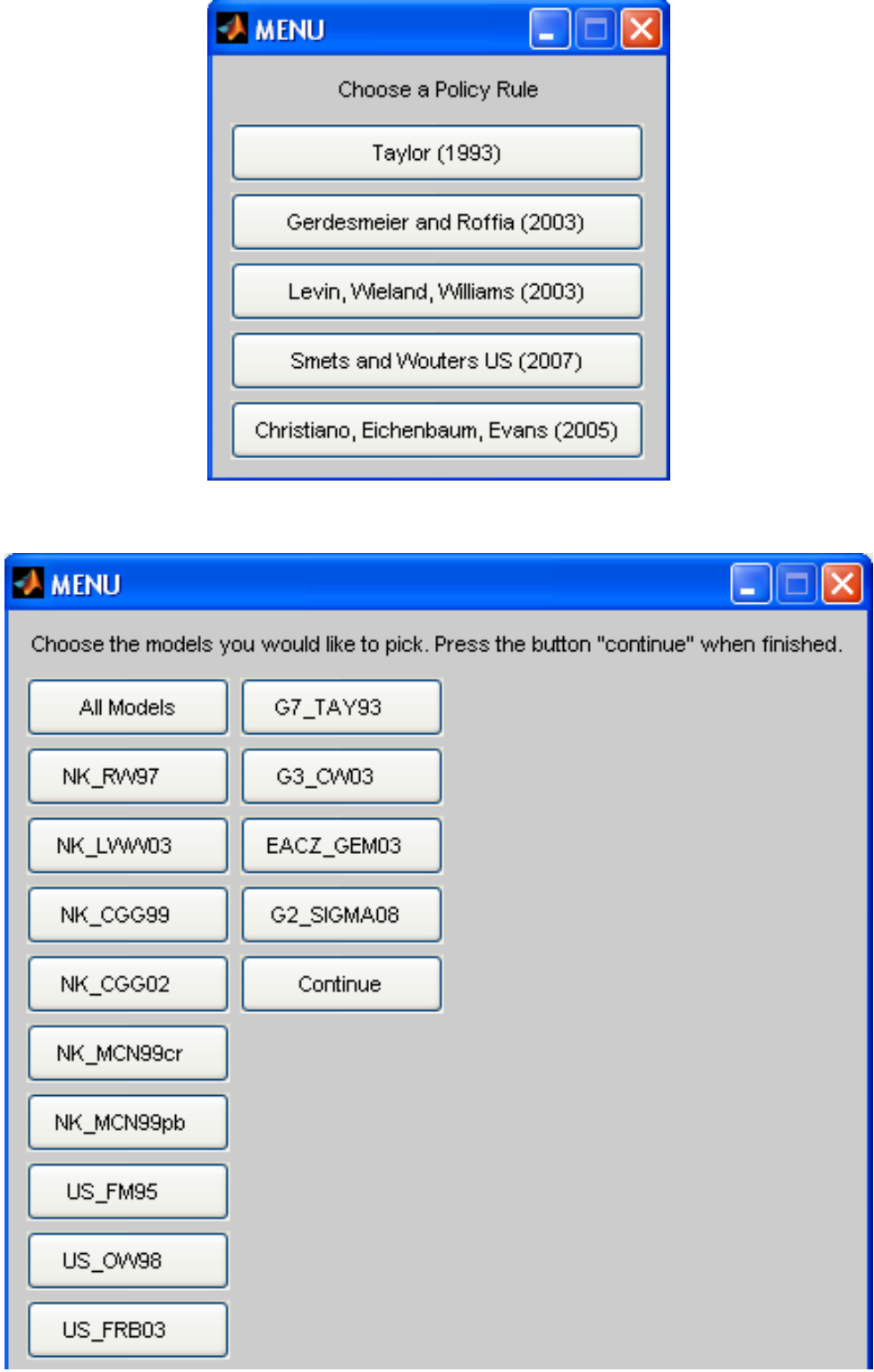
Figure 6: Macro Model Data Base Menu: Choice of Statistics

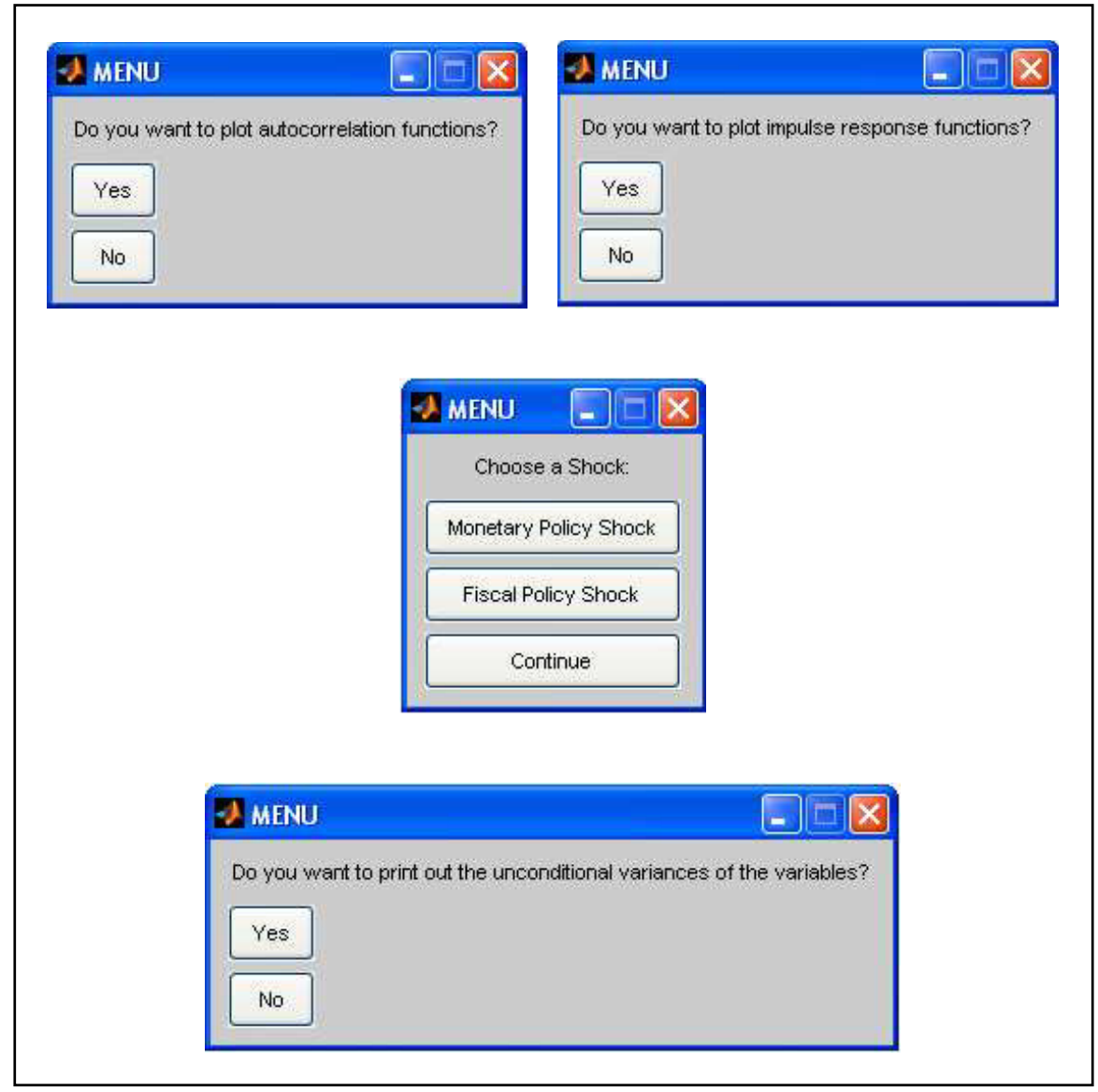

\section{Choosing a monetary policy rule}

Once the MMB.m file is executed a menu appears that allows you to select a particular interest rate rule. The original interest rate rules of the models in the data base have been replaced with a fairly general monetary policy rule that allows many possible parameterizations. In the MMB Version 1.2 it is possible to choose among the five parameterizations discussed in section 3 of this paper and listed in Table 7. A particular rule is chosen by clicking on the respective button in the menu. Only one rule may be selected. The name of the chosen rule will be displayed in the MATLAB command window.

\section{Selecting the models}

Next, a menu with a list of all models included in the data base appears. One can select as many models as desired by clicking on the respective model button. The name of each selected model will be listed in the command window. In order to proceed to the next menu you have to click on the continue button. You can also choose to use all models by clicking on the corresponding button. Be aware that in this case it might take quite some time until all models are solved. Table 6 in the main 
part of the paper lists the models contained in the MMB version 1.2. A short description of each of these models is given in B.

\section{Choosing statistics and graphical output}

Having chosen the models and a policy rule, the user can make some choices regarding the output to be displayed. First, a menu pops up where the user can decide whether to plot autocorrelation functions of the common variables. Afterwards, one can decide whether to plot impulse response functions. In case only one model is selected, one has the option to shock several innovations contemporaneously. Impulse responses can be plotted for a unit monetary policy shock and a unit fiscal policy shock. In case only one model is selected, one can also choose among the original shocks of the model. Finally, the user can choose to display the unconditional variances of the common variables for each of the selected models. The choices will again be documented in the command window. The numerical results for the selected options will be stored in an excel sheet called results.xls in the $M M B$ folder.

\section{A.3 Structure of the MMB.m file}

MMB.m, the main file of the model data base, is divided into three parts: An initialization part, where the macroeconomic models are listed, some basic functions of the model data base are described and choices of models, policy rules, shocks and computations are made. In the second part of the file the models are solved using Dynare and impulse response functions and autocorrelation functions are computed. The third part is devoted to the presentation of the results, i.e. setting up graphs of the chosen statistics. As we use cell mode one can easily see where each block starts and ends. ${ }^{27}$ The structure of the MMB.m file is illustrated in Figure 7. All variables used and generated in this file are saved in a structure variable called modelbase. For example the number of periods to be plotted can be found by typing modelbase.horizon. Table 8 lists the most important variables in the structure variable modelbase. In the following, the three separate parts of MMB.m are explained in more detail.

\footnotetext{
${ }^{27} \mathrm{~A}$ cell starts with two comment sign, i.e. with $\% \%$. When setting the cursor in a cell, the background colour of this cell turns to yellow and can thus easily be spotted.
} 
Figure 7: STRUCTURE OF THE MMB.m FILE

\begin{tabular}{|c|}
\hline 1. Initialization \\
\hline Introductory textblock \\
\hline Defining vectors of models \\
\hline Initializing a choice set of policy rules \\
\hline Programming user menus \\
\hline 2. Solving the model and computing statistics \\
\hline Storing user choices \\
\hline Initializing a loop over selected models \\
\hline Stepwise model solution \\
\hline Storing model solutions and statistics \\
\hline 3. Plotting the results \\
\hline Extracting statistics for common variables \\
\hline Plotting results as chosen by the user \\
\hline
\end{tabular}


modelbase.totaltime modelbase.savepath modelbase.names modelbase.variabledim modelbase.horizon modelbase.mycolor modelbase.rule modelbase.models modelbase.option(1) modelbase.option(2) modelbase.option(3) modelbase.option(4) modelbase.option(5) modelbase.homepath modelbase.namesshock modelbase.innos modelbase.modeltime modelbase.setpath modelbase.epsilon modelbase.info modelbase.AUTR modelbase.AUTlgy_ modelbase.IRF modelbase.IRFlgy_ total CPU time (in seconds) used by the modelbase path for the excel file that contains the output names of all models dimension of model-specific shocks number of periods to be plotted color vector for the graphs chosen rule chosen models autocorrelation functions impulse response functions shock several innovations contemporaneously plot impulse responses for original model variables unconditional variances of common variables path of the modelbase folder names of shocks contained in the modelbase chosen shocks CPU time (in seconds) used for solving each model paths of the modelfolders of chosen models counts the number of loops equals 1 if a model has no determinate solution; otherwise 0 contains the autocorrelation functions contains variable names that correspond to the autocorrelation functions contains the impulse response functions contains variable names that correspond to the impulse response functions

\section{Part 1 of MMB.m: Initialization}

This first block of the MMB.m file is the only part where the user has to make changes when adding a model. First, the most important instructions on how to use the macro model data base and how to add models to it are repeated within a text block of comment lines. Detailed instructions on adding models to the data base can be found in A.5. Afterwards some namevectors for the models are set up. A variable of interest for the user is modelbase.horizon. If you want to change the number of periods that are plotted, you need to modify this entry. The vector names contains the names of the models. These are used later on to produce proper legends of the graphs. The vector mycolors contains a line specification for each model for the graphs that are plotted in part 3 of the file. When adding new models to the data base the number of models might exceed the entries in mycolors at some point. In this case the user needs to add entries to this vector.

A text block follows that describes a very general monetary policy rule that is used for each model and that nests the policy rules listed in Table 7. For each rule it is shown how the original represen- 
tation is transformed into the respective general rule representation. The parameters in the general policy rule are denoted according to the following scheme: The first three letters are cof to indicate a coefficient rather than a variable. The next three letters are int, which are the first three letters of interest since this equation determines the interest rate. The next three letters are the first three letters of the variable the coefficient responds to, c.f. cofintout for the output gap coefficient in the interest rate equation. The next letter is either $f$ for coefficients of forward looking variables, $b$ for coefficients of backward looking (lagged) variables. This letter is just omitted in case of contemporaneous variables. A number follows that indicates the number of leads or lags. An example is the coefficient on inflation expected one-period-ahead: cofintinff1.

After the general policy rule a menu is set up with the name rule to choose from among the policy rules. Afterwards, the parameters of the general policy rule are set according to the specific policy rule chosen and stored in the file policy_param.mat. The parameters are loaded later on in the specific model files to initialize the chosen policy function. If one wants to add an additional policy rule to the macro model data base, one can easily extend the policy rule menu and add an additional set of values for the parameters of the general policy rule. It is not necessary to change the model files.

A second menu with the name model is set up where the user can choose a subset of the models contained in the model database. The identification numbers of the chosen models are saved in the vector models. Menus that let us choose whether to plot autocorrelation functions, impulse response functions and whether to shock monetary or fiscal policy follow. As in the model files the monetary policy shock has the name interest_ and the fiscal policy shock has the name fiscal_. This convention is important to address the shocks of the right equations after having solved the model.

\section{Part 2 of MMB.m: Solving the model and computing statistics}

Before solving the models using Dynare all choices made so far have to be saved in the file Modelbase as Dynare clears the workspace before solving a model. A loop over all models that are saved in the vector modelbase.models is initialized. For every cycle of the loop the current directory is changed according to the entries of the vector modelbase.names to the subfolder of the specific model that is used during the current cycle. Using the command dynare followed by the model abbreviation, c.f. dynare NK_CGG99 to solve the model of Clarida et al. (1999), calls the software Dynare to translate the Dynare syntax in a convenient way.

Afterwards the function stoch_simul_modelbase.m is called to solve the model and compute autocorrelation functions, impulse response functions and unconditional variances. The results are appended to the file Modelbase before we return to the beginning of the loop to solve the next model.

Part 3 of MMB.m: Plotting the results 
Having solved the models the last part of the MMB.m file is devoted to processing and presenting the results. Therefore, figures for impulse response functions of the common variables to each shock and autocorrelation functions are set up and plotted for each model. The common variables can be easily identified within the whole output of each model using the function loc that searches for positions of string variables in vectors like modelbase.IRFlgy_.

\section{A.4 Structure of the model files}

The model files are written in the syntax of Dynare and have a common structure. As an example we take the simple New-Keynesian model by Rotemberg and Woodford (1997) to explain the structure of the mod-files, its model specific parts and the common model data base blocks. The current example is based on the Dynare 3 version of the database but we will point out any differences in the corresponding Dynare 4 mod-file. The mod-file is shown in Figure 8 and Figure 9. However, the explanations apply to all models. In the following, the two main parts of a mod-file, the preamble and the model block, are described step by step. 
Figure 8: Structure of THE MOdel Files: The Preamble

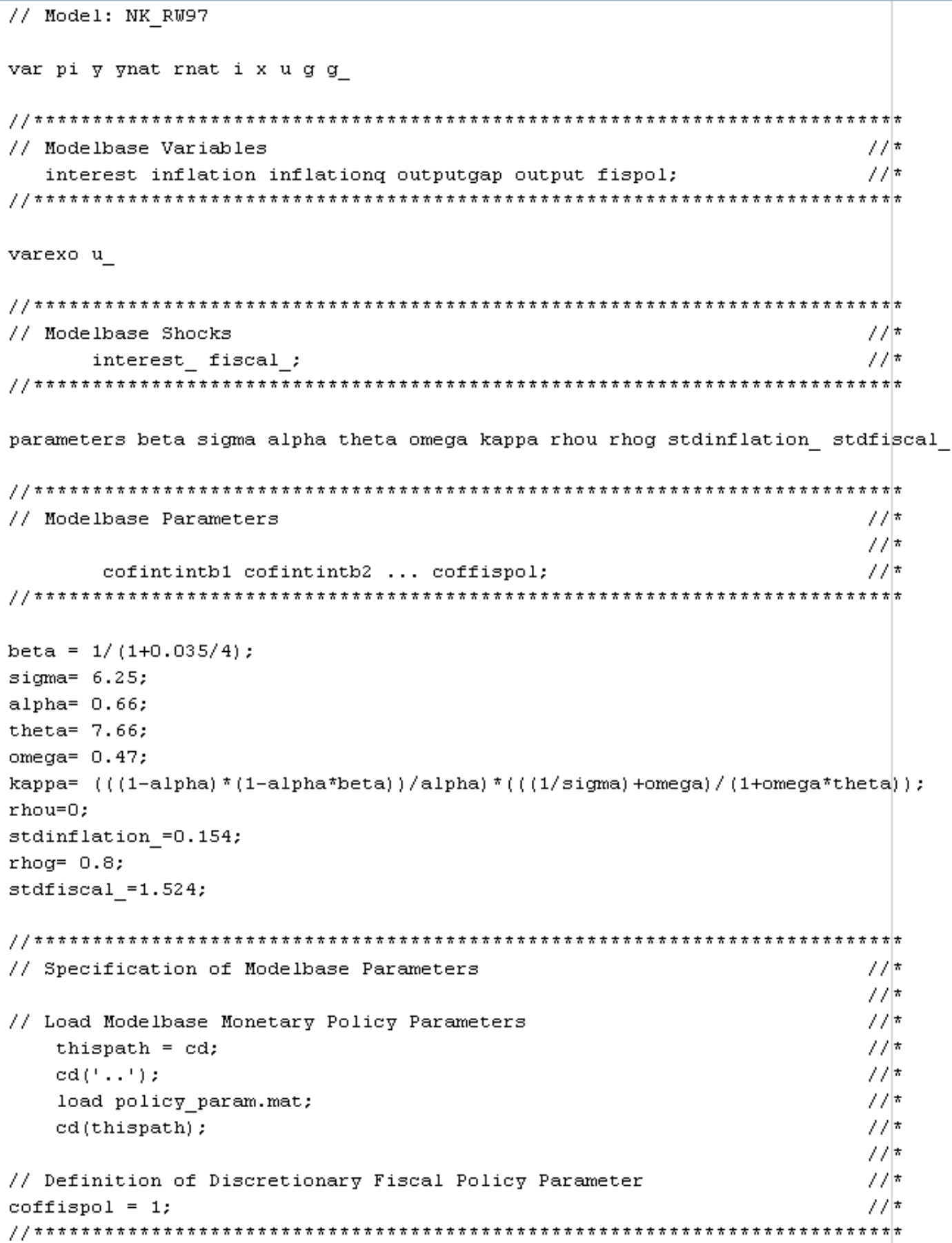


Figure 9: STRUCTURE OF THE MODEL FILES: THE MODEL BLOCK

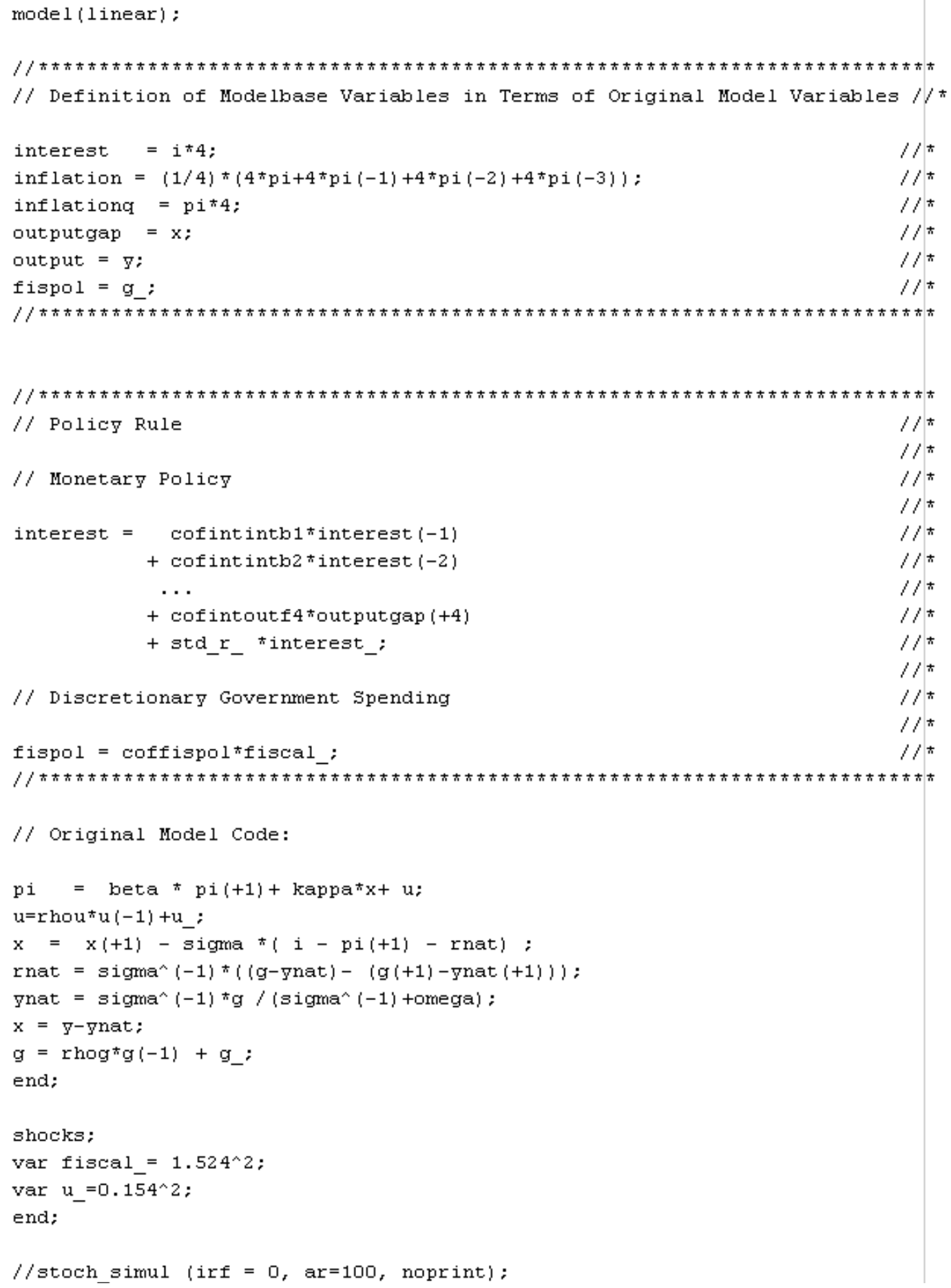




\section{Part 1: The preamble}

- Each model file begins with some information about the model. This should include the title, the authors, the publication etc. In front of this description you will find the symbols //, which denote a comment in Dynare.

- The file then starts with the initialization of the model variables. In our example shown in Figure 8 the model-specific endogenous variables are listed in line 3 after the keyword var: $p i, y, y n a t$, rnat, $i, x, u, g$ and $g_{-}$. The latter in fact represents an exogenous government spending shock, however it has to be initialized as endogenous variable for reasons that will be explained below. It follows a Modelbase block in lines 5 to 8 in which the common variables

are introduced. In general, Modelbase blocks are separated through //******* symbols from the rest of the file.

- Following the keyword varexo in line 10 the exogenous variables are initialized. In our example this is $u_{-}$, a cost push shock as well as the common interest rate shock, interest_ and the common fiscal policy shock, fiscal_in line 14. Note that in some models with no treatment of government spending, the latter Modelbase shock may be left out.

- In line 17 following the keyword parameters the model-specific parameters are initialized.

- It follows the Modelbase block in which the Modelbase parameters are intitialized. In Figure 8 line 22 we have for brevity reasons only included three policy parameters. In the actual modfiles there are many more leads and lags. These are the parameters of the general monetary policy function, except for the last one, coffispol, which enters the common discretionary government spending equation.

Note, that in the mod-files of the database version compatible with Dynare 4, one first defines the Modelbase parameters and then the model-specific parameters.

- Afterwards numerical values are assigned to the model-specific parameters in lines 25 to 34 .

- Finally a Block called Specification of Modelbase Parameters is added. First in lines 39 to 43 the numeric values of the parameters of the selected monetary policy rule are loaded. They are contained in the file policy_param.mat in the main folder $M M B$. For models in which the original shocks are expressed in percent/100 the parameter $s t d \_r$. has to be reset to 100 after the parameter-loading command. In our example this would have to be done in line 44. However, the shocks in this model are already expressed in percentage terms. Secondly, the discretionary fiscal policy parameter coffispol is defined as a function of the model-specific parameters in order to obtain a government spending shock of one percent of GDP. The exact implementation 
of the common fiscal policy shock will be described below. In our example no adjustment is needed and hence coffispol is set equal to one.

- In the Dynare 4 version of the database, the command lines to load the Modelbase parameters have changed as shown in Figure 10.

Figure 10: LoAding Modelbase PARAMETERS in the Dynare 4 Version of MMB

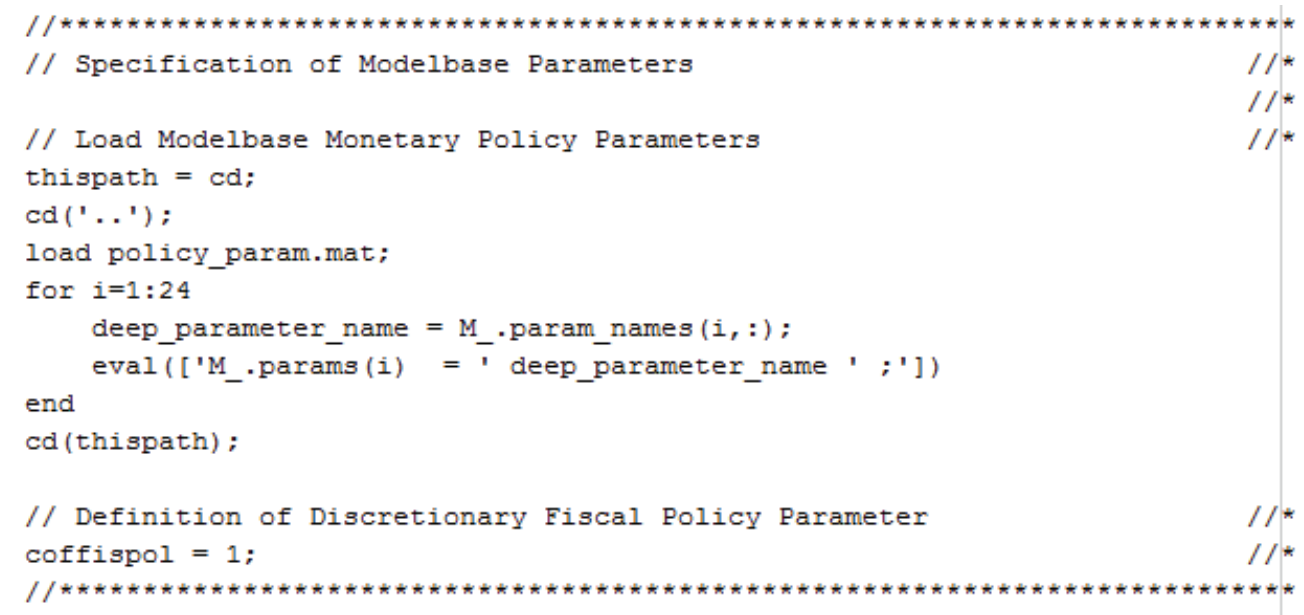

\section{Part 2: The model block}

- The model block starts in line 49 of Figure 9 as indicated by the keyword model followed by linear, which tells Dynare that the equations are already linearized and thus reduces computing time.

- In the Modelbase block going from lines 51 to 60 the common variables are defined in terms of the original model variables. The variable interest denotes the annualized short-term interest rate, inflation is annual inflation, inflationq represents annualized quarterly inflation, outputgap and output denote the output gap and output, respectively. The common variable fispol represents discretionary fiscal policy. It is set equal to the model-specific government spending shock variable, which in the case of our example is $g_{-}$. Note again, that this model-specific shock has to be initialized as an endogenous variable. This allows us the keep the original model equation for government spending unchanged. 
- It follows the common Policy Rule block. In lines 66 to 72 the common monetary policy rule is specified. Again for reasons of brevity we have not displayed the complete general policy rule in Figure 9. Below in line 76, the common equation for discretionary government spending is specified.

- The original model equations are then specified in lines 81 to 87 . Note in particular that also the government spending equation in line 87 has remained unchanged. The model section ends in line 88 with the required keyword end.

- Finally the variance covariance matrix is specified in lines 91 and 92 between the keywords shocks and end. Importantly, the variance of the original model-specific government spending shock has been assigned to the common fiscal policy shock variable fiscal_. Hence, the common shock fiscal_affects the fiscal policy variable fispol through the common discretionary government spending expression in line 76 which is set equal to the model-specific government spending shock $g_{-}$in line 59.

- The stoch_simul command in line 96 is commented out. Alternatively one can also delete this command.

\section{A.5 Adding models to the macro model data base}

Adding a new model to the data base consists of three steps. First, the original model has to be translated into a Dynare mod-file and the common Modelbase variables have to be defined as functions of the original model variables. Second, the mod-file must be stored under the model name in a folder with exactly the same label. Third, the new model has to be initialized in the file MMB.m. In the following, each of these steps is described in detail.

\section{Step 1: Creating the mod-file}

- The first task when adding a new model to the macro model data base is to create a Dynare mod-file. The file should start with a comment section giving some information about the associated reference paper(s) for the model.

- The file must have the usual structure of a Dynare mod-file. That is, one starts with the initialization of variables, shocks and parameters. Then the equations describing the model follow and finally the variance-covariance structure of the shocks is specified.

- However, each of the before mentioned sections has to be augmented by a Modelbase block. This Modelbase block should be visually separated from the original model sections through a comment line $/ / * * * * * * *$. 
- After the initialization of the original model variables, the common block Modelbase Variables follows. It consists of the six common variables interest, inflation, inflationq, outputgap, output and fispol. Those variables will be described below. If output is not specified in the model, then the common variable output has to be left out. Furthermore, in some small models, one may have to leave out the fispol variable. This common block corresponds to lines 5 to 8 in Figure 8.

- The common block Modelbase Shocks is added after the initialization of the original model shocks as in lines 12 to 15 of Figure 8. It consists of a common monetary policy shock, interest_, and of a common fiscal policy shock, fiscal_.

- The third common block is the Modelbase Parameters section. Following the initialization of the original model parameters, the common Modelbase parameters are preset, consisting of the monetary policy rule parameters and the discretionary fiscal policy parameter coffispol. For the Dynare 4 version of the Modelbase, one first defines the Modelbase parameters and afterwards the original model-specific parameters.

- It follows the numeric specification of the parameters. This is done first for the model-specific parameters and then separately for the common Modelbase parameters in the block called Specification of Modelbase Parameters. First, the parameter values of the selected monetary policy rule are loaded. They are contained in the file policy_param.mat in the main folder $M M B$. For models in which the original shocks are expressed in percent/100 the parameter $s t d \_r$ has to be reset to 100 after the parameter-loading command. This specification is required for the proper calculation of impulse response functions. In our example this would have to be done in line 44. However, the shocks in the example are already expressed in percentage terms. Secondly, the discretionary fiscal policy parameter coffispol is defined as a function of the model-specific parameters such that a unit government spending shock has a unit impact on output. In our example no adjustment is needed and hence coffispol is set equal to one. In the Dynare 4 version of the Modelbase the command lines to load the policy rule parameters are slightly different, as documented in Figure 10.

- Following the beginning of the model section, i.e. before the original model equations are specified, a model-specific Modelbase block has to be added in order to define the common Modelbase variables in terms of original model variables. This is done in lines 52 to 59 in our example. The variable interest is defined as the annualized short-term interest rate set by the policy maker. The variable inflation denotes the year-on-year inflation rate in percent and inflationq denotes the annualized quarter-to-quarter inflation rate in percent. If for instance the original model variable representing quarterly inflation is not annualized, then inflationq 
would have to be specified as four times the original quarter-to-quarter inflation variable. The common variables outputgap and output represent the output gap and output, respectively.

- The variable fispol specifies the common discretionary fiscal policy variable. For implementation of the discretionary fiscal policy variable, one does not have to change the original model equations. The original shock that should represent the common fiscal policy shock has to be initialized as endogenous variable, i.e. following the command var instead of varexo. In our example the original government spending shock $g_{-}$is initialized in this way. Furthermore, in the section in which the shock variances are specified, this original shock has to be replaced by the common shock fiscal_. The fispol variable has to be set equal to the original shock variable. If there does not exist a fiscal policy shock in the original model, fiscal_ and fispol should not be initialized.

- Afterwards the common Policy Rule block is added to the mod-file, specifying the general monetary policy rule, like it is done in lines 68 to 72 in Figure 9. For the sake of brevity we have not displayed the complete general policy rule in our example. The original monetary policy rule has to be commented out in the original model code. In case the model contains a fiscal policy shock, common discretionary government spending is also specified in the Policy Rule block, expressing fispol as a function of the fiscal_shock, as in line 76 of Figure 9. Hence, the common shock fiscal_affects the fiscal policy variable fispol through this common discretionary government spending expression and fispol is set equal to the model-specific government spending shock $g_{-}$in line 59. The orginal model equations following this block remain unchanged.

- The variances of the two common shocks are specified together with the variances/covariances of the model-specific shocks. Specifically, the variance of the monetary policy shock interest_ is set equal to zero and therefore it does not have to show up explicitly. For the fiscal policy shock fiscal_one adopts the original covariance specification of the replaced shock if available. Otherwise one sets the variance of the fiscal policy shock equal to zero.

- Finally, one has to delete or out-comment the commands for finding the steady state and solving the model as it is done in line 95 of our example.

\section{Step 2: Storing the mod-file}

- Next, the file has to be stored as mod-file under the model name. In the example, the $N K \_R W 97$ model is stored as $N K \_R W 97 . m o d$. The name of small calibrated New Keynesian models should start with $N K$, models of the US economy should start with US and models of the 
Euro area should start with $E A$. The full model name should allow for the identification of the specific model among the other Modelbase models. The file must be stored in a folder that has to be created under exactly the same model name and that is positioned in the main folder $M M B$.

Step 3: Initializing the model in the MMB.m file

- In the final step, one initiates the model in the main file MMB.m. For this task, one has to open MMB.m. After some lines of comments on how to add a model, a textblock with a table of models currently implemented in the Modelbase follows. This table is also shown in the workspace when the program is run. The new model has to be added to this table by itemizing the model name followed by the reference. For instance, the model named NK_RW97 is added as NK_RW97: Rotemberg, Woodford (1997).

- Next, the model name has to be added at the corresponding position to the vector modelbase.names.

- Finally, a new entry has to be added at the corresponding position to the vector modelbase.variabledim. This entry has to be 1 if the standard deviations of the model-specific shocks are expressed in percent and it has to be 2 if the standard deviations are expressed in percent/100. 


\section{B A detailed overview of available models}

This section describes the structure and the most important features of the different models in the macro model data base.

Most models assume that expectations of future realizations of model variables such as for example future exchange rates, prices, interest rates, wages and income are formed in a model-consistent, rational manner. A few models assume backward-looking expectations formation, in particular the models from Rudebusch and Svensson (1999) and Orphanides (2003). Most, but not all models are linear, or linear approximations of nonlinear models. In this case the variables appear as percentage deviations from their steady state values. There are many differences in model structure, in terms of size, in terms of countries covered, or the extent of microeconomic foundations considered.

\section{B.1 Small Calibrated Models}

\section{B.1.1 NK_RW97: Rotemberg and Woodford (1997)}

The model and the estimation strategy is discussed in detail in Rotemberg and Woodford (1997). The equations of this model can be derived from the behavior of optimizing agents. The expectational IS equation and the policy rule together can be viewed as determining aggregate demand, while the New-Keynesian Phillips curve equation determines aggregate supply. The Phillips curve equation can be obtained as a log-linear approximation to the first-order condition of optimizing firms with either Calvo-style staggered price contracts (Yun, 1996) or convex costs of price adjustment (Rotemberg, 1982). The IS equation can be obtained as a log-linear approximation of the representative household's first-order equation in a model in which consumption, leisure, and real money balances are each additively separable in the utility function, and total consumption demand (private and government consumption) is equal to aggregate output.

- Aggregate Demand: Standard New Keynesian IS curve.

- Aggregate Supply: Standard New Keynesian Phillips curve.

- Shocks: A cost-push shock following an AR(1) process, the common monetary policy shock, a government spending shock representing the common fiscal policy shock.

- Calibration/Estimation: Rotemberg and Woodford (1997) match the empirical impulse response functions to a monetary policy shock in a VAR (detrended real GDP, inflation, funds rate) and the empirical variances with the variances and the theoretical impulse responses from the model to all three shocks. Quarterly U.S. data for the period 1980:Q1-1995:Q2 is used. The estimated parameters are taken from Woodford (2003) table 6.1. However, we do not have 
information on the calibration of the shock processes. Hence, we employ the estimation results from Adam and Billi (2006) for the NK_RW97 shock specifications.

\section{B.1.2 NK_LWW03: Levin et al. (2003)}

This model is used for comparison in the robustness analysis of monetary policy rules by Levin et al. (2003). Its structure is similar to the NK_RW97 model presented above, but without explicit treatment of government spending.

- Aggregate Demand: Standard New Keynesian IS curve.

- Aggregate Supply: Standard New Keynesian Phillips curve.

- Shocks: A cost-push shock, a shock to the real interest rate and the common monetary policy shock.

- Calibration/Estimation: In calibrating the model, the parameter values of Woodford (2003) adjusted for annualized variables as in Levin et al. (2003) are used.

\section{B.1.3 NK_CGG99: Clarida et al. (1999), hybrid model}

The model is similar to NK_RW97 but it features a hybrid Phillips curve with endogenous persistence in inflation. Also, government spending is not treated explicitly. The model and its implications for monetary policy are discussed in detail in Clarida et al. (1999) from page 1691 onwards.

- Aggregate Demand: Hybrid New Keynesian IS curve.

- Aggregate Supply: Hybrid New Keynesian Phillips curve.

- Shocks: A cost-push shock, a demand shock and the common monetary policy shock.

- Calibration/Estimation: We use the same parametrization as in in NK_RW97, however expected inflation enters the Phillips curve with a weight of 0.52 and lagged inflation with a weight of 0.48. In the IS curve the expected output gap has a weight of 0.56 and the lagged output gap has a weight of 0.44 .

\section{B.1.4 NK_CGG02: Clarida et al. (2002), 2-country model}

Clarida et al. (2002) derive a small-scale, two-country, sticky-price model to analyse optimal monetary policy. The two countries are symmetric in size, preferences and technology. 
- Aggregate Demand: Households maximize their lifetime utility, where the utility function is separable in consumption and leisure, subject to an intertemporal budget constraint. They own the firms, are a monopolistically competitive supplier of labor to the intermediate firms and additionally hold their financial wealth in the form of one-period, state-contingent bonds, which can be traded both domestically and internationally.

- Aggregate Supply: Domestic production takes place in two stages. First there is a continuum of intermediate goods firms, each producing a differentiated material input under monopolistic competition using a production function that is linear in labor input and includes an exogenous technology parameter. They set nominal prices on a staggered basis ï $;$ la Calvo and receive a subsidy in percent of their wage bill to achieve an undistorted steady state. Final goods producers then combine these inputs into output, which they sell to households under perfect competition. Wages are perfectly flexible. Thus, all workers will charge the same wage and work the same amount of hours. Clarida et al. (2002) introduce an exogenous time-varying elasticity of labor demand to vary the wage-mark-up over time. The system of equations is collapsed into an IS equation and a Phillips curve, which determine the output gap and inflation, conditional on the path of the nominal interest rate both for the domestic and the foreign economy.

- Foreign sector: Producer currency pricing is assumed so that the Law of one price holds for the final consumption good and the CPI based real exchange rate is unity. Together with the assumption of complete markets this ensures that the consumption levels are equal in both countries at any point in time.

- Shocks: A cost push shock and the common monetary policy shock.

- Calibration/Estimation: We take the parametrization of the small open economy model in Gali and Monacelli (2005) to calibrate the model. Gali and Monacelli (2005) calibrate the stochastic properties of the exogenous driving forces by fitting AR(1) processes to log labor productivity in Canada, which is their proxy for the domestic country, and log U.S. GDP, which they use as proxy for world output. The sample period comprises 1963:1-2002:4.

\section{B.1.5 NK_MCN99: McCallum and Nelson (1999)}

The model in McCallum and Nelson (1999) is used to monitor the performance of operational monetary policy rules. Two distinct variants of the model are used, mainly differing in the choice of the aggregate supply setup. In the first setup, aggregate supply is based on a standard Calvo-Rotemberg (NK_MCN99cr) specification of the Phillips curve where inflation is linked to expected inflation and 
the output gap. In the second setup of the model, the authors introduce the so-called P-bar price adjustment (NK_MCN99pb) where price changes occur in order to gradually eliminate deviations of actual from market clearing values of output.

- Aggregate Demand: Standard New Keynesian IS and LM curve.

- Aggregate Supply: Two setups: (i) Standard New Keynesian Phillips curve (NK_MCN99cr), (ii) P-bar price adjustment (NK_MCN99pb).

- Shocks: A shock to the IS curve which follows an AR(1) process, a shock to the LM curve, an investment shock, a shock on capacity output and the common monetary policy shock.

- Calibration/Estimation: The model equations are estimated individually by ordinary least squares and instrumental variable estimation for U.S. data. The sample period comprises 1955-1996.

\section{B.1.6 NK_IR04: Ireland (2004)}

Ireland (2004) develops a small New Keynesian model with real money balances entering both the forward-looking IS curve and the Phillips curve. The model is used to study the role of money in the U.S. business cycle.

- Aggregate Demand: A representative household maximizes expected utility, nonseparable between consumption and real money balances while separable in leisure, subject to a budget constraint. The optimizing behavior of this household leads to a forward-looking IS curve with real money balances entering the specification. This is due to the non-separability of real balances to consumption in the utility function, as real balances affect the marginal rate of intertemporal substitution.

- Aggregate Supply: A representative firm produces final goods according to a constant-returnsto-scale technology, using labor and intermediate goods as inputs. On the other hand, intermediate goods are produced under a linear technology using labor as input. The representative intermediate goods-producing firm has monopolistic power in the market, therefore acting as a price-setter. However, price setting is subject to Rotemberg quadratic adjustment costs. The optimizing behavior of this firm leads to a forward-looking Phillips curve with real money balances entering the specification.

- Shocks: An overall preference shock, a real money balances preference shock, a productivity shock and a monetary policy shock.

- Calibration/Estimation: Estimated via maximum likelihood using U.S. quarterly data over the period 1980:Q1-2001:Q3. 


\section{B.1.7 NK_BGG99: Bernanke et al. (1999)}

Bernanke et al. (1999) introduce credit market imperfections into an otherwise standard New Keynesian model with capital and show that these financial frictions contribute to propagate and amplify the response of key macroeconomic variables to nominal and real shocks. An agency problem arises due to asymmetries of information in borrower-lender relationships. The economy is inhabited by three types of agents, risk-averse households, risk-neutral entrepreneurs and retail firms.

- Aggregate Demand: Households gain utility from consumption, leisure and real money balances. Household optimization results in a standard dynamic IS equation. Entrepreneurs use capital and labor to produce wholesale goods that are sold to the retail sector. Each period, entrepreneurs have to accumulate capital that becomes available for production in the subsequent period. Entrepreneurs have to borrow from households via a financial intermediary to finance capital purchases. Since the financial intermediary has to pay some auditing costs to observe the idiosyncratic return to capital, an agency problem arises. The optimal contract leads to an aggregate relationship of the spread between the external finance costs and the risk-free rate and entrepreneurs' financial conditions represented by the leverage ratio.

- Aggregate Supply: Retail firms act under monopolistic competition. They buy wholesale goods produced by entrepreneurs in a competitive market and differentiate them at zero cost. Price stickiness is introduced via the Calvo framework. Bernanke et al. (1999) assume that reoptimizing firms have to set prices prior to the realization of shocks in that period, so that previous period's expectations of the output gap and future inflation enter the New Keynesian Phillips curve.

- Shocks: The model exhibits a technology shock, a demand shock and the common monetary policy shock. Since we have no information about the variances of the shock terms, we set all shock variances equal to zero.

- Calibration/Estimation: The model is calibrated at quarterly frequency.

\section{B.1.8 NK_GM05: Gali and Monacelli (2005)}

Gali and Monacelli (2005) develop a model of a small open economy which is part of a world economy comprised of a continuum of small open economies sharing identical preferences, technology and market structure but facing imperfectly correlated productivity shocks. With this framework, the authors analyze the macroeconomic implications of three different rule-based policy regimes for a small open economy, pointing out the trade-offs the authorities face between the stabilization of the nominal exchange rate, domestic inflation and the output gap. 
- Aggregate Demand: The representative household in a small open economy seeks to optimize its utility separable between consumption and leisure subject to its budget constraint. Consumption is a composite of domestic and foreign goods, weighted by the degree of home bias in preferences, which represents the index of country openness. The dynamic IS equation is similar to that found for a closed economy but with the degree of openness influencing the sensitivity of the output gap to interest rate changes. Furthermore, the natural interest rate depends on the expected growth of world output.

- Aggregate Supply: Differentiated goods are produced from a typical firm using a linear technology with labor as input. Firms face price stickiness a la Calvo as in the case of a closed economy. Importantly, marginal costs are increasing in the terms of trade and in world output. The degree of country openness affects the slope of the New Keynesian Phillips curve of the small open economy, thus affecting the response of inflation to variations in the output gap.

- The Foreign Sector: Purchasing Power Parity and the law of one price hold. There is prefect exchange rate pass-through. Under the assumption of complete international financial markets, an international risk sharing in the form of the uncovered interest rate parity is obtained.

- Shocks: A domestic productivity shock and a world demand shock.

- Calibration/Estimation: The model is calibrated mostly to fit some characteristics of the Canadian economy. In order to calibrate the stochastic properties of the exogenous driving forces, AR(1) processes are fitted, using quarterly, HP-filtered data over the sample period 1963:Q12002:Q4.

\section{B.1.9 NK_GK09: Gertler and Karadi (2009)}

Gertler and Karadi (2009) build a quantitative monetary DSGE model with financial intermediaries that face endogenously determined balance sheet constraints. The authors use the model to analyse unconventional monetary policy measures.

- Aggregate Demand: The representative household's utility is separable in consumption and leisure and allows for habit formation in consumption. Households postpone their consumption by holding deposits with the financial intermediaries. The amount of deposits is determined in such a way as to guarantee that the bankers' incentive constraint is satisfied. Expected-lifetime utility is maximized, choosing consumption and labor supply to the intermediate firms.

- Aggregate Supply: The financial intermediaries issue contingent claims to firms, financed by the deposits. An agency problem between the intemediaries and the depositors generates an 
endogenous leverage constraint with respect to the leverage ratio of the financial intermediaries. Competitive firms produce intermediate goods using labor services and capital, the latter of which is produced by the capital producer. The retail firms have monopolistic power and repackage intermediate output. Nominal frictions are introduced in the form of Calvo sticky prices. Non-reoptimizing firms index their prices to previous periods inflation rate.

- Shocks: Capital quality shock, which affects the effective quantity of the capital stock.

- Calibration/Estimation:The financial sector parameters are chosen to satisfy a steady state interest rate spread of 100 basis points, a steady state leverage ratio of four, and an average horizon of bankers of a decade. The calibration of the conventional parameters is mostly following Christiano et al. (2005).

\section{B.1.10 NK_CK08: Christoffel and Kuester (2008)}

Christoffel and Kuester (2008) incorporate search and matching frictions à la Mortensen and Pissarides (1994) into an otherwise standard New Keynesian business cycle model.

- Aggregate Demand: There is a large number of identical families in the economy. Each family consists of unemployed and employed members with time-additive expected utility preferences and an external habit. The representative family pools the labor income of its working members, unemployment benefits of the unemployed members and financial income. The family maximizes its welfare function by choosing consumption and nominal bond holdings subject to its budget constraint.

- Aggregate Supply: There are three sectors of production in the economy. Firms in the first sector produce a homogeneous intermediate good where labor is the only production input. The production process is subject to matching frictions. Nominal wages in the labor sector are Calvo staggered. The wholesale sector demands labor goods as the only production input in a perfectly competitive market to produce differentiated goods using a constant-return-toscale production technology. Subject to price-setting impediments à la Calvo, the intermediate good is sold under monopolistic competition to a final retail sector. Retailers bundle differentiated goods into a homogeneous consumption/investment basket. These goods are then sold to consumers and government.

- Shocks: Three shocks: a serially correlated shock to the risk premium that drives a wedge between the return on bonds held by the families and the interest rate set by the central bank, an $\mathrm{AR}(1)$ labor sector-wide technology shock process, and a government spending shock. 
- Calibration/Estimation: The model is calibrated to US data from 1964:Q1 to 2006:Q3. The underlying data set used covers data on output, hours worked, total wages, wages per employee, real hourly wages, vacancies, the civilian unemployment rate, the inflation rate and the interest rate.

\section{B.1.11 NK_CKL09 and EA_CKL09: Christoffel et al. (2009)}

Christoffel et al. (2009) explore the role of labor markets for monetary policy in the Euro Area in a closed-economy, single-country New Keynesian model with Mortensen and Pissarides (1994) type of matching frictions. To allow for a direct channel from wages to inflation, the model builds on the right-to-manage framework of Trigari (2006). Moreover, Christoffel et al. (2009) incorporate staggered wage-setting à la Calvo and account for job-related fixed costs as in Christoffel and Kuester (2008). The aim of the paper is to investigate to which extent a more flexible labor market would alter the business cycle behavior and the transmission of monetary policy, employing a genuine Euro Area calibration (NK_CKL09). Second, by estimating the model with Bayesian techniques (EA_CKL09) they analyze to which extent labor market shocks are important determinants of business cycle fluctuations. The results support current central bank practice to put considerable effort into monitoring Euro Area wage dynamics and treat some of the other market information as less important for monetary policy.

- Aggregate Demand: The demand as well as the supply structure follow closely the one described in Christoffel and Kuester (2008). The economy consists of a large number of identical families that comprise unemployed and employed members with time-additive expected utility preferences that exhibit an external habit. The representative family pools the labor income of its working members, unemployment benefits of the unemployed members and financial income from assets that family members hold via a mutual fund. Each household also owns representative shares of all firms in the economy. It maximizes the sum of unweighted expected utilities of its individual members, by taking consumption, saving, vacancy posting, and labor supply decisions on their behalf.

- Aggregate Supply: The economy consists of three production sectors. The labor packers use exactly one worker as input to produce a homogeneous intermediate good labeled labor good. The process of labor bargaining is governed by wage rigidities. The wholesale sector buys the labor good from the labor packers in a perfectly competitive market and produces differentiated goods using a constant-return-to-scale production technology. These goods are sold under monopolistic competition to a final retail sector at a price that is subject to impediments à la Calvo and to a partial indexation rule. Retailers bundle the differentiated goods into a homogeneous consumption/investment basket and sell it to the consumers and to the government. 
- Shocks: Three labor market shocks: a shock to the costs of posting a vacancy, a shock to the rate of separation, and a shock to the bargaining power of workers; a government spending shock; a wholesale sector cost-push shock.

- Calibration/Estimation: For the calibration exercise (NK_CKL09) a quarterly Euro Area data set from 1984:Q1 to 2006:Q3 is used. The model is also estimated with Bayesian techniques (EA_CKL09) employing output, year-on-year inflation, the nominal interest rate, wages per employee, unemployment and proxies for total hours worked and vacancies as observable variables.

\section{B.1.12 NK_RW06: Ravenna and Walsh (2006)}

Ravenna and Walsh (2006) build a New Keynesian model with a cost channel of monetary transmission and study optimal monetary policy.

- Aggregate Demand: The model economy consists of households, firms, the government, and financial intermediaries interacting in asset, goods, and labor markets. Households maximize their expected present discounted value of utility defined over a composite consumption good, a taste shock and leisure. The composite good consists of differentiated products produced by final goods producers. Households enter each period with cash holdings, receive their wage income and use it to make deposits at the financial intermediary. The remaining cash balances are available for the purchase of consumption goods. At the end of a period, households receive profit income from the financial intermediary and firms, and the principal and interest on their deposits at the intermediary.

- Aggregate Supply: The goods market is characterized by monopolistic competition, and the adjustment of prices follows the Calvo setting. Firms must borrow money from the financial intermediary at the gross nominal interest rate to pay for part of their wage bill.

- Shocks: A composite demand shock.

- Calibration/Estimation: The model is calibrated to the US economy.

\section{B.2 Estimated U.S. Models}

\section{B.2.1 US_FM95: Fuhrer and Moore (1995a)}

The model is described in Fuhrer and Moore (1995a) and Fuhrer and Moore (1995b). We employ the parametrization used in Levin et al. (2003). Fuhrer and Moore introduce a new wage contracting model where agents care about relative real wages in order to match the strong inflation persistence observed in U.S. data. 
- Aggregate Demand: The US_FM95 model represents aggregate spending by a single reducedform equation corresponding to an IS curve. The current output gap depends on its lagged values over the past two quarters and the lagged value of the long-term real interest rate, which is defined as a weighted average of ex-ante short-term real interest rates with a duration of 40 quarters.

- Aggregate Supply: The aggregate price level is a constant mark-up (normalized to one) over the aggregate wage rate. The aggregate wage dynamics are determined by overlapping wage contracts. In particular, the aggregate wage is defined to be the weighted average of current and three lagged values of the contract wage rate. The real contract wage, that is the contract wage deflated by the aggregate wage, is determined as a weighted average of expected real contract wages, adjusted for the expected average output gap over the life of the contract. This specification yields a hybrid Phillips curve that depends additionally on current and past demand and expectations about future demand.

- Shocks: An ad hoc supply shock and the common monetary policy shock.

- Calibration/Estimation: Full-information maximum likelihood estimation on U.S. data from 1966-1994.

- Replication: We replicated the impulse response functions for annualized quarterly inflation and the output gap to a 100 basis point innovation to the federal funds rate in Figure 2 of Levin et al. (2003).

\section{B.2.2 US_OW98: FRB Monetary Studies, Orphanides and Wieland (1998)}

This is a small open economy model described in Orphanides and Wieland (1998) and used to investigate the consequences of the zero bound on nominal interest rates.

- Aggregate Demand: The US_OW98 model disaggregates real spending into five components: private consumption, fixed investment, inventory investment, net exports, and government purchases. The aggregate demand components exhibit partial adjustment to their respective equilibrium levels, measured as shares of potential GDP. Partial adjustments reflect habit persistence. Equilibrium consumption and fixed investment are functions of permanent income (discounted at 10 percent) and depend on the long-term real rate. The long-term nominal interest rate is an average of expected future nominal short-term rates. The long-term real rate is determined by the Fisher equation. Inventory investment depends on three lags of output. Government spending is an $\mathrm{AR}(1)$ process. 
- Aggregate Supply: The structure is similar to the US_FM95 model. In US_FM95 and US_OW98, the aggregate price level is a constant mark-up over the aggregate wage rate.

- Foreign Sector: Net exports depend on domestic output, world output, the real exchange rate and lagged net exports. The exchange rate is determined by an UIP condition.

- Shocks: Five demand shocks including the common fiscal policy shock in the government spending equation, an ad hoc cost push shock to the nominal wage contracts and the common monetary policy shock.

- Calibration/Estimation: The model is estimated for the period 1980-1996 using U.S. data. The demand block is estimated via IV-estimation equation-by-equation. For the supply side simulation-based indirect inference methods are used.

- Replication: We replicated the impulse response functions for annualized quarterly inflation and the output gap to a 100 basis point innovation to the federal funds rate in Figure 2 of Levin et al. (2003).

\section{B.2.3 US_FRB03: FRB-US model}

The FRB model is a large-scale model of the U.S. economy with a relatively detailed representation of the supply side of the economy. The version US_FRB03 was linearized by Levin et al. (2003).

- Aggregate Demand: Real spending is divided into five components: private consumption, fixed investment, inventory investment, net exports and government purchases. The broad components are disaggregated further i.e. spending on fixed investment is separated into equipment, nonresidential structures and residential construction. Government spending is divided into six sub-components, each of which follows a simple reduced-form equation that includes a counter-cyclical term. The specification of most non-trade private spending equations follows the generalized adjustment cost model due to Tinsley (1993).

- Aggregate Supply: Potential output is modeled as a function of the labor force, crude energy use, and a composite capital stock, using a three-factor Cobb-Douglas production technology. The equilibrium output price is a mark-up over a weighted average of the productivity-adjusted wage rate and the domestic energy price. The specification of the wage and price dynamics follows the generalized adjustment cost framework used in the aggregate demand block. Wage inflation depends on lagged wage inflation over the previous three quarters, as well as expected future growth in prices and productivity, and a weighted average of expected future unemployment rates. Price inflation depends on its own lagged values over the past two quarters, as well 
as expected future changes in equilibrium prices and expected future unemployment rates. In addition, both wages and prices error-correct to their respective equilibrium levels. A vertical long-run Phillips curve is imposed in estimation. The model contains a detailed accounting of various categories of income, taxes, and stocks, an explicit treatment of labor markets, and endogenous determination of potential output. Long-run equilibrium in the model is of the stock-flow type; the income tax rate and real exchange rate risk premium adjust over time to bring government and foreign debt-to-GDP ratios back to specified (constant) levels.

- Foreign sector: The full model includes detailed treatments of foreign variables. Twelve sectors (countries or regions) are modeled, which encompass the entire global economy. In the model used in the Modelbase the full set of equations describing the foreign countries is replaced by two reduced form equations for foreign output and prices, to reduce computational cost.

- Shocks: The model exhibits a large range of shocks to which we add the common monetary policy shock and a fiscal shock that equally affects all three components of federal government spending such that a unit fiscal policy shock affects output by 1 percent.

- Replication: We replicated the impulse response functions for annualized quarterly inflation and the output gap to a 100 basis point innovation to the federal funds rate in Figure 2 of Levin et al. (2003).

\section{B.2.4 US_SW07: Smets and Wouters (2007)}

Smets and Wouters (2007) develop a medium-scale closed economy DSGE-Model and estimate it for the U.S. with Bayesian techniques. The model features a deterministic growth rate driven by laboraugmenting technological progress, so that the data do not need to be detrended before estimation.

- Aggregate Demand: Households maximize their lifetime utility, where the utility function is nonseparable in consumption and leisure, subject to an intertemporal budget constraint. Smets and Wouters (2007) include external habit formation to make the consumption response in the model more persistent. Households own firms, rent capital services to firms and decide how much capital to accumulate given certain capital adjustment costs. They additionally hold their financial wealth in the form of one-period, state-contingent bonds. Exogenous spending follows a first-order autoregressive process with an iid-normal error term and is also affected by the productivity shock.

- Aggregate Supply: The final goods, which are produced under perfect competition, are used for consumption and investment by the households and by the government. The final goods producer maximizes profits subject to a Kimball (1995) aggregator of intermediate goods, which 
introduces monopolistic competition in the market for intermediate goods and features a non constant elasticity of substitution between different intermediate goods, which depends on their relative price. A continuum of intermediate firms produce differentiated goods using a production function with Cobb-Douglas technology and fixed costs and sell these goods to the finalgood sector. They decide on labor and capital inputs, and set prices according to the Calvo model. Labor is differentiated by a union using the Kimball aggregator, too, so that there is some monopoly power over wages, which results in an explicit wage equation. Labor packers buy the labor from the unions and resell it to the intermediate goods producer in a perfectly competitive environment. Sticky wages ï; la Calvo are additionally assumed. The Calvo model in both wage and price setting is augmented by the assumption that prices that can not be freely set, are partially indexed to past inflation rates.

- Shocks: A total factor productivity shock, a risk premium shock, an investment-specific technology shock, a wage and a price mark-up shock and two policy shocks: the common fiscal policy shock entering the government spending equation and the common monetary policy shock.

- Calibration/Estimation: The model is estimated for the U.S. with Bayesian techniques for the period 1966:1-2004:4 using seven key macroeconomic variables: real GDP, consumption, investment, the GDP deflator, real wages, employment and the nominal short-term interest rate.

- Replication: We replicated the impulse response functions to a positive one standard deviation monetary policy shock in Figure 6 of Smets and Wouters (2007). The variables include output, hours, quarterly inflation and the interest rate.

\section{B.2.5 US_ACEL: CEE/ACEL by Altig et al. (2005)}

The purpose of the authors is to build a model with optimizing agents that can account for the observed inertia in inflation and persistence in output (Christiano et al., 2005). In the version by Altig et al. (2005) firm-specific capital is introduced to get a Calvo parameter consistent with the microeconomic evidence of price re-optimizations on average once every 1.5 quarters. The Modelbase contains four different specifications of the CEE/ACEL model, labeled by $\mathrm{m}=$ monetary policy shock, $\mathrm{t}=$ technology shock and sw $=\mathrm{SW}$ assumptions, i.e. no cost channel and no timing constraints as in Taylor and Wieland (2009).

- Aggregate Demand: The representative household's utility is separable in consumption and leisure and allows for habit formation in consumption. Expected-lifetime utility is maximized, choosing optimal consumption and investment, as well as the amount of capital services supplied to the intermediate firms (homogenous capital model) and portfolio decisions. Investment 
adjustment costs are introduced. Furthermore, the household determines the wage rate for its monopolistically supplied differentiated labor services whenever it receives a Calvo signal. In those periods, in which it does not receive a signal, the wage is increased by the lagged inflation rate augmented by the steady state growth rate of a combination of the neutral technology shock and the shock to capital embodied technology. Labor services are sold to a competitive firm that aggregates the differentiated services and supplies the resulting aggregated labor to the intermediate goods firms.

In the firm-specific capital model, the capital stock is owned by the firms.

- Aggregate Supply: The final consumption good is produced under perfect competition using differentiated intermediate goods as inputs. Each intermediate good is producted by a monopolist employing capital (which is firm-specific in one variant of the model) and labor services. The production function is augmented by a technology shock. Capital is pre-determined. Hence, if capital is firm-specific, marginal costs depend positively on the firm's output level. Furthermore, it is assumed that the monopolistic firms have to pay the wage bill in advance which requires borrowing from a financial intermediary. Nominal frictions are introduced in the form of Calvo sticky prices. Non-reoptimizing firms index their prices to previous periods inflation.

- Shocks: The common monetary policy shock, a neutral technology shock and an investment specific technology shock.

- Calibration/Estimation: The model has been estimated by matching the empirical impulse response functions to a monetary policy shock in a ten variable VAR with the theoretical impulse responses from the model to a monetary policy shock. Quarterly U.S. data from 1959:Q22001:Q4 is used.

- Replication: Using the US_ACELm model we replicated the impulse response functions for annualized quarterly inflation, output, annualized quarterly money growth and the annualized quarterly interest rate to a one standard deviation monetary policy shock.

\section{B.2.6 US_NFED08: Edge et al. (2008)}

The US_NFED08 is a version of the medium-scale closed economy model as in Edge et al. (2008) used for estimation in Wieland and Wolters (2011). In this model, specifications regarding production and expenditures are motivated by the long-run and cyclical properties observed in the U.S. data. Production sectors in Edge et al. (2008) differ in the rate of the technological growth while expenditures are categorized as business spending and household spending. The model as in Edge et al. (2008) is 
used at the Federal Reserve Board as a complimentary model for policy analysis along FRB/US and other small models.

- Aggregate Demand: Households derive utility from four sources: purchases of the consumer non-durable goods and non-housing services, the flow of services from their rental of consumerdurable capital, the flow of services from their rental of residential capital, and leisure. Internal habit persistence is present in all three components of consumption. Households supply differentiated labor to two production sectors. They face quadratic wage adjustment costs when setting wages. Furthermore, they face additional costs when changing the mix of labor supplied to each of the production sectors. The consumption components and the disutility from labor are subject to specific AR(1) aggregate shocks.

- Aggregate Supply: There are two production sectors in this model, differing on what type of final goods and services they are producing. One of the sectors (comprised of businesses and institutions) produces slow-growing "consumption" goods and services while the other sector (only businesses) produces fast-growing "capital” goods. Final goods are an aggregate (using Dixit-Stiglitz technology) of sector-specific differentiated intermediate goods. The latter are produced by intermediate goods producers by combining aggregated labor with utilized non-residential capital in a Cobb-Douglas production function. Labor input for each sector is aggregated using Dixit-Stiglitz technology. The level of productivity in the Cobb-Douglas production function has a common and a sector specific factor. Based on historical data for the U.S., faster technological progress for capital-specific goods is assumed. Price setting decisions (under price adjustment costs) of intermediate goods firms deliver a New Keynesian Phillips curve with backward and forward-looking terms. Capital owners choose how much residential capital, non-residential capital and consumer durables will be invested in each production sector. These decisions are subject to investment and capital adjustment costs. In addition, the decision for the utilization of non-residential capital is subject to utilization costs.

- Shocks: A shock to preferences over durables, a shock to preferences over non-durables and non-housing services, a shock to preferences over residential capital, a shock to preferences over leisure, a shock to efficiency of investment in non-residential capital, a shock to efficiency of investment in residential capital, a shock to efficiency of investment in consumer durable goods, a mark-up shock, a shock to the elasticity of substitution between the differentiated intermediate goods inputs, an economy-wide productivity shock, a sector specific productivity shock, an intermediate labor substitution shock, a labor substitution shock, a monetary policy shock. 
- Calibration/Estimation: Estimated with Bayesian methods, using quarterly U.S. data for the period 1984:Q1-2004:Q4.

\section{B.2.7 US_RS99: Rudebusch and Svensson (1999)}

Rudebusch and Svensson (1999) set up a simple linear model of the U.S. economy which is used to examine the performance of different policy rules taking into account an inflation targeting monetary policy regime. The model equations are backward looking.

- Aggregate Demand: An IS curve relates the output gap to its own lags and the difference between the average federal funds rate and the average inflation rate over the current and three preceding quarters.

- Aggregate Supply: Phillips curve of the accelerationist form.

- Shocks: A cost-push shock, a demand shock and the common monetary policy shock.

- Calibration/Estimation: The model equations are estimated individually by ordinary least squares for U.S. data. The sample period comprises 1961:1-1996:2.

\section{B.2.8 US_OR03:Orphanides (2003)}

Orphanides (2003) conducts a counterfactual analysis based on the historical experience of the United States economy to give an example of the difficulties in identifying robust policy strategies. The counterfactual analysis gives an insight how inflation and the output gap would have evolved from the 1960 s to the 1990s if the Federal Reserve had actually followed two distinct activist monetary policy rules taking into account the difference between realistic and non-realistic assumptions on the availability of information on the output gap.

- Aggregate demand: The demand side of the structural model of the economy is represented by an IS equation which relates the output gap to its own lags, lags of inflation and the federal funds rate.

- Aggregate supply: The supply side is represented by an accelerationist form of the Philips curve with an adaptive representation of inflation expectations.

- Shocks: A cost-push shock, a demand shock and the common monetary policy shock.

- Calibration/estimation: The Aggregate Demand and Aggregate Supply equation are estimated in a setup that can be interpreted as a mildly restricted structural vector autoregression (VAR) of up to four lags estimated using quarterly data from 1960 to 1993. 


\section{B.2.9 US_PM08 and US_PM08fl: Carabenciov et al. (2008)}

Carabenciov et al. (2008) design and estimate two versions of a small projection model for the U.S. economy: one with financial real linkages, US_PM08fl and one without, US_PM08. These models are part of the IMF research agenda in developing a Small Quarterly Global Projection Model (GMP) which consists of many small country models integrated into a single global market. Both versions of the model consist of few behavioral equations, focusing on the joint determination of output, unemployment, inflation and the federal funds rate.

- Aggregate Demand: The behavioral IS curve relates the output gap to its past and expected future value, to the past value of the short interest rate gap and to a disturbance term. This specification allows for inertia and persistent effects of the shocks. In the model with financial linkages, US_PM08fl, the output gap is a function of a financial variable as well, constructed using information from FED's quarterly Senior Loan Officer Opinion Survey on Bank Lending Practices. This variable enters in the form of a shock and it is supposed to reflect the bank lending conditions (tightening or loosening). Thus, if lending conditions are tighter than anticipated, the effect will be a lower output gap and a weaker economy.

- Aggregate Supply: In the Phillips curve equation, inflation is linked to its past and expected future values, to the lagged output gap and a disturbance term. This representation reflects the way agents set their prices: a share of them uses indexation to past inflation and others are forward looking. These expectations are based on model-consistent estimates of future inflation.

- Shocks: A shock to the level and the growth rate of potential output, a shock to the level and the growth rate of the equilibrium rate of unemployment, a shock to the equilibrium real interest rate. In the model with financial linkages, US_PM08fl, a financial shock is introduced in addition and cross correlations of the error terms between certain shocks are allowed.

- Calibration/Estimation: Both models are estimated with Bayesian techniques, using U.S. quarterly data over the period 1994:Q1-2008:Q1.

\section{B.2.10 US_DG08: DeGraeve (2008)}

DeGraeve (2008) uses a medium-scale New Keynesian model like in Smets and Wouters (2007) enriched with financial frictions as in Bernanke et al. (1999) to estimate and explore the role of the external finance premium in propagating shocks for the U.S. economy. Conditional on certain shocks, he finds that a framework with financial frictions and investment adjustment costs may give rise to a financial "decelerator". 
- Aggregate Demand: As in Smets and Wouters (2007), households maximize their lifetime utility function, non-separable in consumption and leisure, subject to an intertemporal budget constraint. Preferences for consumption are subject to habit persistence. They own firms, hold financial wealth in the form of one-period, state-contingent bonds and supply labor monopolistically. Wage stickiness is introduced via the Calvo framework.

- Aggregate Supply: Apart from the intermediate and final goods firms as in Smets and Wouters (2007), a financial intermediary, capital goods producers and entrepreneurs are introduced in the model to match the structure as in Bernanke et al. (1999) and Christiano, Motto, and Rostagno (2003). Intermediate goods firms face price rigidity a la Calvo while capital good producers face convex investment adjustment costs. On the other side, the presence of entrepreneurs and the financial intermediary brings financial frictions into play. Entrepreneurs borrow from financial intermediaries to buy capital (from capital producers), decide on capital utilization, rent capital services to intermediate goods firms and sell non-depreciated capital back to capital producers. However, after the purchase of the capital stock, entrepreneurs are hit by an idiosyncratic shock, observable only by them. This leads to the costly state verification framework a la Bernanke et al. (1999), giving raise to extra costs, above the risk-free rate. The optimal contract between entrepreneurs and the financial intermediary leads to an aggregate relationship of the spread between the external finance costs and the risk-free rate and entrepreneurs' financial conditions represented by the leverage ratio.

- Shocks: A preference shock, a labor supply shock, a total factor productivity shock, an investment technology shock, a government spending shock, an inflation target shock, a monetary policy shock, a wage and price mark-up shock.

- Calibration/Estimation: The model is estimated using Bayesian methods on quarterly U.S. data for the period 1954:Q1-2004:Q4.

\section{B.2.11 US_CD08: Christensen and Dib (2008)}

Christensen and Dib (2008) develop and estimate a DSGE model characterized by price stickiness, capital adjustment costs and financial frictions with the aim of evaluating the importance of the financial accelerator in the amplification and propagation of the effects of the transitory shocks to the U.S. economy. US_CD08 is a closed economy model like in Ireland (2003) enriched with financial frictions as in Bernanke et al. (1999). The model is estimated in two versions, with and without the financial accelerator mechanism.

- Aggregate Demand: The representative household derives utility from consumption, real money balances and leisure. Consumption and real balances are subject to a preference shock and a 
money demand shock, respectively. The household keeps deposits at the financial intermediary, supplies labor to the entrepreneurs and earns dividends from retailer firms.

- Aggregate Supply: The production sector is comprised of entrepreneurs, capital producers and retailers. The set up introducing the financial frictions is similar to Bernanke et al. (1999), apart from the fact that the debt contracts in Christensen and Dib (2008) are written in terms of the nominal interest rate. This specification allows for debt inflation effects, as unanticipated changes in inflation will affect the real cost of debt payment and the entrepreneurial net worth. Entrepreneurs borrow from financial intermediaries to buy capital from capital producers and produce intermediate goods. Due to asymmetric information between the entrepreneurs and financial intermediaries, the demand for capital is dependent on the entrepreneurs' financial conditions. Capital producers combine efficient investment goods and existing capital to produce new capital, subject to capital adjustment costs, which slow down the response of investment to different shocks. On the other side, retailers buy wholesale goods from entrepreneurs, differentiate them at no cost and sell them in a monopolistic competitive market, subject to price stickiness as in Calvo (1983) and Yun (1996).

- Shocks: A preference shock, a money demand shock, a technology shock, an investment shock and a monetary policy shock.

- Calibration/Estimation: The model is estimated using a maximum-likelihood procedure with Kalman filter on quarterly U.S. data for the period 1979:Q3-2004:Q3.

\section{B.2.12 US_IAC05: Iacoviello (2005)}

Iacoviello (2005) develops a New Keynesian model with nominal and financial frictions, where debt contracts are written in nominal terms and some agents face collateral constraints tied to housing values. This gives rise to an accelerator effect for demand shocks and a decelerator effect for supply shocks. The model can match the response of the aggregate demand to housing price shocks and the hump-shaped dynamics of output to inflation surprises, observed from U.S. data.

- Aggregate Demand: There are two types of households, the "patient" and the "impatient" ones. They both derive utility from consumption, holdings of housing, real money balances and leisure. However they discount the future differently, with the impatient household discounting the future more heavily. This specification induces the impatient household to face borrowing constraints, consistent with standard lending criteria used in the mortgage market where the borrowing is limited to a fraction of the housing value. For both types of households, the holding of housing is subject to housing adjustment costs. 
- Aggregate Supply: Entrepreneurs produce a homogeneous intermediate good using a CobbDouglas technology with labor from both types of households, capital and real estate as inputs. Housing and variable capital are subject to adjustment costs. Following Kiyotaki and Moore (1997), a limit on the obligation of the entrepreneurs is assumed. Entrepreneurs discount the future more heavily than the patient households. Both assumptions assure that the borrowing constraint is binding for entrepreneurs. In addition there are retailers who buy the intermediate goods from the entrepreneur, differentiate them at no cost and sell them at a price that can be re-optimized every period only with a certain probability. The optimization problem of the retailers yields a forward-looking Phillips curve.

- Shocks: A housing preference shock, an inflation shock, a technology shock and a monetary policy shock.

- Calibration/Estimation: A mixture of calibrated and estimated parameters. Estimation of parameters is done by minimizing a measure of the distance between the VAR impulse responses and model responses, using quarterly U.S. data for the period 1974:Q1-2003:Q2.

\section{B.2.13 US_MR07: Mankiw and Reis (2007)}

Mankiw and Reis (2007) develop a general equilibrium model where rigidities come from the fact that agents are inattentive and do not update information regularly when setting prices, wages and deciding on consumption. US_MR07 is a model with information stickiness. Estimation of the model using U.S. data confirms the presence of such rigidities, especially for consumers and workers.

- Aggregate Demand: Infinitely lived households are of two types: consumers and workers. Their utility function is additively separable in consumption and leisure. They are able to save and borrow by trading bonds between themselves. Workers choose how much to work and what wage to charge for the particular variety of labor over which they hold a monopoly. Both consumers and workers take decisions but only a fraction of them, randomly drawn from their respective population, obtain new information and can re-optimize their actions. If they obtain new information, they revise their plans for future consumption and labor supply, respectively. Both, the aggregate demand (IS equation) and the equation of wages, depend on the sum of past expectations of current economic conditions, reflecting the fact that households have different sets of information. The stickier the information is (low share of informed households), the smaller the impact of shocks on spending and wages, since fewer consumers and workers are aware of them. The natural (long-run) equilibrium corresponds to a situation where all agents are perfectly informed. 
- Aggregate Supply: Firms produce output using labor and sell their differentiated goods in a monopolistic competitive market. Firms are constrained in information gathering in the same fashion as households. Each period, a fraction of firms, randomly drawn from the population, obtains new information and recalculates the optimal price. The optimizing process of the firms leads to a Phillips curve equation where the price level is determined as a sum of past expectations of current economic conditions (prices, output, marginal costs, technology shocks). The summation captures the fact that firms have different sets of information. Shocks to the variables in the Phillips curve equation will have gradual effects as some firms remain unaware of these shocks and only react to them once they update their information set.

- Shocks: A mark-up good shock, a mark-up labor shock, a government shock, a technology shock and a monetary policy shock.

- Calibration/Estimation: Estimated with maximum likelihood and Bayesian methods, using quarterly U.S. data for the period 1954:Q3-2006:Q1.

\section{B.2.14 US_RA07: Rabanal (2007)}

Rabanal (2007) incorporates a cost channel of monetary transmission into an otherwise standard medium-scale New Keynesian DSGE model by assuming that a fraction of firms need to borrow money to pay their wage bill prior to their sales receipts. The model is estimated on US data in order to analyze whether the cost channel empirically accounts for the so-called price puzzle.

- Aggregate Demand: Households obtain utility from consuming the final good and disutility from supplying labor, they own intermediate firms, lend capital services to firms and make investment and capital utilization decisions. Moreover, their utility function displays external habit formation. Capital is predetermined at the beginning of a period, but households can adjust its utilization rate subject to adjustment costs. Financial markets are assumed to be complete.

- Aggregate Supply: Intermediate good producers combine labor and capital services to produce their goods while taking the capital utilization rate decision of households as given. A fraction of intermediate good producers have to pay their wage bill every period before they sell their product. These firms borrow at the riskless nominal interest rate. Goods and labor markets are characterized by monopolistic competition. Prices and wages are set in a staggered way, following the formalism of Calvo (1983). Indexation to last period's average inflation rate is assumed for firms and households whenever they are not allowed to reoptimize. A continuum of final good producers operating under perfect competition uses intermediate goods for the production of final goods. 
- Shocks: Four orthogonal structural shocks are introduced in the model. The government spending and technology shocks follow an AR(1) process. The monetary and the price markup shock are assumed to be iid processes.

- Calibration/Estimation: The model is estimated using Bayesian techniques on quarterly US data. The data set used comprises four key macroeconomic variables: real output, real wage, inflation rate and the nominal interest rate over the period 1959:Q1-2004:Q4.

\section{B.2.15 US_IR11: Ireland (2011)}

Ireland (2011) estimates a New Keynesian model for the US economy in order to compare the Great Recession of 2007-09 with its two immediate predecessors, the milder recessions of 1990-91 and 2001.

- Aggregate Demand: The utility function of the representative household is additively separable in consumption, real money balances and hours worked, and features habit formation in consumption. The household enters each period with money and bonds. At the beginning of each period, it receives a lump-sum nominal transfer from the central bank. Moreover, the household decides about the purchase of new bonds, the supply of labor and the consumption of finished goods. At the end of each period, the household receives nominal dividend payments resulting from the ownership of intermediate-goods-producing firms.

- Aggregate Supply: During each period, the representative intermediate-goods-producing firm hires labor to manufacture intermediate goods according to a constant-return-to-scale technology. The representative intermediate-goods-producing firm has monopolistic power, acting as a price-setter. However, price setting is subject to Rotemberg quadratic adjustment costs. The intermediate goods are then used by the finished-goods-producing firms to manufacture final goods under perfect competition.

- Shocks: An AR(1) preference shock, a cost-push shock in form of a shock to the price mark up, a technology shock that follows a random walk with drift and a monetary policy shock.

- Calibration/Estimation: The model is estimated via maximum likelihood using U.S. quarterly data on output growth, the inflation rate and the short-term nominal interest rate over the period 1930:Q1-2009:Q4. 


\section{B.3 Estimated Euro Area Models \\ B.3.1 EA_CW05: Coenen and Wieland (2005)}

Coenen and Wieland (2005) develop a small-scale macroeconomic model for various staggered pricing schemes. We use a version with the nominal contract specification of Taylor (1980), labeled EA_CW05ta, and a version with the relative real wage contract specification of Fuhrer and Moore (1995a), labeled EA_CW05fm.

- Aggregate Demand: The aggregate demand equation is backward looking: two lags of aggregate demand (should account for habit persistence in consumption, adjustment costs and accelerator effects in investment) and one lag of the long-term interest rate (allows for a transmission lag of monetary policy). The long-term nominal interest rate is an average of expected future nominal short-term rates. The long-term real rate is determined by the Fisher equation.

- Aggregate Supply: As in US_FM95 and US_OW98.

- Shocks: A demand shock, a contract wage shock and the common monetary policy shock.

- Calibration/Estimation: The model has been estimated on data from the ECB Area Wide Model data set from 1974:1-1998:4. The contract wage specifications have been estimated by a limited information indirect inference technique while the IS equation has been estimated by means of the GMM.

- Replication: We replicated the impulse response functions of annual inflation and the output gap to a 100bps temporary unanticipated rise in the nominal short term rate in the upper panel of Figure 7 of Kuester and Wieland (2005) for both versions of the model.

\section{B.3.2 EA_AWM05: Area Wide model linearized by Dieppe, Kuester and McAdam (2005)}

The model is described in Fagan, Henry, and Mestre (2005). It was one of the first models to treat the Euro area as a single economy. In the Modelbase we use the linearized version from Dieppe, Kuester and McAdam (2005) that is also used in Kuester and Wieland (2005). The EA_AWM05 is an open economy model of the Euro area. Expectation formation is largely backward-looking. Activity is demand-determined in the short-run but supply determined in the long-run with employment having converged to a level consistent with the exogenously given level of equilibrium unemployment. Stock-flow adjustments are accounted for, e.g., the inclusion of a wealth term in consumption.

- Aggregate Demand: Demand is disaggregated into private consumption, government consumption, investment, variation of inventories, exports, and imports. The term structure (12-year bond) is forward-looking. Private consumption is specified as a function of households' real 
disposable income and wealth, where the latter consists of net foreign assets, public debt and the capital stock. The change in the log of the investment/output ratio depends on the real interest rate, the real GDP/capital stock ratio and the lagged investment/output ratio. The authors stress that this investment equation represents the key channel through which interest rates affect aggregate demand. Government consumption is treated as exogenous.

- Aggregate Supply: Output follows a whole economy production function. Short-run employment dynamics are driven by output growth and real wages. The deflator for real GDP at factor costs, which according to Fagan et al. (2005) is the key price index of the model, is a function of unit labor costs, import prices, the output gap and inflation expectations. The growth rate of wages depends on consumer price inflation, productivity and the unemployment gap, defined as the deviation of the current unemployment rate from the NAIRU.

- Foreign sector: Besides extra-area flows, exports and imports also include intra-area flows. World GDP and world GDP deflator are treated as exogenous variables. The exchange rate is a forward-looking variable determined by uncovered interest rate parity.

- Shocks: Employment shock, factor cost-push shock, private consumption cost-push shock, gross investment cost-push shock, gross investment shock, exports cost-push shock, imports cost-push shock, private consumption shock, term structure shock, common fiscal policy shock and common monetary policy shock.

- Calibration/Estimation: Estimation on Euro area data equation by equation from 1970:1-1997:4, whereas the estimation period of some equations starts later, but not later than 1980:1.

- Replication: We replicated the impulse response functions of annual inflation and the output gap to a 100bps temporary unanticipated rise in the nominal short term rate in the upper panel of Figure 7 of Kuester and Wieland (2005).

\section{B.3.3 EA_SW03: Smets and Wouters (2003)}

The EA_SW03 model of Smets and Wouters (2003) is a medium-scale closed economy DSGE model with various frictions and estimated for the Euro area with Bayesian techniques.

- Aggregate Demand: Households maximize their lifetime utility, where the utility function is separable in consumption, leisure and real money balances, subject to an intertemporal budget constraint. Smets and Wouters (2003) include external habit formation to make the consumption response in the model more persistent. Households own firms, rent capital services to firms and decide how much capital to accumulate given certain capital adjustment costs. They 
additionally hold their financial wealth in the form of cash balances and one-period, statecontingent bonds. Exogenous spending is introduced by a first-order autoregressive process with an iid-normal error term.

- Aggregate Supply: The final goods, which are produced under perfect competition, are used for consumption and investment by the households and by the government. The final goods producer maximizes profits subject to a Dixit-Stiglitz aggregator of intermediate goods, which introduces monopolistic competition in the market for intermediate goods and features a constant elasticity of substitution between individual, intermediate goods. A continuum of intermediate firms produce differentiated goods using a production function with Cobb-Douglas technology and fixed costs and sell these goods to the final-goods sector. They decide on labor and capital inputs, and set prices according to the Calvo model. Labor is differentiated over households using the Dixit-Stiglitz aggregator, too, so that there is some monopoly power over wages, which results in an explicit wage equation. Sticky wages a la Calvo are additionally assumed. The Calvo model in both wage and price setting is augmented by the assumption that prices that can not be freely set, are partially indexed to past inflation rates.

- Shocks: Ten orthogonal structural shocks are introduced in the model. Three preference shocks in the utility function: a general shock to preferences, a shock to labor supply and a money demand shock. Two technology shocks: an AR(1) process with an iid shock to the investment cost function and a productivity shock to the production function. Three cost push-shocks: shocks to the wage and price mark-up, which are iid around a constant and a shock to the required rate of return on equity investment. And finally two monetary policy shocks: a persistent shock to the inflation objective and a temporary common monetary policy shock. In addition, the common fiscal policy shock is added in the form of a government spending shock. Since government spending is expressed in output units, we set the coefficient which scales the shock to unity to achieve a shock size of one percent of GDP.

- Calibration/Estimation: The model is estimated using Bayesian techniques on quarterly Euro area data. The data set used is comprised of seven key macroeconomic variables consisting of real GDP, real consumption, real investment, the GDP deflator, real wages, employment and the nominal interest rate over the period 1970:1-1999:4.

- Replication: We replicated the impulse response functions of annual inflation and the output gap to a 100bps temporary unanticipated rise in the nominal short term rate in the upper panel of Figure 7 of Kuester and Wieland (2005). 


\section{B.3.4 EA_SR07: Euro Area Model of Sveriges Riksbank, Adolfson et al. (2007)}

Adolfson et al. (2007) develop an open economy DSGE model and estimate it for the Euro area using Bayesian estimation techniques. They analyse the importance of several rigidities and shocks to match the dynamics of an open economy.

- Aggregate Demand: Households maximize lifetime utility subject to a standard budget constraint. Preferences are separable in consumption, labor and real cash holdings. Persistent preference shocks to consumption and labor supply are added to the representative utility function. Internal habit formation is imposed with respect to consumption. Aggregate consumption is specified as a CES function, being composed of domestically produced as well as imported consumption goods. Households rent capital to firms. Capital services can be increased via investment and via an increase in the capital utilization rate, where both options are involved with costs. Total investment in the domestic economy is represented by a CES aggregate consisting of domestic and imported investment goods. Households are assumed to be able to save through acquiring domestic bonds and foreign bonds in addition to holding cash and accumulating physical capital. A premium on foreign bond holdings assures the existence of a well-defined steady state. Households monopolistically supply a differentiated labor service. Wage stickiness is introduced in the form of the Calvo model augmented by partial indexation. Government consumption of the final domestic good is financed via taxes on capital income, labor income, consumption and payroll. Any surplus or deficit is assumed to be carried over as a lump-sum transfer to households.

- Aggregate Supply: The final good is produced via a CES aggregator using a continuum of differentiated intermediate goods as inputs. The production of intermediate goods requires homogeneous labor and capital services as inputs and is affected by a unit-root technology shock representing world productivity as well as a domestic technology shock. Fixed costs are imposed such that profits are zero in steady state. Due to working capital, (a fraction of) the wage bill has to be financed in advance of the production process. Price stickiness of intermediate goods is modeled as in the Calvo (1983) model. In addition, partial indexation to the contemporaneous inflation target of the central bank and the previous periods inflation rate is included for those firms that do not receive a Calvo signal in a given period. This results in a hybrid new Keynesian Phillips curve.

- Foreign sector: Importing firms are assumed to buy a homogeneous good in the world market and differentiate it to sell it in the domestic market. Similarly, exporting firms buy the homogeneous final consumption good produced in the domestic economy and differentiate it to sell it abroad. Specifically, the differentiated investment and consumption import goods are 
aggregated in a second step via a CES function, respectively. The same applies to the export goods. Calvo pricing is also assumed for the import and export sector, allowing for incomplete exchange rate pass-through in the short run. The foreign economy is described by an identified VAR model for foreign prices, foreign output and the foreign interest rate.

- Shocks: Unit root technology shock, stationary technology shock, investment specific technology shock, asymmetric technology shock, consumption preference shock, labor supply shock, risk premium shock, domestic mark-up shock, imported consumption mark-up shock, imported investment mark-up shock, export mark-up shock, inflation target shock, the common monetary policy shock, shocks to the four different tax rates and a government spending shock which represents the common fiscal policy shock and which we have adjusted so that we achieve a shock size of one percent of GDP.

- Calibration/Estimation: The model is estimated using Bayesian estimation techniques for the Euro area using quarterly data from 1970:1-2002:4 in order to match the dynamics of 15 selected variables. According to the authors, they calibrated those parameters that should be weakly identified by the 15 variables used for estimation.

- Replication: We replicated the impulse response functions for annualized quarterly inflation, output, employment and the annualized interest rate to a one standard deviation monetary policy shock in Figure 3 of Adolfson et al. (2007).

\section{B.3.5 EA_QUEST3: Ratto et al. (2009)}

Ratto et al. (2009) develop and estimate an open economy DSGE model for the euro area with emphasis on monetary and fiscal rules, in order to explore their stabilization properties. The role of fiscal policy is explored in an environment with rules for government consumption, investment and transfers and with financial frictions in the form of liquidity-constrained households.

- Aggregate Demand: There are two types of households: liquidity- and non-liquidity-constrained households. They posses the same utility function, non-separable in consumption and leisure with habit persistence in both consumption and leisure. Liquidity-constrained households do not optimize, they just consume their labor income. On the other side, non-liquidity-constrained households have access to domestic and foreign currency denominated assets, accumulate capital subject to investment adjustment costs and rent it to firms, earn profits from owning the firms and pay taxes. Income from foreign financial assets is subject to an external financial intermediation risk premium while real asset holdings are subject to an equity risk premium. Both types of households supply differentiated labor to a trade union which sets the wages by maximizing their joint utility (weighted by the share of each type). The wage setting process 
is subject to a wage mark-up and to slow adjustments in the real consumption wage. The wage mark-up arises because of wage adjustment costs and the fact that a part of workers index the growth rate of wages to past inflation.

- Aggregate Supply: The final goods, which are produced from monopolistically competitive firms, are used for household consumption, investment, government consumption and export. These goods are produced with a Cobb-Douglas production function with capital and production workers (labor adjusted for overhead labor) as inputs. These firms face technological and regulatory constraints, restricting their price setting, employment and capacity utilization decisions. The final goods producer maximizes profits subject to these specific adjustment costs (all having convex functional forms) and demand conditions. Investment good producers combine domestic and foreign final goods using a CES aggregator to produce investment goods which are sold to non-liquidity-constrained households in a perfectly competitive market.

- The Foreign Sector: Demand behavior is considered the same for the home country and the rest of the world, therefore export demand and import demand are symmetric. Both equations are characterized by a lag structure in relative prices which captures delivery lags. Export firms buy domestic goods, transform them using a linear technology and sell them in the foreign market, charging a mark-up over the domestic prices. The same situation is faced by importer firms. Mark-up fluctuations arise because of price adjustment costs in both sectors. Mark-up equations are given as a function of past and future inflation and are also subject to random shocks.

- Shocks: A wage mark up shock, a price mark-up shock, a monetary policy shock, a fiscal policy shock, world demand shock, a risk premium shock, a technology shock, an investment shock, a consumption shock, a trade shock, a labor demand shock, a foreign monetary policy shock.

- Calibration/Estimation: Estimated with Bayesian methods, using quarterly data for the euro area for the period 1981:1-2006:1.

\section{B.3.6 EA_GE10: Gelain (2010)}

The model of Gelain (2010) incorporates financial frictions à la Bernanke et al. (1999) into a New Keynesian DSGE model which closely follows the structure of the model developed in Smets and Wouters (2003). The structural model allows for a dynamic analysis of the external finance premium. The paper shows that the estimated premium is not necessarily countercyclical as suggested by former studies on the Euro Area external finance premium. In the presence of certain shocks the premium responds procyclically. 
- Aggregate Demand: A representative household maximizes its intertemporal utility function choosing the level of consumption, hours worked and the amount of bank deposits, subject to a budget constraint. The household's consumption preferences exhibit habit formation.

- Aggregate Supply: Each household is a monopolistic supplier of differentiated labor services requested by the domestic firms. After setting their wages in a Calvo staggered way, households inelastically supply the firms' demand for labor at the ongoing wage rate. An indexation rule is assumed for those households who are not allowed to re-optimize.

The production sector consists of three types of firms: entrepreneurs, capital producers and retailers. Entrepreneurs hire labor from households and buy capital from capital producers to produce intermediate goods using a Cobb-Douglas production technology. Entrepreneurs have a finite expected lifetime horizon. The capital purchases are financed partly by the entrepreneur's net worth and partly by borrowing from a financial intermediary. The presence of asymmetric information between entrepreneurs and lenders creates a financial friction as in Bernanke et al. (1999). Entrepreneurs can reoptimize their prices only from time to time, as in Calvo (1983).

Capital producers buy final goods to produce capital subject to investment adjustment costs. Retailers operate in a perfectly competitive market, they use a Dixit-Stiglitz technology using the entrepreneurs' intermediate goods as inputs.

- Shocks: The model exhibits eight shocks. Two preference shocks, a shock to investment adjustment costs, a technology shock in entrepreneurs' production function, a wage and a price mark up shock, a government spending shock and a monetary policy shock.

- The model is estimated using Bayesian techniques on quarterly Euro Area data for 1980:Q1 to 2008:Q3. The data set used is comprised of seven key macroeconomic variables aggregated for the Euro Area consisting of real GDP, real consumption, real gross investment, hours worked, the nominal short term interest rate, real wages per head and inflation rate.

\section{B.4 Estimated/Calibrated Multi-Country Models}

\section{B.4.1 G7_TAY93: Taylor (1993b) G7 countries}

Taylor (1993b) describes an estimated international macroeconomic framework for policy analysis in the G7 countries: USA, Canada, France, Germany, Italy, Japan and the UK. The model consists of 98 equations and a number of identities. This model was the first to demonstrate that it is possible to construct, estimate, and simulate large-scale models for real-world policy analysis (Yellen, 2007). Taylor (1993b) argues that a multicountry model is appropriate for the evaluation of policy questions like the appropriate mix of fiscal and monetary policy or the choice of an exchange rate policy. 
- Aggregate Demand: The IS components are more disaggregated than in the US_OW98 model. For example, spending on fixed investment is separated into three components: equipment, nonresidential structures, and residential construction. The specification of these equations is very similar to that of the more aggregated equations in the US_OW98 model. The aggregate demand components exhibit partial adjustment to their respective equilibrium levels. In G7_TAY93, imports follow partial adjustment to an equilibrium level that depends on U.S. income and the relative price of imports, while exports display partial adjustment to an equilibrium level that depends on foreign output and the relative price of exports. Uncovered interest rate parity determines each bilateral exchange rate (up to a time-varying risk premium); e.g., the expected one-period-ahead percent change in the DM/U.S.\$ exchange rate equals the current difference between U.S. and German short-term interest rates.

- Aggregate Supply: The aggregate wage rate is determined by overlapping wage contracts. In particular, the aggregate wage is defined to be the weighted average of current and three lagged values of the contract wage rate. In contrast to the US_FM95 model and the US_OW98 model, G7_TAY93 follows the specification in Taylor (1980), where the current nominal contract wage is determined as a weighted average of expected nominal contract wages, adjusted for the expected state of the economy over the life of the contract. This implies less persistence of inflation than in the US_FM95 and the US_OW98 model. The aggregate price level is not set as a constant mark-up over the aggregate wage rate as in US_FM95 and US_OW98. Prices are set as a mark-up over wage costs and imported input costs. This mark-up varies and prices adjust slowly to changes in costs. Prices follow a backward-looking error-correction specification. Current output price inflation depends positively on its own lagged value, on current wage inflation, and on lagged import price inflation, and responds negatively (with a coefficient of -0.2 ) to the lagged percent deviation of the actual price level from equilibrium. Import prices adjust slowly (error-correction form) to an equilibrium level equal to a constant mark-up over a weighted average of foreign prices converted to dollars. This partial adjustment of import and output prices imposes somewhat more persistence to output price inflation than would result from staggered nominal wages alone.

- Foreign sector: G7_TAY93 features estimated equations for demand components and wages and prices for the other G7 countries at about the level of aggregation of the U.S. sector. Financial capital is mobile across countries.

- Shocks: Interest rate parity shock, term structure shock, durable consumption shock, nondurable consumption shock, services consumption shock, total consumption shock, aggregate consumption shocks for Germany and Italy, for the other countries disaggregated, nonresiden- 
tial equipment investment shock, nonresidential structures investment shock, residential investment shock, inventory investment shock, fixed investment shock, inventory investment shock, real export shock, real import shock, contract wage shock, cost-push shock, import price shock, export price shock, fiscal policy shock, where we have adjusted the size of the fiscal policy shock for the U.S. - the common fiscal shock - so that a unit shock represents a 1 percent of GNP shock and a monetary policy shock where again the common Modelbase monetary policy shock enters the monetary policy rule for the U.S..

- Calibration/Estimation: The model is estimated with single equation methods on G7 data from 1971-1986.

- Replication: We replicated the impulse response functions for annualized quarterly inflation and the output gap to a 100 basis point innovation to the federal funds rate in Figure 2 of Levin et al. (2003).

\section{B.4.2 G3_CW03: Coenen, Wieland $(2002,2003)$ G3 countries}

In this model different kinds of nominal rigidities are considered in order to match inflation and output dynamics in the U.S., the Euro area and Japan. Staggered contracts by Taylor (1980) explain best inflation dynamics in the Euro area and Japan and staggered contracts by Fuhrer and Moore (1995a) explain best U.S. inflation dynamics. The authors evaluate the role of the exchange rate for monetary policy and find little gain from direct policy response to exchange rates.

- Aggregate Demand: The open-economy aggregate demand equation relates output to the lagged ex-ante long-term real interest rate and the trade-weighted real exchange rate and additional lags of the output gap. The demand equation is very similar to the G7_TAY93 model without any sectoral disaggregation. Lagged output terms are supposed to account for habit persistence in consumption as well as adjustment costs and accelerator effects in investment. The lagged interest rate allows for lags in the transmission of monetary policy. The exchange rate influences net exports and thus enters the aggregate demand equation. The long term nominal interest rate is an average of expected future nominal short-term rates. The long-term real interest rate is determined by the Fisher equation.

- Aggregate Supply: For the U.S., relative real wage staggered contracts by Fuhrer and Moore (1995a) are used (see the US_FM95 model for a detailed exposition). For the Euro area and Japan the nominal wage contracts by Taylor (1980) are used. Note that Taylor contracts, with a maximum contract length exceeding two quarters, result in Phillips curves that explicitly include lagged inflation and lagged output gaps. Thus, the critique that with Taylor contracts 
inflation persistence is solely driven by output persistence (Fuhrer and Moore, 1995a) is mitigated.

- Foreign sector: All three countries are modeled explicitly. The Modelbase rule replaces monetary policy for the U.S.. For the Euro area and Japan the original interest rules remain. Foreign output does not affect domestic output directly, but indirectly via the exchange rate in the demand equation. The bilateral exchange rates are determined by UIP conditions.

- Shocks: Contract wage shocks, demand shocks and the common monetary policy shock which is added for the U.S..

- Calibration/Estimation: Euro area data, (fixed GDP weights at PPP rates from the ECB areawide model database), U.S. data and Japanese data. For the U.S. and Japan OECD's output gap estimates are used. For the Euro area log-linear trends are used to derive potential output. The estimation is robust to different output gap estimations. Demand block: GMM estimation where lagged values of output, inflation, interest rates, and real exchange rates are used as instruments. Supply side: simulation-based indirect inference methods. Estimation period: U.S. 1980:1-1998:4, Euro area 1980:1-1998:4 and Japan 1980:1-1997:1.

- Replication: We replicated the impulse response functions to 0.5 percentage points demand shocks in the United States, the Euro Area und Japan plotted in Figure 3 of Coenen, Wieland (2003). Variables include the output gap, annual inflation and the short-term nominal interest rate of the United States, the Euro Area and Japan.

\section{B.4.3 EACZ_GEM03: IMF model of Euro Area and Czech Republic, Laxton and Pesenti (2003)}

The model is a variant of the IMF's Global Economy Model (GEM) and consists of a small and a large open economy. The authors study the effectiveness of Taylor rules and inflation-forecast-based rules in stabilizing variability in output and inflation. They check if policy rules designed for large and relatively closed economies can be adopted by small, trade-dependent countries with less developed financial markets and strong movements in productivity and relative prices and destabilizing exposure to volatile capital flows. In contrast to Laxton and Pesenti (2003) we focus on the results for the large open economy (Euro area) rather than the small open economy (Czech Republic).

- Aggregate Demand: Infinitely lived optimizing households; government spending falls exclusively on nontradable goods, both final and intermediate. Households face a transaction cost if they take a position in the foreign bond market. 
- Aggregate Supply: Monopolistic intermediate goods firms produce nontradeable goods and tradable goods. It exists a distribution sector consisting of perfectly competitive firms. They purchase tradable intermediate goods worldwide (at the producer price) and distribute them to firms producing the final good (at the consumer price). Perfectly competitive final good firms (Dixit-Stiglitz aggregator) use nontradable and tradeable goods and imports as inputs. Households are monopolistic suppliers of labor and wage contracts are subject to adjustment costs. Households own domestic firms, nonreproducable resources and the domestic capital stock. Markets for land and capital are competitive. Capital accumulation is subject to adjustment costs. Labor, capital and land are immobile internationally. Households trade a short-term nominal bond, denominated in foreign currency. All firms exhibit local currency pricing, thus exchange rate pass-through is low.

- Shocks: Risk premium shock, productivity shock, shock to the investment depreciation rate, shock to the marginal utility of consumption, government absorption shock where the one affecting the large foreign economy represents the common fiscal policy shock, shock to the marginal disutility of labor, preference shifter. We add the common monetary policy shock to the policy rule of the large economy.

- Calibration/Estimation: Calibrated to fit measures of macro-variability of the Euro area (1970:12000:4) and Czech Republic (1993:1-2001:4).

- Notes: Due to the symmetric setup of the model, we use the same policy rule in both countries.

- Replication: We replicated the standard deviations of annual inflation, the output gap and the first difference of the interest rate under the optimal Taylor rule implied by the loss function specification 2 of Laxton and Pesenti (2003) as listed in the second row of Table 4 in their paper.

\section{B.4.4 G2_SIGMA08: FRB-SIGMA by Erceg et al. (2008)}

The SIGMA model is a medium-scale, open-economy, DSGE model calibrated for the U.S. economy. Erceg et al. (2008) in particular take account of the expenditure composition of U.S. trade and analyse the implications for the reactions of trade to shocks compared to standard model specifications.

- Aggregate Demand: There are two types of households: households that maximize a utility function separable in consumption, with external habit formation and a preference shock, leisure and real money balances, subject to an intertemporal budget constraint (forward-looking households) and the remainder that simply consume after-tax disposable income (hand-tomouth households). Households consume, own the firms and accumulate capital, which they 
rent to the intermediate goods producers. Erceg et al. (2008) introduce investment adjustment costs a la Christiano et al. (2005), where it is costly for the households to change the level of gross investment. Households also choose optimal portfolios of financial assets, which include domestic money balances, government bonds, state-contingent domestic bonds and a non-state contingent foreign bond. It is assumed that households in the home country pay an intermediation cost when purchasing foreign bonds, which ensures the stationarity of net foreign assets. Households rent their labor in a monopolistic market to firms, where forward-looking households set their nominal wage in Calvo-style staggered contracts analogous to the price contracts and hand-to-mouth households simply set their wage each period equal to the average wage of the forward-looking households.

- Aggregate Supply: Intermediate-goods producers have an identical CES production function and rent capital and labor from competitive factor markets. They sell their goods to final goods producers under monopolistic competition and set prices in Calvo-style staggered contracts. Firms, who don't get a signal to optimize their price in the current period, mechanically adjust their price based on lagged aggregate inflation. Final good producers in the domestic and foreign market assemble the domestic and foreign intermediate goods into a single composite good by a CES production function of the Dixit-Stiglitz form and sell the final good to households in their country. Erceg et al. (2008) introduce quadratic import adjustment costs into the final goods aggregator, which are zero in steady state. It is costly for a firm to change its share of imports in a final good relative to their lagged aggregate shares. Thus the import share of consumption or investment goods is relatively unresponsive in the short-run to changes in the relative price of imported goods even while allowing the level of imports to jump costlessly in response to changes in overall consumption or investment demand. Government purchases are assumed to be a constant fraction of output. Government revenue consists of income from capital taxes (net of the depreciation write off), seignorage income and revenue from lump-sum taxes (net of transfers). The government issues bonds to finance the difference between government revenue and expenditure. Lump-sum taxes are adjusted both in response to deviations of the government debt/GDP ratio from a target level and to the change in that ratio.

- Foreign sector: Local currency pricing is assumed. Intermediate goods producers price their product separately in the home and foreign market leading to an incomplete exchange rate pass-through. Erceg et al. (2008) point out, that empirically imports and exports in the U.S. are heavily concentrated, with about 75 percent in capital goods and consumer durables, but the production share of capital goods and consumer durables is very low. To account for this fact in the two-country model they allow the import share in the final good aggregator for investment 
goods to be higher than the import share in the final good aggregator for consumption goods.

- Shocks: Since we have no information about the variances of the shock terms, we set all shock variances equal to zero. The government spending shock of the home country represents the common fiscal policy shock. The common monetary policy shock is added for the home country.

- Calibration/Estimation: The model is calibrated at a quarterly frequency. Parameters of the original monetary policy rule are estimated using U.S. data from 1983:1-2003:4.

- Replication: We replicated the impulse response functions for real exports, real imports and the exchange rate to a foreign investment demand sock represented by a decline in the foreign capital income tax rate as plotted in Figure 3 (disaggregated trade case) of Erceg et al. (2008).

\section{B.4.5 EAUS_NAWM08: Coenen et al. (2008)}

Coenen et al. (2008) use a calibrated, two-country version of the New Area-Wide Model developed at the European Central Bank to examine the Euro Area tax structure and the potential benefits and spillovers of a tax reform (reducing labor market distortions). The real effects of fiscal policies are analyzed in an environment with heterogeneous households. Countries in Coenen et al. (2008) are symmetric but of different size where the U.S. represents the rest of the world.

- Aggregate Demand: Only a share of households have access to domestic and international financial markets, accumulates capital and holds money. The other part of households do not have access to financial markets and neither holds capital. They smooth consumption solely by adjusting their money holdings. Both types of households maximize a lifetime utility function with external habit in consumption and supply differentiated labor services with monopoly power in wage setting. Wages are determined in a la Calvo (1983) fashion. Households that receive permission to re-optimize their wages choose the same wage while the other part follows an indexation scheme, with wages being a geometric average of past changes in the price of the consumption good. Households gross income is subject to a rich taxation structure. They pay taxes on consumption purchases, on wage income, on rental capital income and on dividend income. Furthermore, they pay social security contributions, a lump-sum tax and receive transfers. Purchases of consumption, financial investment in international markets and capital utilization are subject to specific proportional costs.

- Aggregate Supply: Producers are distinguished between producing tradable and non-tradable goods. The intermediate goods firm produces a single, tradable differentiated good using an increasing-returns-to-scale Cobb-Douglas technology with capital services and labor as inputs. 
These goods are sold both in domestic and foreign market under monopolistic competition. Price setting is subject to staggered price contracts a la Calvo (1983). Firms that receive permission to re-optimize their prices choose the same price (be it for the domestic or for the foreign market) while the other firms follow an indexation scheme, with prices being a geometric average of past changes in the aggregate price indexes. The final goods firms produce three non-tradable final goods: private consumption goods, investment goods and public consumption goods. Final non-tradable private consumption and private investment goods are modeled in an analogous manner. These final goods are assembled with CES technology, combining intermediate domestic and imported foreign goods. Varying the use of imported intermediate goods in the production process is subject to adjustment costs, therefore changes in the relative price of imported goods go unreflected in the short-run. These final goods are sold taking the price as given. On the other side, the public consumption good is a composite of only domestically produced intermediate goods.

- The Foreign Sector: The demand for imported goods is equal to the sum of the respective demands for intermediate goods for private consumption and investment. These intermediate goods are sold in the home market by the foreign intermediate-good producer. The price of the intermediate good imported from abroad is equal to the price charged by the foreign producer (local currency pricing).

- Shocks: A government spending shock, a transfer shock, a productivity shock, a monetary policy shock. (Distortionary tax rates on consumption, on dividends, on rental capital income, on labor income and payments on social security contributions are given as exogenous processes but constant).

- Calibration/Estimation: The model is calibrated to the Smets and Wouters (2003) model, with steady-state ratios based on observed data for the euro area and U.S., respectively.

- Replication: All impulse responses to different fiscal policy shocks, as appearing in Coenen et al. (2008), have been replicated.

\section{B.4.6 EAES_RA09: Rabanal (2009)}

Rabanal (2009) uses a two-country, two-sector DSGE model of a currency union with nominal rigidities to study the sources of persistent inflation differentials between the EMU and one of its member countries, Spain. Moreover, the paper aims at explaining the first moments of the data by introducing time trends for the country- and sector-specific technology shock processes that can give rise to permanent inflation differentials in the model. 
- Aggregate Demand: Households in Spain and in the rest of EMU have utility functions separable in consumption and leisure and displaying external habit formation in consumption. The composite consumption good is defined as a CES aggregate consisting of domestic tradable and nontradable, and foreign tradable goods. Preferences are assumed to be the same across countries, but countries differ with respect to the composition of their consumption basket.

- Aggregate Supply: Each economy is characterized by two sectors. Monopolistic intermediate firms use labor, supplied by the households, as the only input to produce tradable and nontradable goods. They set prices to maximize profits subject to a set of demand equations. Price setting follows a modified version of the Calvo framework with two indexation mechanisms in place that account for the fact that steady state inflation might be non-zero. Across countries the same production technologies are deployed but countries differ in the degree of wage and price stickiness and in the degree of indexation.

- Foreign sector: Rabanal (2009) models two countries in the European monetary union of unequal size. They produce differentiated tradable goods that are imperfect substitutes of each other, but there is no price discrimination for the same type of good across countries.

- Shocks: Ten shocks are introduced in the model: sector- and country-specific AR(1) shock processes for the government spending and the technology shock with an Euro Area tradable shock component, and an iid monetary policy shock.

- Calibration/Estimation: The model is estimated using Bayesian estimation techniques using quarterly euro area data for the period 1996:Q1-2007:Q4.

\section{B.5 Estimated Models of Other Countries}

\section{B.5.1 CL_MS07: Medina and Soto (2007)}

Medina and Soto (2007) develop a small-open economy DSGE model for the Chilean economy. The CL_MS07 is structurally similar to models developed by Christiano et al. (2005), Altig et al. (2005), and Smets and Wouters (2007). Still, a richer specification for the production sector and for fiscal policy is designed to account for special characteristics of the Chilean economy.

- Aggregate Demand: There are two types of households, Ricardian and non-Ricardian households. The Ricardian type households maximize a utility function separable in consumption, leisure and real money balances subject to their intertemporal budget constraint. They have access to three types of assets, namely money and one-period non-contingent foreign and domestic bonds. Each of these households is a monopolistic supplier of differentiated labour and only a fraction of them can re-optimize their nominal wage. Rigidity a la Calvo in wage setting 
follows Erceg, Henderson, and Levin (2000). Households that cannot re-optimize their wages follow an updating rule considering a geometric weighted average of past CPI inflation and the inflation target. On the other side, the non-Ricardian households do not have access to any of the assets and own no shares in domestic firms. They simply consume the after-tax disposable income and set their wage equal to the average wage of the Ricardian households. The aggregate consumption for both types of households is a composite of a core consumption bundle (domestic and foreign goods, given by a CES aggregator) and oil consumption.

- Aggregate Supply: The economy is characterized by three types of firms: intermediate tradablegoods producers, import goods retailers and commodity good producers. Intermediate-goods producers have monopoly power and maximize profits by choosing the prices of their differentiated goods subject to the corresponding demands, and the available technology with labor, capital and oil as inputs. Capital is rented to them from a representative firm which accumulates capital and assembles new capital goods subject to investment adjustment costs. Optimal price setting of intermediate-goods producers is subject to a Calvo probability. Firms that cannot re-optimize their price follow a rule with partial indexation to past inflation and the inflation target. The pricing structure leads to a hybrid New Keynesian Phillips curve. A commodity good producer is introduced in the model to match a particular relevant sector for the Chilean economy, namely the cooper sector. This firm produces a homogeneous commodity good only for export. The production technology follows an exogenous stochastic process that does not require any input. The price of the homogeneous commodity good is determined in the foreign market.

- Foreign sector: Local currency pricing is introduced through a la Calvo price stickiness faced by import goods retailers, which resale foreign goods in the domestic market. This allows for incomplete exchange rate pass-through in the short-run, important for expenditure-switching effects of the exchange rate. A CES technology is used to combine a continuum of differentiated imported varieties to produce a final foreign good, which is consumed by households and used for assembling new capital goods.

- Shocks: a transitory productivity shock, a permanent productivity shock, a commodity production shock, a labor supply shock, an investment adjustment cost shock, a preference shock, a government expenditure shock, a monetary policy shock, a foreign commodity price shock, a foreign oil price shock, a foreign output shock, a foreign interest shock, a foreign inflation shock and a price of imports shock.

- Calibration/Estimation: The model is estimated using Chilean quarterly data for the period 1987:1-2005:4. 


\section{B.5.2 CA_ToTEM10: Murchison and Rennison (2006)}

CA_ToTEM10 represents the 2010 vintage of ToTEM (Terms-of-Trade Economic Model) which is an open-economy, DSGE model developed by Murchison and Rennison (2006). The Bank of Canada uses this model as a tool for policy analysis and projections for the Canadian economy.

- Aggregate Demand: Households are classified as "lifetime income" consumers and "current income" consumers, reflecting the fact that not all consumers can access credit markets. Lifetime income consumers smooth their consumption across time through borrowing and saving while "current income" consumers consume their current income each period. Lifetime income consumers choose consumption, domestic and foreign bond holdings, labor supply and wages to maximize a utility function non-separable in consumption and leisure subject to a dynamic budget constraint. Both types of households supply differentiated labor services giving them power when negotiating the wages with the domestic producers. However, renegotiation of the wages is allowed only once in six months, on average, and only a constant proportion of wage contracts are renewed every period. The dynamic wage equation is a function of past and expected future wage inflation and an error-correction component.

- Aggregate Supply: The production sector is comprised of final good producers, an import sector and a commodity sector. Final goods firms produce consumption goods and services, investment goods, and export goods. The production process of these goods is analogous, differing only on the share of imported goods used in production. In this process, first a capital-labor composite is produced using CES technology, which is then combined with a commodity input to produce the domestic good. Final goods then are a combination of the domestic good and the imported good. Through these steps, the firm faces capital adjustment costs, investment adjustment costs and labor adjustment costs. Final goods firms sell their differentiated goods in a monopolistic competitive fashion having power over prices. However, not all firms can re-optimize their prices every period. A share of firms updates prices according to a geometric average of lagged core inflation and expectations of the inflation target. In ToTEM, pricing decisions are considered as strategic complements, where firms have a strong incentive to follow what other firms do. The commodity sector is represented by a domestic firm operating in a competitive market, producing commodities using capital services, labor and land under a CES technology. These raw goods are either sold to a continuum of imperfectly competitive commodity distributors or exported (for the world price of the commodity denominated in Canadian currency). The commodity distributors repackage the commodity goods and sell them to households and to the final goods producers. These distributors face nominal rigidities a la Calvo in price setting, which limits the degree of exchange rate pass-through to consumer 
prices in the short-run.

- The Foreign Sector: The import sector is represented by firms who buy imported goods in the world market for a given world price (law of one price holds). These goods are sold to domestic firms, which use them as inputs in their respective production functions. Imperfect exchange rate pass-through in the short-run is present as the price of imports is temporarily fixed in the currency of the importing country and because import firms face nominal rigidities a la Calvo when setting prices. As in other sectors, imported goods inflation is a function of past and expected future imported goods inflation and an error-correction component. Export goods firms are part of the final good producers sector as discussed above. They have some degree of market power and therefore face a downward-sloped demand curve (rest of the world demand).

- Shocks: A demand shock, a risk-premium shock, an inflation target shock, a commodity price shock, a technology shock, world demand shock and a price mark-up shock.

- Calibration/Estimation: Calibrated with parametrization chosen to match univariate autocorrelations, bivariate correlations and variances estimated using Canadian data for the period 1980-2004.

\section{B.5.3 BRA_SAMBA08: Gouvea et al. (2008)}

Gouvea et al. (2008) build and estimate a small open economy model for the Brazilian economy. The BRA_SAMBA08 model is developed at the Central Bank of Brazil to provide support for its policy decisions. This version of the model is used as a tool to analyze the response of the Brazilian economy when subject to different shocks.

- Aggregate Demand: There are two types of households: optimizers and rule-of-thumbers. Both maximize a similar utility function separable in consumption and leisure but subject to different budget constraints. Unlike the optimizers, the rule-of-thumb households do not have access to credit, asset and capital markets. They just consume their wage income. The optimizers have access to domestic and foreign currency denominated bonds, accumulate capital subject to capital adjustment costs, earn from renting the capital and pay taxes. On the other hand, both types of households supply labor in a competitive market.

- Aggregate Supply: The production sector is comprised of producers and assemblers. Monopolistic competitive firms are the ones producing differentiated goods under a Cobb-Douglas technology with labor, capital services and imported goods as inputs. Following Gali and Gertler (1999), only a fraction of firms are allowed to adjust prices optimally ("forward-looking firms"). The remaining firms follow a rule of thumb. The homogeneous final good is assembled by a 
representative firm using a CES aggregator and is sold in a competitive market. The final good can be used for private consumption, government consumption, investment and exports.

- The Foreign Sector: The world is assumed to be populated by a continuum of small open economies as in Gali and Monacelli (2005), each of them producing a differentiated good in the global market. The demand for home country's exports is obtained from the aggregation of the demands from foreign countries, expressed in a world currency. The domestic importing firm takes the demand for its goods from the producers' input choices.

- Shocks: An inflation target shock, a fiscal target shock, a preference shock, a labor supply shock, an investment shock, a foreign investor's risk aversion shock, a country risk premium shock, a technology shock, a monetary policy shock, a fiscal policy shock, a world imports shock, a world inflation shock and a world interest rate shock.

- Calibration/Estimation: Estimated with Bayesian methods, using quarterly Brazilian data for the period 1999:Q2-2007:Q4.

\section{B.5.4 CA_LS07: Lubik and Schorfheide (2007)}

Lubik and Schorfheide (2007) estimate four small-scale open economy DSGE models with Bayesian techniques for Canada, Australia, New Zealand and the UK. The paper studies to what extent central banks respond to exchange rate movements when setting nominal interest rates, finding that the Bank of Canada and the Bank of England do include the nominal exchange rate in their policy rule. The database contains the model for Canada.

- Aggregate Demand: The model treats the world economy as a continuum of small open economies. The representative household maximizes its utility separable between consumption and leisure subject to its budget constraint. Consumption is a composite of tradable home and foreign goods.

- Aggregate Supply: Differentiated goods are produced by monopolistic-competitive firms using a linear technology with labor being the only production input. The firms set their prices in a Calvo staggered way. The marginal costs depend positively on the terms of trade and world output.

- The Foreign Sector: Purchasing power parity and the law of one price hold. There is perfect exchange rate pass-through. The securities markets are assumed to be complete, and hence international risk sharing in the form of the uncovered interest rate parity is obtained. 
- Shocks: A nominal interest rate shock, a terms of trade shock, a shock to world demand and a shock to the world inflation rate are introduced in the model.

- Calibration/Estimation: The model is estimated with Bayesian methods using quarterly Canadian data for the period 1983:Q1-2002:Q4.

\section{B.5.5 HK_FPP11: Funke et al. (2011)}

Funke et al. (2011) develop a small open economy DSGE model and estimate it for Hong Kong with Bayesian techniques. The model adopts the perpetual youth approach and allows for wealth effects from the stock market on consumption behavior.

- Aggregate Demand: The economy consists of an indefinite number of cohorts facing a constant probability of dying each period, which implies a constant expected effective decision horizon of consumers. Given the lifetime uncertainty, agents' consumption pattern is affected by their expected lifetime wealth (in terms of the wealth in stock market), where the stock price is modeled as the discounted sum of future dividends. In this open economy the consumers are free to allocate their consumption between domestic goods and foreign goods, and the intertemporal allocation is characterized by an otherwise conventional Euler equation that captures the impact of stock-price dynamics.

- Aggregate Supply: Domestic firms act under monopolistic competition and produce consumption goods. Nominal frictions are introduced in the form of Calvo sticky prices. Non-reoptimizing firms index their prices to previous period's domestic producer price inflation.

- The Foreign Sector: The rest of the world is modeled exogenously. Foreign output affects domestic output through international risk sharing directly, and also indirectly via the terms of trade channel.

- Shocks: A productivity shock, a foreign demand shock, a cost push shock and a stock-price gap shock.

- Calibration/Estimation: The model is estimated using Bayesian methods. Funke et al. (2011) employ quarterly data on four observables for the sample 1981:Q1-2007:Q3: the real GDP of Hong Kong, the Hang Seng index, the consumer price index of Hong Kong and US GDP. The last series is used as a proxy for foreign demand. 